\title{
Liver Macrophage Polarization and Function in Hepatotropic Viral Infection
}

\author{
Adam C. Labonte \\ Virginia Beach, Virginia
}

B.S., University of Virginia 2010

M.S., University of Virginia 2012

A Dissertation Presented to the Graduate Faculty of the University of Virginia in Candidacy for the Degree of Doctor of Philosophy

Department of Microbiology

University of Virginia

June 2016 


\begin{abstract}
The liver maintains an immunologically tolerant environment as a result of continuous exposure to food and bacterial constituents from the digestive tract. Hepatotropic pathogens such as hepatitis $\mathrm{C}$ virus ( $\mathrm{HCV}$ ) can take advantage of this niche and establish lifelong chronic infections causing hepatic fibrosis, and hepatocellular carcinoma. Macrophages $(\mathrm{M} \phi)$ play a critical role in regulation of immune responses to hepatic infection and regeneration of tissue. However, the factors crucial for $\mathrm{M} \phi$ in limiting hepatic inflammation or resolving liver damage have not been fully understood. In this work, we demonstrate that expression of the C-type lectin receptor scavenger receptor-AI (SR-AI) is crucial for promoting M2-like M $\phi$ activation and polarization during hepatic inflammation. Liver M $\phi$ uniquely upregulated SR-AI during hepatotropic adenoviral infection and displayed increased expression of alternative $\mathrm{M} \phi$ activation markers such as YM-1, arginase-1, and IL-10 via the activation of Mertk associated with inhibition of mTOR. The expression of these molecules was reduced on M $\phi$ obtained from the livers of infected mice deficient for the gene encoding SR-AI ( $m s r l)$. Furthermore, in vitro studies using an SR-AI-deficient M $\phi$ cell line revealed impeded M2 polarization and decreased phagocytic capacity. Direct stimulation with virus was sufficient to activate M2 gene expression in the wild type (WT) cell line but not in the knockdown cell line. Importantly, tissue damage and fibrosis were exacerbated in SR-AI ${ }^{-/-}$mice following hepatic infection. In contrast, adoptive transfer of WT bone marrow derived M $\phi$ conferred protection against fibrosis in these mice. Taken together, these findings demonstrate that SR-AI expression on liver M $\phi$ promotes recovery from infection-induced tissue damage by mediating a switch to a pro-resolving $\mathrm{M} \phi$ polarization state.
\end{abstract}




\section{Acknowledgements}

Working in MR6 and being a part of the Carter Immunology Center for the duration of my graduate training has been the experience of a lifetime. Every member of the Center contributes to the establishment of an incredible support system for students, and to be a part of it is to truly understand the meaning of collaborative science. Our closest neighbors, the members of the Braciale lab, have always been available to lend a hand, talk about new ideas, teach a technique, or loan an antibody, and for that I thank them. In particular I would like to thank current members Amber Cardani and Amy Newton and former lab members Taeg Kim and Matthew Hufford, whose wisdom and advice have been invaluable - I'm fairly certain that Matt's comments at my qualifying exam practice presentation are the reason that I passed on the first try. I would also like to thank Billy Nash, Awndre Gamache, and Jeff Teoh of the Brown lab, Jessica Harakal and Claudia Rival of the Tung lab, and Andrea Daamen of the Bender lab for all of their suggestions during our group lab meetings and for helping me to find the story in the data. Peggy Morris, Shawn Wood, Michelle Butler, Trip Gill, Darlene Rieckmann-Larosa, and the rest of the Carter Center staff have been greatly helpful over the last several years. Before I came over to the Carter Center, Anjeanette Roberts and Sandy Weirich of the MIC program graciously dedicated their time and energy to help me get set up and get started in my graduate career. And finally, I thank the members of my thesis committee: Dan Engel, Tom Braciale, Norbert Leitinger, and Dean Kedes, whose time and mentorship have been critical to my growth as a scientist over the course of my training.

I could not imagine a better place to spend a graduate career than the Hahn Lab. Dr. Hahn has made a deliberate attempt to foster a positive, productive, and fun work environment and it shows. I would like to thank all current and past members of the Hahn Lab for making 
this experience such a rewarding one. When I first came into the lab Joseph Dolina took me under his wing and provided the foundation of my technical training. Joe could be tough and demanding as a teacher, but I wouldn't have had it any other way. His dedication to his work, his sharp scientific acumen, and his commitment to experimental rigor set high watermarks that I have aspired to meet in my own studies. Similarly I would like to recognize Sue Landes and Annie Tosello-Trampont, whose technical repertoires seemingly knew no bounds, and were always happy to take time out of their busy schedules to do some hands-on teaching and work through experiments with me. Our most recent postdoctoral additions have wasted no time in filling those shoes - Lucas Jennelle, Drew Cobb, and Aditya Dandekar may have only been in the lab with me for a short while, but in that span they have done more to help me troubleshoot and finish my paper than I could ever have expected. Last but not least I would like to thank my fellow graduate students in the Hahn lab. To Celeste Goh and Sowmya Narayanan, it has been an absolute pleasure working alongside you both. Commiserating, celebrating, theorizing, revising, and criticizing - we have had quite the journey together, and you have been unparalleled companions. And of course, no list of Hahn Lab members would be complete without mentioning the inspiring presence of Peter Krueger, whose infectious enthusiasm and joy defined the Hahn Lab Experience during his time here.

School at any level is never easy, but high school can be particularly difficult to navigate, especially when one is still trying to figure out who they are and what they want from their future. I was exceedingly lucky to have not one, but two amazing mentors who took interest in me and invested in my future. I owe a debt of gratitude to Mark Clemente and Jeremy Schratwieser, who instilled in me a lifelong love of science and who even went so far as to fight over whether I would end up as a chemist or a biologist. Sorry Mr. Clemente, it looks like Mr. 
Schrat won this round - although I still think "LEO says GER" is superior to OIL RIG! Further down the road I was able to continue this trend of exceptional teachers by taking nearly every undergraduate course taught by David Kittlesen, including my first immunology course. Dr. Kittlesen is the most skilled and dedicated undergraduate instructor that I ever had the pleasure of knowing, and I thank him for that - little did I know that I would eventually end up in the lab of his thesis mentor, Young Hahn. After spending several years learning from Dr. Hahn it is clear why Dr. Kittlesen is so popular. Dr. Hahn is a consummate mentor and teacher, eternally optimistic and supportive, and absolutely devoted to the success of her students. I thank her for the countless hours she has selflessly dedicated to my training as a scientist.

I can't begin to express my gratitude for my friends outside of the lab: Chuck Schmidt, Erin Kodis, Lizzie and Hannah Rees, Becca and Calin Cole, Carter and Ryan McAuley, Adam and Kara Crutchfield, Daniel and Jessica Lemon, Emily Mercadante, Glen Hirsh, Isaah Vincent, Caitlin Nailor, Katie Margulieux, Ryan Llewellyn, Jon Handing, Louise Ball, and Tom Ellison, who have all helped make the last six years some of the most fun and meaningful of my life. I would especially like to thank Jason Davis, my best friend and best man, who has been my partner in crime since high school and whose regular visits always cheered me up and kept me going, no matter how discouraged or frustrated I was.

Of course, there's no way I would be where I am without the love and encouragement of my family. Mary and Donald Labonte have been the best parents and friends that a son could hope for. They taught me to value knowledge, hard work, creativity, and determination. I thank them for making me who I am today. That goes for the rest of the Labonte and Giannetti clan as well, who are too numerous to list but each of whom has left an indelible mark on my growth as a person. I'd also like to thank Robin Zepp, Ramona Simmons, the Laskeys and the DeRolfs, 
who have been nothing but kind and welcoming over the past several years. I am overjoyed to become part of your family. And finally, I want to thank the other half of my own newly starting family, my amazing fiancée Katie Short. I used to think that the term "other half" was cheesy, but now I know better. Katie has stuck with me through thick and thin, and I never would have made it this far without her support and companionship. It is because of her that I have been able to complete this great achievement, and I know that we will continue to accomplish great things together. 
Dedicated to my parents Donald and Mary, who keep the earth below my feet, and to my fiancée Katie, who lights my way. Your endless patience, advice, support, and love have carried me through these past years and have made this work possible. 


\section{Table of Contents}

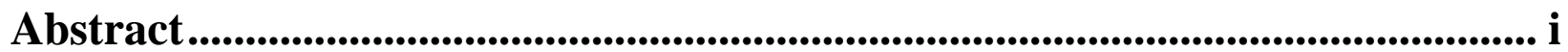

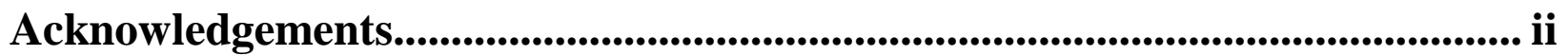

Table of Contents ..................................................................................................... vii

List of Figures.................................................................................................... viii

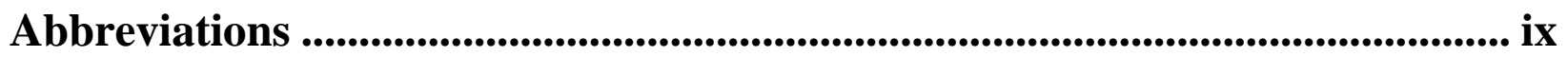

\section{CHAPTER 1}

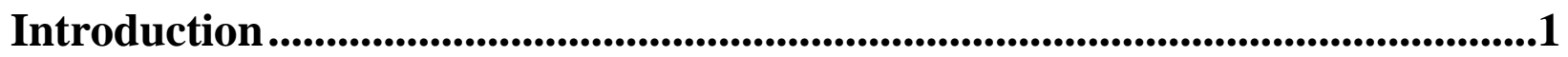

\section{CHAPTER 2}

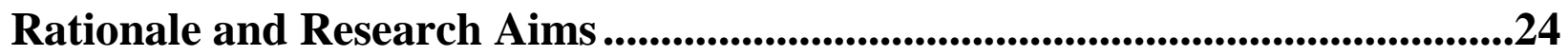

\section{CHAPTER 3}

Expression of scavenger receptor-AI promotes alternative activation of macrophages to limit hepatic inflammation and fibrosis.

\section{CHAPTER 4}

Conclusions and future directions

References. 


\section{List of Figures}

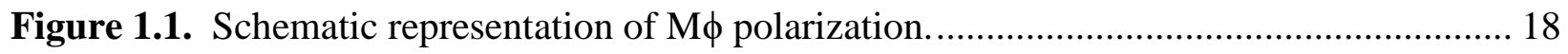

Table 1.1. Phenotypes of common polarization states....................................................... 20

Figure 1.2. Major signaling pathways involved in M1/M2 M polarization........................... 22

Figure 3.1. SR-AI is upregulated on $\mathrm{M} \phi$ following hepatic viral infection............................. 49

Figure 3.2. SR-AI modulates $\mathrm{M} \phi$ activation upon viral insult......................................... 51

Figure 3.3. Infection-induced tissue damage is more severe in the absence of SR-AI............. 53

Figure 3.4. $\mathrm{T}$ cell response to hepatotropic infection is not inhibited by SR-AI. .................... 55

Figure 3.5. $\mathrm{M} \phi$ PD-L1 expression is decreased in the absence of SR-AI................................. 57

Figure 3.6. Generation of a stable MSR knockdown cell line. ........................................... 59

Figure 3.7. SR-AI expression is required for modulation of M $\phi$ activation via mTOR............ 61

Figure 3.8. Gene expression by differentially polarized RAW and MSRC2 cells.................. 63

Figure 3.9. RAW cells, but not MSRC2 cells, exhibit a phagocytosis profile consistent with M2

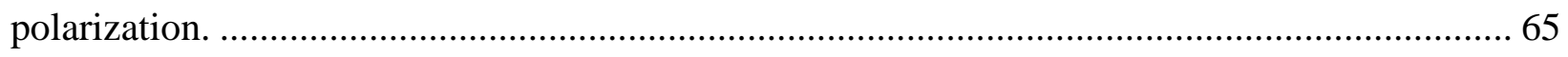

Figure 3.10. Transfer of SR-AI+ M $\phi$ protects against infection-induced tissue damage........... 67

Figure 3.11. Liver NK cell GrB is enhanced in the absence of SR-AI................................. 69 


\section{Abbreviations}

AdOVA

APC

Arg1

ATM

BMDM

BSA

CD

CyTOF

DAMP

DC-SIGN

ESAT-6

FACS

FIZZ1

FRET

GM-CSF/M-CSF

GPC3

GrB

$\mathrm{H} \& \mathrm{E}$

$\mathrm{HCC}$

HCMV

$\mathrm{HCV}$

HDL/LDL
Adenovirus expressing ovalbumin Antigen presenting cell

Arginase 1

Adipose tissue macrophage

Bone marrow derived macrophage

Bovine serum antigen

Cluster of differentiation

Mass cytometry time-of-flight

Danger-associated molecular pattern

Dendritic cell-specific intercellular adhesion molecule-3-grabbing non-integrin

Early secretory antigenic target 6

Fluorescence-activated cell sorting

Found in inflammatory zone 1

Fluorescent resonance energy transfer

(Granulocyte) macrophage colony stimulating factor

Glypican 3

Granzyme B

Hematoxylin and eosin

Hepatocellular carcinoma

Human cytomegalovirus

Hepatitis C virus

High/low density lipoprotein 
HIV-1

IAPP

IFN $\gamma$

IL

iNOS

IRF

JAK

JNK

$\mathrm{KC}$

KLF4

LPS

LTA

Ly6C

MAPK

MDM

Mertk

MIP

MOI

MRC1

MSR1

mTOR

$\mathrm{M} \phi$

NAFLD
Human immunodeficiency virus

Islet amyloid polypeptide

Interferon gamma

Interleukin

Inducible nitric oxide synthase

Interferon-regulatory factor

Janus kinase

C-Jun N-terminal kinase

Kupffer cell

Kruppel-like factor

Lipopolysaccharide

Lipoteichoic acid

Lymphocyte antigen 6 complex, locus $\mathrm{C} 1$

Mitogen-activated protein kinase

Monocyte derived macrophage

Mer receptor tyrosine kinase

Macrophage inflammatory protein

Multiplicity of infection

Mannose receptor 1

Macrophage scavenger receptor 1

Mammalian target of rapamycin

Macrophage

Non-alcoholic fatty liver disease 
NASH

NF- $\kappa B$

NK

NO

PI3K

PIP3

PPAR

qPCR

RBP-J

RETNLA

ROI/ROS

SARS-CoV

SOCS

SR-AI

STAT

TAM

TGF $\beta$

TLR

TNF

TRAIL

Treg

TUNEL

WT
Non-alcoholic steatohepatitis Nuclear factor kappa-light-chain enhancer of activated B cells Natural killer cell Nitric oxide Phosphoinositol-3-kinase Phosphatidylinositol (3,4,5)-triphosphate Peroxisome proliferator-activated receptor Quantitative polymerase chain reaction Recombination signal binding protein for immunoglobulin kappa $\mathrm{J}$ region Resistin-like molecule alpha Reactive oxygen intermediate/ species Sudden acute respiratory syndrome coronavirus Suppressor of cytokine signaling Scavenger receptor AI Signal transducer and activator of transcription Tumor-associated macrophage Transforming growth factor beta Toll-like receptor Tumor necrosis factor TNF-related apoptosis-inducing ligand Regulatory T cell Terminal deoxynucleotidyl transferase dUTP nick end labeling Wild-type 


\section{Chapter 1: Introduction}

\section{Hepatic Pathogens and Liver Physiology}

Chronic liver disease represents a significant health threat and financial burden to the United States hospital system. The liver is a highly susceptible site for persistent infection by several human pathogens. The protozoan parasite Plasmodium falciparum, the causative agent of malaria, begins its lifecycle by invading and reproducing within the structural cells of the liver (hepatocytes) (1). Other hepatic parasites like liver flukes (Fasciola hepatica and F. gigantica) and extraintestinal Entamoeba histolytica lead to the development of liver abscesses and necrosis and are classified by the WHO as significant neglected tropical diseases $(2,3)$. Several species of bacteria can also invade the liver and cause hepatic abscesses and, while they are rare, they are highly fatal (4). The most common cause of hepatitis, however, is viral, and can be traced back to the five major hepatitis viruses: Hepatitis A, B, C, D, and E.

Hepatitis $\mathrm{C}$, the leading cause for liver transplantation, results from infection by the hepatitis $\mathrm{C}$ virus (HCV), a small enveloped RNA virus of the family Flaviviridae. Of the five hepatitis viruses listed above, $\mathrm{HCV}$ is the most remarkable and the most dangerous because it establishes an incredibly persistent infection: roughly $75 \%$ of those infected go on to develop chronic hepatitis, eventually progressing to fibrosis, cirrhosis, and hepatocellular carcinoma (HCC) (5). Approximately 2.7 million Americans have chronic HCV infection, amassing an estimated cost of over \$3.3 billion in 2012 alone, and the incidence of end-stage liver disease from chronic HCV infection is predicted to increase until 2030 (6). Unlike Hepatitis A and Hepatitis $\mathrm{B}$, there is no vaccine against $\mathrm{HCV}$, and while new antiviral therapeutics like sofosbuvir report extremely high clearance rates and less severe side effects than the previous 
standard treatment of pegylated interferon (IFN) and ribavirin, they remain prohibitively expensive to obtain and do not treat severe fibrosis (7).

The challenge of developing a successful HCV vaccine is due to the same reason that HCV is so readily able to establish persistent infections: the liver provides a uniquely tolerogenic niche that HCV has evolved to exploit. Due to its role in filtering nutrient- and waste productenriched blood that drains from the digestive system via the hepatic portal vein, the liver needs to be able to come into contact with highly inflammatory stimuli without mounting an immune response in order to maintain homeostasis (8). Several cell types within the liver's considerable immune compartment orchestrate and maintain this immunotolerant state, the largest constituent of which are liver macrophages, which comprise $80 \%$ of the macrophages in the human body (9).

\section{Macrophages}

Macrophages $(\mathrm{M} \phi)$ represent a ubiquitous yet complex and nuanced population of immune cells that play essential roles in both disease and homeostasis throughout the body (10). In addition to monocytes and $\mathrm{M} \phi$ circulating throughout the bloodstream, specialized tissueresident M $\phi$ can be found in most major organs, including Kupffer cells in the liver, Langerhans cells in the skin, microglia in the brain, splenic red pulp $\mathrm{M} \phi$, lung alveolar $\mathrm{M} \phi$, adipose tissue $\mathrm{M} \phi$, and bone osteoclasts, to name a few (11-14). While some identify these populations as the endpoint of bone marrow monocyte maturation, several lines of evidence indicate that tissue resident $\mathrm{M} \phi$ originate during embryogenesis in association with their specific tissue independently from blood monocytes and monocytes/ $\mathrm{M} \phi$ recruited to sites of inflammation 
$(11,15,16)$. Regardless of their location, $\mathrm{M} \phi$ are responsible for the maintenance of healthy tissues through phagocytic clearance of apoptotic cells and foreign materials and through tissue repair and remodeling during wound healing (17-20). M $\phi$ are also major regulators of the inflammatory response to disease and infection, acting as a bridge between innate and adaptive immunity by monitoring the microenvironment through an array of surface receptors and secreting appropriate cytokines and chemokines $(21,22)$.

Depending on the stimuli they encounter, tissue resident and circulatory $\mathrm{M} \phi$ populations can be directed to distinct phenotypic programs in a process known as M polarization (Fig. 1.1, Table 1.1). The diverse properties of different M $\phi$ subsets can have drastic effects on health and disease within the tissues where they reside; while the induction of a particular subset can be protective during homeostasis or disease, this process can be altered or subverted to enhance pathogenesis and disease progression (by, for example, inappropriately dampening the immune response or exacerbating harmful inflammation) (23).

\section{Phenotypic Polarization of M $\phi$}

The most well-described and commonly reported paradigm of $\mathrm{M} \phi$ polarization is the M1/M2 polarization axis (24-26). Originally named to reflect relationships to the Th1/Th2 polarization of immune responses, $\mathrm{M} 1$ and $\mathrm{M} 2 \mathrm{M} \phi$ are also referred to as classically or alternatively activated $\mathrm{M} \phi$, respectively $(27,28)$.

Classical activation is stimulated by microbial products and proinflammatory cytokines (IFN $\gamma$ and/or LPS or TNF), and the resulting M1 M $\phi$ are characterized by high antigen presentation, high production of IL-12 and IL-23, and high production of nitric oxide (NO) and 
reactive oxygen intermediates (ROI) (29). M1 M $\phi$ have been shown to produce several other inflammatory cytokines like TNFa; IL-1, 6, and 12; Type I IFN; CXCL1-3, 5 and 8-10; CCL2-5 and 11; CXCL16; and CX3CL1 (24,30).

By contrast, alternative/M2 activation is mediated by IL-4, IL-10 and IL-13, which were initially thought to produce "deactivated $\mathrm{M} \phi "$ (25). M2 M $\phi$ are marked by the upregulation of several surface molecules including Dectin-1, DC-SIGN, mannose receptor (MRC1/CD206), scavenger receptor A (SR-AI), scavenger receptor B-1, CD163, CCR2, CXCR1, and CXCR2 $(24,25,27) . \mathrm{M} 2 \mathrm{M} \phi$ exhibit altered cytokine and chemokine production, and typically produce high levels of IL-10 and low levels of IL-12 (31). CCL1, CCL2, CCL17, CCL18, CCL22, CCL24 and IL-1Ra are also made by alternatively activated M $\phi$ (24). Genetic studies of M2 M $\phi$ in mouse models have identified additional signatures of alternative activation, including arginase 1 (Arg1), YM1 (a member of the chitinase family) and FIZZ1 (found in inflammatory zone 1, RETNLA) (32,33). Generally, the M2 polarization state is characterized by little to no secretion of proinflammatory cytokines, increased secretion of anti-inflammatory cytokines, enhanced scavenging of cellular debris, promotion of tissue remodeling and repair, and, in some cases, increased capacity to fight parasitic infections (34). Additionally, the concept of resolution of inflammation has evolved and is no longer perceived as a passive process that simply occurs when the insult disappears, but rather as a highly orchestrated process coordinated by a complex regulatory network of cells and anti-M1 mediators called pro-resolving mediators (35).

$\mathrm{M} 2 \mathrm{M} \phi$ can be further divided into three subtypes according to their inductive stimuli and secreted chemokines (36). M2a M $\phi$ are stimulated by IL-4 and IL-13 and produce CCL24, CCL22, CCL17, and CCL18, which are recognized by CCR3, CCR4, and CCR8 and promote 
recruitment of eosinophils, basophils, and Th2 cells. M2b M $\phi$ result from activation by immune complexes in combination with TLR agonists (like LPS) and selectively produce CCL1, which recruits Tregs. IL-10 drives M $\phi$ polarization to M2c cells, which produce CCL16 and 18, recruiting eosinophils and naïve T cells, respectively.

A full understanding of the M1/M2 paradigm of $\mathrm{M} \phi$ polarization, however, contains some caveats. First, M1 and M2 M $\phi$ as defined in the foundational literature most likely do not exist as distinct categories, but rather should be considered as extremes at either end of a continuum of overlapping functional states (37). Indeed, $\mathrm{M} \phi$ with combinations of M1 and M2 markers can be found in atherosclerotic plaques and some murine tumors $(38,39)$. Second, unlike the irreversible phenotypic changes seen in lymphocytes after exposure to polarizing cytokines, M $\phi$ polarization is both transient and plastic (26,40-42). For example, M2 M $\phi$ can be reprogrammed to express M1 genes following exposure to TLR ligands or IFN $\gamma(43,44)$. Additionally, while there is partial overlap of M1-and M2-identifying markers in murine and human studies, there are still markers in each system that fail to translate to the other. The chitinase-like proteins YM1 and YM2, along with FIZZ1, are markers of murine M2 polarization which lack human orthologs, while CCL14, CCL18, and CCL23 are human-restricted M2 markers with no murine orthologs $(25,45,46)$. Finally, there are other specially activated $\mathrm{M} \phi$ (M4, Mhem, Mres, and Mox) that have been described in atherosclerosis and may lie on a separate activation axis from M1/M2 M $\phi$ (Fig. 1.1). These atherosclerotic M $\phi$ subsets have been discussed in recent reviews $(47,48)$. 


\section{Signaling Pathways Involved in M $\phi$ Polarization}

The network of molecular mediators that regulate M1/M2 polarization in response to various stimuli is incompletely understood, but several signaling pathways have been implicated in this process (Fig. 1.2). One of the major pathways identified is the JAK/STAT pathway, which mediates responses to a collection of different cyotkines and growth factors and regulates processes from hematopoiesis and immune development to lactation and adipogenesis (49). Binding of IFN $\gamma$ to its cell surface receptor leads to activation of receptor-associated JAKs, which in turn cause STAT1 to dimerize and translocate to the nucleus where it initiates transcription of genes that promote M1-associated functions like enhanced microbicidal activity and proinflammatory cytokine production (50,51). M $\phi$-specific deletion of SOCS3, an inhibitor of cytokine and JAK/STAT signaling, was found to increase levels of the M1 genes IL-1 $\beta$, IL-6, IL-12, IL-23, and iNOS (52) and increase phosphorylation of STAT1 and STAT3 (53).

In contrast, STAT6 is activated by IL-4 and IL-13 to induce M2 polarization (54-56). CJun N-terminal kinase (JNK), a mitogen-activated protein kinase (MAPK) involved in cell proliferation, transformation, differentiation, and apoptosis is likely involved in this pathway (57). Upon activation, JNK can phosphorylate serine 707 on STAT6, thereby deactivating it (58). A study of M $\phi$ polarization in obesity showed that mice lacking the JNK activator MLK3 were also deficient in M1 M $\phi$ polarization (59). The transcription factors PPAR $\gamma$ and PPAR $\delta$ are activated by STAT6 and necessary for M2 polarization, and PPAR $\delta^{-/-} \mathrm{M} \phi$ exhibit enhanced activation of JNK following treatment with adipocyte-conditioned medium, which contains the M2 cytokines IL-4 and IL-13 (60,61). The zinc-finger transcriptional regulator Krüppel-like factor $4(\mathrm{KLF} 4)$ is involved in this pathway as well and cooperates with STAT6 to skew

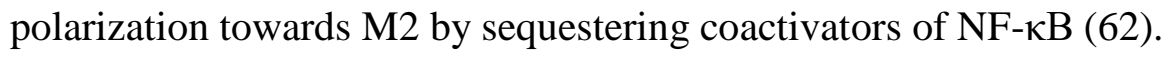


Furthermore, the phosphoinositol-3-kinase (PI3K) signaling pathway, which activates multiple kinase cascades through the production of the second messenger PIP3, regulates M $\phi$ survival and gene expression via activation of the Akt family of serine/threonine protein kinases $(63,64)$. Knockout studies have demonstrated that M1 polarization depends on the activation of Akt2 while M2 polarization requires Akt1 (65). In addition, the PI3K/Akt signaling pathway controls the activation of mTOR, which promotes M1 polarization (66-68).

Interferon-regulatory factor (IRF) proteins are also regulators of $\mathrm{M} \phi$ polarization. IRF5 is associated with M1 polarization and promotes the transcription of genes encoding IL-12 while repressing the gene that encodes IL-10 (69). Notch signaling through the nuclear transducer RBP-J controls expression of IRF8, which induces M1 gene expression (70). IRF4 is highly expressed in adipose tissue $\mathrm{M} \phi$ (ATM) and its deletion leads to increased production of IL-1 $\beta$ and TNF $\alpha$ and expression of M1 markers, indicating that IRF4 activation contributes to M2 polarization (71). The IRFs also underlie the ability of GM-CSF and M-CSF to induce polarization: GM-CSF leads to downstream activation of IRF5 (M1) while M-CSF leads to IRF4 (M2) activation (72).

\section{Bacterial Infections}

Given the ability of $\mathrm{M} \phi$ to acquire enhanced microbicidal abilities following stimulation with microbial products and the preeminent roles of $\mathrm{M} \phi$ in both innate and adaptive immune responses, one might predict that pathogens would evolve strategies to redirect and alter $\mathrm{M} \phi$ activation in their favor. Several transcriptome analysis studies have established that innate immune cells, particularly $\mathrm{M} \phi$, engage in a common response to pathogen challenge that 
involves a shared pattern of gene expression $(73,74)$. A multi-study review of transcriptional responses of mononuclear phagocytes to bacteria and bacterial components focusing specifically on genes involved in $\mathrm{M} \phi$ polarization identified a common response program that mainly involved the upregulation of M1-associated genes, including the cytokines TNF, IL-6, IL-12, IL$1 \beta$, the cytokine receptors IL-7R and IL-15RA, the chemokines CCL2, CCL5, and CXCL8, and the chemokine receptor CCR7 (75). This M1 activation program is typically associated with protection against bacterial disease, and M1 polarization has been shown to aid host control of several bacteria, including Listeria monocytogenes, Salmonella typhimurium, Mycobacterium tuberculosis, Mycobacterium ulcerans, and Chlamydia infections (75-80).

Consequently, several pathogenic bacteria, especially intracellular species, have developed mechanisms to interfere with M $\phi$ polarization in order to enhance their own survival. Some species accomplish this by blunting M1 polarization to reduce inflammation and microbicidal functions of $\mathrm{M} \phi$. The intracellular form of the enteropathogen Shigella flexneri produces an altered, hypoacetylated form of LPS that evades recognition by TLR4 and elicits decreased production of proinflammatory cytokines from murine bone marrow derived $\mathrm{M} \phi$ (BMDM) (81). During pulmonary infection in mice, Staphylococcus aureus induces Akt1 signaling to enhance SOCS1 activity and inhibit NF- $\mathrm{B}$ activity, shifting M $\phi$ from an antimicrobial M1 phenotype to a functionally inert one (82). M. tuberculosis secretes the virulence factors lipoarabinomannan and early secretory antigenic target-6 (ESAT-6), which inhibit M1 activation by inhibiting phagosome maturation and $\mathrm{NF}-\kappa \mathrm{B}$ activation, respectively (83). M. tuberculosis also subverts the inflammatory response by stimulating Wnt6 signaling in infected M $\phi$ in granulomatous lesions in the lung, driving M2-like polarization (84). S. aureus biofilms are resistant to $\mathrm{M} \phi$ invasion, but those $\mathrm{M} \phi$ that do successfully penetrate catheter- 
associated biofilms in vitro display decreased expression of IL-1 $\beta, \mathrm{TNF} \alpha$, and iNOS expression but robust Arg1 expression, signifying an M2 profile (85). S. typhimurium has been shown to preferentially associate with M2 M $\phi$, and PPAR $\delta$ expression is upregulated in Salmonellainfected M $\phi$ while PPAR $\delta$ deficiency severely inhibits bacterial replication and persistence (86). Interestingly, the dependency of S. typhimurium on PPAR $\delta$ expression was shown to be due to its metabolic effects rather than its ability to reduce production of antimicrobial mediators by promoting M2 polarization, and it remains to be determined whether S. typhimurium directly augments PPAR $\delta$ activity to promote persistence.

\section{Viral Infections}

Similar to evasion strategies employed by bacterial pathogens, many viruses take advantage of the $\mathrm{M} \phi$ polarization system to enhance their own growth and virulence. However, unlike bacterial pathogens, which generally tend to thrive within and encourage production of M2-polarized $\mathrm{M} \phi$, viral pathogens more commonly activate M1 polarization. This inflammatory phenotype is often correlated with disease severity. HCV preferentially infects hepatocytes and establishes a chronic inflammatory infection, often leading to fibrotic cirrhosis and HCC (87). It has been demonstrated that the viral protein NS3 enhances IL-12 and TNF $\alpha$ production by THP$1 \mathrm{M} \phi$, implicating M1 polarization in sustaining inflammation (88). Furthermore, activation of $\mathrm{M} \phi$ with TLR agonists triggers the secretion of $\mathrm{TNF} \alpha$, which promotes HCV entry into polarized hepatoma cells by relocalizing the tight junction protein and HCV entry factor occludin (89). Of the three common clades of avian $\mathrm{H} 5 \mathrm{~N} 1$ influenza virus circulating in poultry in China (2.3.2, 2.3.4, and 7), clade 2.3.4 is the most successful at infecting, replicating within, and inducing cytopathic effects in human monocyte-derived M $\phi$ (MDM) (90). H5N1 clade 2.3.4 also 
stimulated the highest expression of IL-1 $\beta$, IL-6, IL-8, TNF $\alpha$, IFN $\gamma$, and MCP-1 in MDMs (90). $\mathrm{M} 2 \mathrm{M} \phi$ polarization by $S$. aureus, which is commonly present among the airway mucosal microbiota, inhibits influenza-mediated lung injury, implying that M1 M $\phi$ exacerbate flu infection (91).

Nonetheless, some viruses do benefit by skewing $\mathrm{M} \phi$ polarization towards an M2 phenotype. During infection by severe acute respiratory syndrome coronavirus (SARS-CoV), lung damage resulting from both intrinsic viral infection and dysregulation of the host immune response rapidly progresses to diffuse alveolar damage, resulting in acute respiratory distress syndrome and pulmonary fibrosis $(92,93)$. A recent study revealed that SARS-CoV-infected mice lacking hematopoeitic STAT1 expression have greater weight loss and lung pathology associated with upregulation of the M2 indicators YM1, FIZZ1, IL-4, and IL-13 (94). Absence of lung disease and prefibrotic lesions in infected STAT1/STAT6 ${ }^{-/-}$double-knockout mice also supported the notion that M2 M $\phi$ contribute to SARS-CoV pathogenesis. Human cytomegalovirus (HCMV) has a more complex relationship with M $\phi$ polarization. The HCMV gene UL111A encodes a homolog of human IL-10 that is capable of polarizing monocytes towards an anti-inflammatory M2c phenotype including high expression of the scavenger receptor CD163, suppression of MHC expression, and exppression of heme oxygenase 1 (which suppresses TNF $\alpha$ and IL-1 $\beta$ ) (95). Additionally, HCMV optimally infects M2- but not M1polarized M $\phi$ and late-phase HCMV infection is dependent on the M1-promoting activation of mTOR (96). Accordingly, HCMV-activated M $\phi$ have been shown to adopt an M1 transcriptome profile in self-defense (97). HIV-1 similarly seems to benefit from M2 polarization: HIV-1 displays impaired viral DNA synthesis, delayed proviral integration, and reduced proviral transcription in M1 M $\phi$, while the M2a surface receptor DC-SIGN facilitates HIV-1 entry, DNA 
synthesis, and transmission from infected M $\phi$ to CD4+ T cells (98-100). Notably, clathrinmediated endocytosis of HIV-1 is increased in M1 and decreased in M2 M $\phi$, but this method of endocytosis leads to increased viral degradation and is unlikely to result in productive infection (101). Yet, like HCMV, HIV-1 infection of MDMs drives them toward M1 polarization, and the viral protein Nef is preferentially taken up by $\mathrm{M} 2 \mathrm{M} \phi$ and stimulates an M2-to-M1 transition $(83,100,102)$. These contradictions may be explained by a viral survival strategy that takes advantage of both $\mathrm{M} 1$ and $\mathrm{M} 2 \mathrm{M} \phi$ as means to different ends: $\mathrm{M} 2 \mathrm{M} \phi$ as a reservoir of replication and $\mathrm{M} 1 \mathrm{M} \phi$ to recruit fresh immune cells to spread the infection. This can also be inferred from the ability of proinflammatory cytokines and chemokines from HCMV-infected $\mathrm{M} \phi$ to enhance virus replication and dissemination $(34,103,104)$.

\section{Diabetes, Obesity, and Non-alcoholic Steatohepatitis}

Type 1 diabetes is an autoimmune disease that results in high blood sugar following the destruction of insulin-producing pancreatic beta cells via activation of innate immunity and expansion of auto-reactive T cells and autoantibody-producing B cells. Monocytes/M $\phi$ from patients with Type 1 diabetes present a pro-inflammatory profile (high levels of TNFa, IL-6 and IL$1 \beta$ ) when compared to normal subjects (105-107). Moreover, elevated levels of glucose and islet amyloid polypeptide (IAPP) deposition lead to the activation of TLRs and inflammasomes, resulting in beta cell death and decreased insulin secretion (108). Recently, it has been suggested that M1 M $\phi$ may contribute to diabetes-related complications such as cardiovascular diseases by altering the immune system of type 1 diabetics (109). Furthermore, the sustained increase of growth hormone in murine models of type 1 diabetes leads to a reduction of diabetes symptoms by attenuating the apoptosis and increasing the expansion of beta cells (110). Growth hormone also triggers M2 
polarization of $\mathrm{M} \phi$ via modulation of the cytokine milieu, stimulating the activity of suppressor $\mathrm{T}$ cells and limiting Th17 cell activation (110).

Obesity is a major health problem in western countries and a risk factor for insulin resistance, type 2 diabetes, hepatic steatosis, and artherosclerosis. Obesity is closely associated with chronic inflammation in adipose tissues, suggesting that the chronic excess of nutrients triggers an immune response in adipose tissues (111-113). White adipose tissues store energy in form of fat and regulate systemic metabolism through the release of adipokines by adipocytes that control insulin sensitivity in the liver and skeletal muscle $(114,115)$. In lean subjects and mice, adipose tissue M $\phi$ (ATM) present an M2 phenotype and are critical to maintaining insulin sensitivity in adipocytes through IL-10 production $(62,116,117)$. In metabolic homeostasis, M2 ATMs are maintained by IL4 and IL-13 secreted by adipocytes in a PPAR $\gamma / \delta$ - and KLF4-dependent manner $(57,118)$. In obese subjects and mice, adipocytes release proinflammatory mediators (i.e. CCL2/MCP-1, TNF $\alpha, \mathrm{CCl} 5$, CCL8 and free fatty acid), promoting the infiltration of Ly6C ${ }^{\text {hi }}$ inflamFmatory monocytes which differentiate into M1-polarized ATMs that express high levels of TNF $\alpha$, iNOS, IL-6 and IL-1 $\beta$ (115,116,119-122). Therefore, the severity of obesity-related metabolic dysfunctions correlates with M1 ATM infiltration whereas chronic inflammation in adipose tissue inhibits the production of adiponectin, thus contributing to the development of insulin resistance in surrounding adipocytes $(116,122)$.

Recently NAFLD (Non-alcoholic fatty liver disease) has emerged as an obesity-related health problem characterized by steatosis (accumulation of lipids in hepatocytes). Hepatic steatosis can evolve to non-alcoholic steatohepatitis (NASH) when accompanied by liver injury (ballooning hepatocytes) and hepatic inflammation, which may be associated with fibrosis and eventually culminates in cirrhosis and HCC. The development of the complex pathology of NASH involves a 
variety of liver cells including hepatocytes, hepatic $\mathrm{M} \phi$, and stellate cells. Inflammatory mediators, especially those derived from adipose tissues, the gut, and the liver, have recently been reported to play a major role in initiating and controlling the progression of NASH by regulating lipid metabolism (123-125). In particular, the activation of innate immune cells such as Kupffer cells and infiltrating blood-derived monocytes is a major event of NASH development. In homeostatic conditions, Kupffer cells perform immune surveillance by removing pathogens and toxins from the circulation and maintain liver tolerance through IL-10 secretion (8). Kupffer cells communicate with a variety of hepatic immune cells and interact directly with hepatocytes passing through the space of Disse (124). In early mouse models of diet-induced steatohepatitis, Kupffer cells are the first innate cells responding to injured hepatocytes and differentiate toward M1 M $\phi$, promoting the recruitment of blood-derived CD11 bint $^{\text {Ly6C }}{ }^{\text {hi }}$ monocytes through secretion of TNF $\alpha$ and chemokines (MCP-1 and IP-10) (126). The recruitment of these inflammatory M1-polarized Ly6C ${ }^{+}$ blood-derived monocytes is dependent on CCR2 and MCP1 (127-130). The hallmarks of NASH (i.e. steatosis, low-grade inflammation, and hepatic recruitment of M1-polarized M $\phi$ ) are reduced/delayed following specific depletion of Kupffer cells or by silencing of TNF $\alpha$ in myeloid cells (126). Moreover, M1-polarized Kupffer cells also produce inflammatory mediators such as IL$1 \beta$ and ROS, which induce hepatic steatosis and fibrosis $(129,131)$. NF- $\kappa \mathrm{B}$ and JNK activation in Kupffer cells may contribute to development of hepatic inflammation by promoting M1-like M $\phi$ polarization (57).

Liver $\mathrm{M} \phi$ are also implicated in the severity of NASH via the expression of Toll-like receptors (TLR2, TLR4, TLR9, MyD88) and scavenger receptors (scavenger receptor A and CD36) $(129,132-134)$. TLRs and scavenger receptors trigger pro-inflammatory responses following recognition of hepatic free fatty acids, damage-associated molecular pattern (DAMPs) expressed by 
steatotic hepatocytes, and/or bacterial products derived from the gut $(135,136)$. NASH patients show increased intestinal permeability, resulting in greater hepatic abundance of bacterial products and other TLR ligands derived from the gut via portal vein circulation (137). The imbalance of gut flora may influence liver disease by activating TLRs expressed on liver cells and leading to the activation of NLPR3 $(108,135,136,138)$. In models of diet-induced NASH and obesity, inflammasome-deficient mice develop more severe NASH which is fully transferable to WT mice upon prolonged cohousing, suggesting that commensal bacteria in the GI tract play an important role in NASH disease progression $(108,122,138,139)$.

\section{Cancer}

$\mathrm{M} \phi$ are a highly influential cell type in most varieties of cancer and are recruited to all solid tumors (140). The contributions of different subsets of polarized M $\phi$ to the tumor microenvironment and cancer progression are therefore a subject of great interest. $\mathrm{M} 1 \mathrm{M} \phi$ are generally considered to be beneficial to the host, and peritumoral M $\phi$ that express $\mathrm{M} 1$ cytokines like IFN $\gamma$, IL-1 $\beta$, and IL-6 have been shown to have antitumoral effects and are associated with improved prognoses (141-145). M1 M $\phi$ may have the opposite effect in virally induced cancers, however: administration of IFN $\gamma$ or TNF $\alpha$ to patients infected with Kaposi sarcoma virus enhances disease progression, and PBMCs from infected tissues have themselves been found to produce elevated levels of IFN $\gamma$ or TNF $\alpha$ endogenously (146). Proinflammatory M $\phi$ are also harmful in intraocular tumors, where TNF $\alpha$ - and iNOS-dependent antitumor responses lead to necrosis of bystander cells and destruction of the eye (147).

M2-polarized tumor-associated M $\phi$ (TAM), on the other hand, have been repeatedly and consistently associated with unfavorable effects like tumor growth, angiogenesis, and metastasis 
in malignant cancers (34). The M2 cytokines IL-4, IL-13, and IL-10 are present within the tumor microenvironment and TAMs from various cancer models have been shown to express an M2 activation profile that includes enhanced expression of CD163, MRC-1, c-type lectins, IL10, and Arg-1 and decreased production of IL-12 (148-151). The small secretory lectin Reg3 $\beta$ is an important inhibitor of inflammation in pancreatic and intestinal tissues, and deficiency of Reg3 $\beta$ (an activator of the STAT3 pathway) drastically impairs pancreatic tumor growth by skewing M $\phi$ polarization away from M2 and towards M1 (152). M2 TAMs have also been shown to increase fibroblastic morphology, vimentin and snail expression, metalloproteinase activity, and proliferation and migration of pancreatic cancer cells, implicating them in the development of eptihelial-mesenchymal transition and metastasis (153). In HCC, high expression of the heparin-sulfate proteoglycan glypican-3 (GPC3) on the surface of cancer cells is associated with increased $\mathrm{M} \phi$ infiltration in human patients, and human/mouse xenograft transplantation with a GPC3-overexpressing cell line leads to infiltration by M $\phi$ expressing M2specific markers $(154,155)$. M2 TAMs worsen HCC both by promoting tumor growth and angiogenesis and by encouraging liver fibrosis through IL-13 and TGF $\beta$ secretion (26).

\section{Therapies Targeting M $\phi$ Polarization}

Given that $\mathrm{M} \phi$ play important roles in maintaining tissue homeostasis and fighting disease, polarized $\mathrm{M} \phi$ subsets that specifically contribute to the pathogenesis or amelioration of various diseases present themselves as attractive targets for therapeutic intervention. Different therapeutic strategies include either targeting the polarized $\mathrm{M} \phi$ themselves or manipulating the signaling pathways involved in the process of $\mathrm{M} \phi$ polarization to a desirable outcome. 
Bacterial biofilms that form on body surfaces or on surgical implants lead to chronic and recurrent infections, and are difficult to treat with antibiotics $(156,157)$. Early, local administration of M1 M $\phi$ or the C5a receptor agonist EP67, which stimulates M1 polarization, significantly attenuated biofilm formation in a mouse model (158). Furthermore, treatment of established biofilms significantly reduced bacterial burden compared to antibiotic treatment, suggesting the potential of a therapeutic alternative (158). Microbes themselves may also prove to be useful sources of therapeutics that modulate $\mathrm{M} \phi$ polarization. In vitro application of extracellular polysaccharide secreted by an oligotrophic bacteria found in Lop Nur Desert, Bacillus sp. LBP32, was found to limit LPS-induced inflammation in the M $\phi$ cell line RAW 264.7 by inhibiting NF- $\kappa \mathrm{B}$ and JNK activation and may prove useful in diseases characterized by excessive M1 polarization (159). Similarly, the small-molecule compound bis- $N$-norgliovictin isolated from the marine-derived endophytic fungus S3-1-c inhibits LPS-induced M1 polarization of RAW 2.6.4 cells and murine peritoneal $\mathrm{M} \phi$, and improves survival in mouse models of sepsis (160). As a proof of concept for treating inflammatory gastrointestinal diseases, a lab strain of E. coli was created that secretes a Herpes virus homolog of IL-10 via a Secdependent transporter construct. Viral IL-10 delivered in this manner was shown to activate STAT3 and suppress TNF $\alpha$ production in the J774.1 murine M $\phi$ cell line (161).

IKK $\beta$, a downstream mediator of insulin resistance and activator of the NF- $\kappa \mathrm{B}$ pathway (and therefore of M1 polarization), is inhibited by anti-inflammatory salicylates like aspirin, which attenuates hyperglycemia and hyperinsulinemia in obese rodents $(162,163)$. Several small trials in patients with type 2 diabetes have demonstrated that treatment with salicylates results in a marked reduction of diabetic metabolic parameters and improved glycemic control (115). 
Apolipoprotein A-I mimetics are a class of therapeutic molecules that attempt to modulate HDL to treat atherosclerosis and are the subject of extensive clinical and mechanistic study, as reviewed in Leman et al., 2013. Interestingly, the mimetic D4F also has potential for cancer therapy: D4F inhibits the M2-associated scavenger receptor SR-AI/SRA on TAMs, preventing metastatic spread (165).

Anticancer therapies also seek to convert protumoral M2 M $\phi$ into M1 M $\phi . \mathrm{M} 2 \mathrm{M} \phi$ generated by IL- 6 and prostaglandin $\mathrm{E}_{2}$ secreted by cervical cancer cells can be repolarized to M1 by coculture with Th1 cells, and this interaction could possibly be reproduced by activation with CD40L and IFN $\gamma$ (166). Moreover, IFN $\gamma$ was shown to successfully switch M2 TAMs purified from human ovarian tumors to an M1 phenotype, and the addition of IFN $\gamma$ skewed de novo tumor-induced M2 differentiation of monocytes to favor M1 polarization (167). Other potentially therapeutic molecules found to repolarize TAMs from an M2 to an M1 phenotype include zoledronic acid, CpG oligonucleotide, and histidine-rich glycoprotein (168-170). 


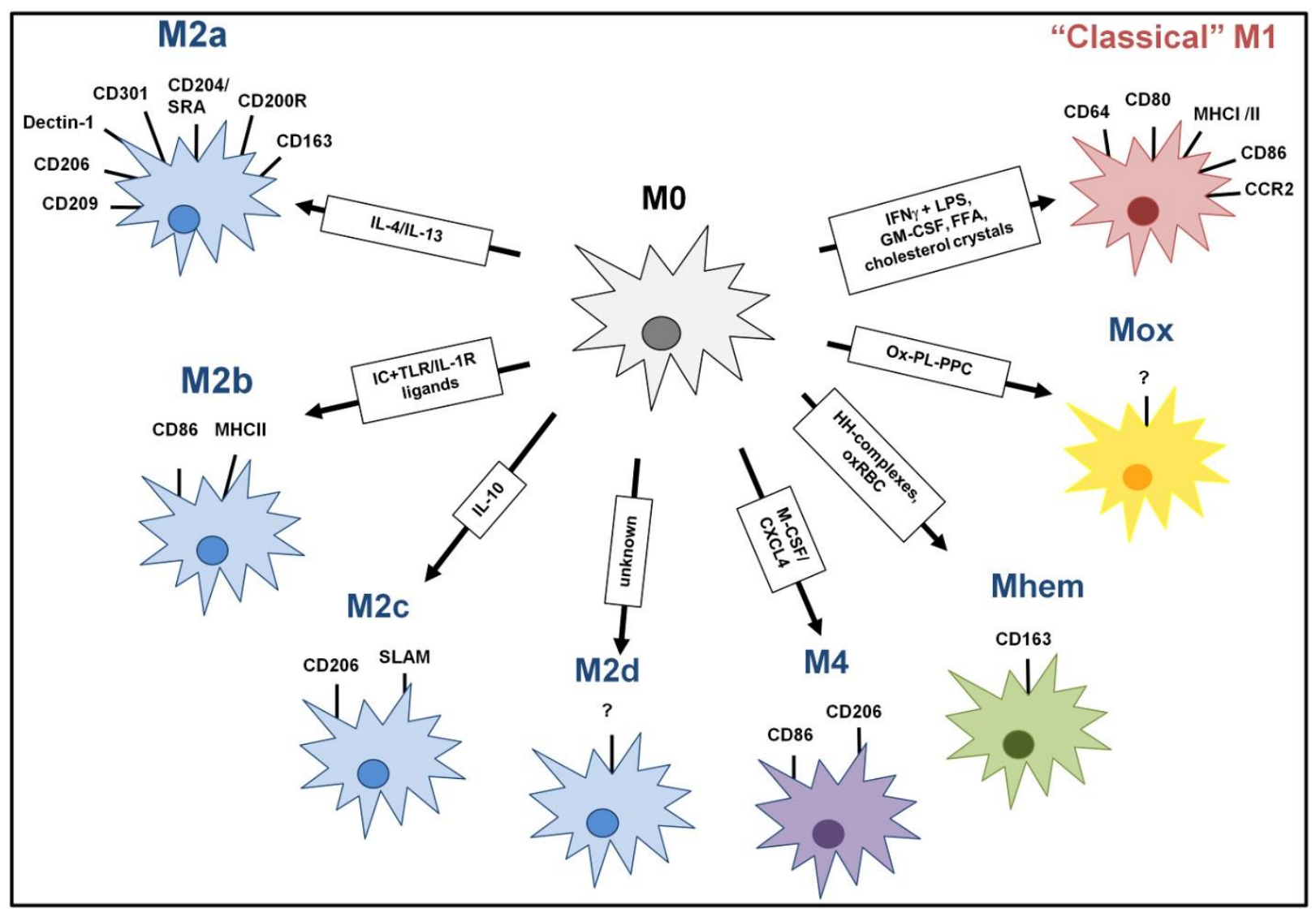


Figure 1.1. Schematic representation of $\mathbf{M} \phi$ polarization. While M1/classically activated macrophages are typically induced by IFN $\gamma$ and microbial products like LPS, different stimuli lead to the development of an array of finely tuned alternately activated states. IC, Immune complex; HH, Hapto-hemoglobin; OxRBC, oxidized red blood cells; Ox-PL-PPC, ox-PL 1palmitoyl-2arachidonoyl-sn-glycero-3-phosphorycholine; FFA, free fatty acid. 


\begin{tabular}{|c|c|c|c|}
\hline $\begin{array}{l}\text { Polarization } \\
\text { State }\end{array}$ & Gene expression & Cytokines & Chemokines \\
\hline M1 & $\begin{array}{c}\text { CD80, CD86, } \\
\text { MHC I/II, IL-1R I, } \\
\text { TLR2, TLR4, iNOS }\end{array}$ & $\begin{array}{c}\text { TNF } \alpha, \text { IL-1, IL-6, } \\
\text { IL-12, IL-15, IL-23, } \\
\text { ROS, iNOS, type I IFN }\end{array}$ & $\begin{array}{c}\text { CXCL1-3, CXCL5, } \\
\text { CXCL8-10, CXCL16, } \\
\text { CCL2-5, CCL8, CCL11, } \\
\text { CCL15, CCL20, } \\
\text { CX3CL1 }\end{array}$ \\
\hline M2a & $\begin{array}{l}\text { CD163, MHC II, SR, } \\
\text { CD206, MR, IL-1R II } \\
\text { YM-1, Fizz1, Arg-1 }\end{array}$ & $\begin{array}{c}\text { IL-10, TGF } \beta, \text { IL-12, } \\
\text { IL-1Ra }\end{array}$ & $\begin{array}{l}\text { CCL1, CCL2, CCL24, } \\
\text { CCL22, CCL17, CCL18 }\end{array}$ \\
\hline M2b & $\begin{array}{c}\text { CD86 } \\
\mathrm{MHC} \text { II }\end{array}$ & IL-10, IL-1, TNF $\alpha$, IL-6 & $\begin{array}{c}\text { CCL1, CCL20, CXCL1, } \\
\text { CXCL2, CXCL3 }\end{array}$ \\
\hline M2c & $\begin{array}{l}\text { CD163, TLR1, MR, } \\
\text { Arg-1, YM-1, TLR8 }\end{array}$ & IL-10, TGF $\beta$ & CCL16, CCL18 \\
\hline M2d & VEGF & IL-10, VEGF & $\begin{array}{l}\text { CCL5, CXCL10, } \\
\text { CXCL16 }\end{array}$ \\
\hline M4 & $?$ & $\mathrm{TNF} \alpha$ & CCL18, CCL20 \\
\hline Mhem & $\mathrm{HO}-1$ & IL-10 & $?$ \\
\hline Mox & $\begin{array}{l}\mathrm{HO}-1, \mathrm{SD}-1, \\
\text { TR-reductase }\end{array}$ & $?$ & $?$ \\
\hline
\end{tabular}


Table 1.1. Phenotypes of common polarization states. SR, Scavenger receptor: MR, Mannose receptor; HO-1, Heme Oxygenase-1; VEGF, Vascular endothelial growth factor; SD-1, sulfiredocin-1; TR-reductase, thioredoxin-reductase. (Kadl et al., 2010; Leitinger and Schulman, 2013; Murray and Wynn, 2011) 


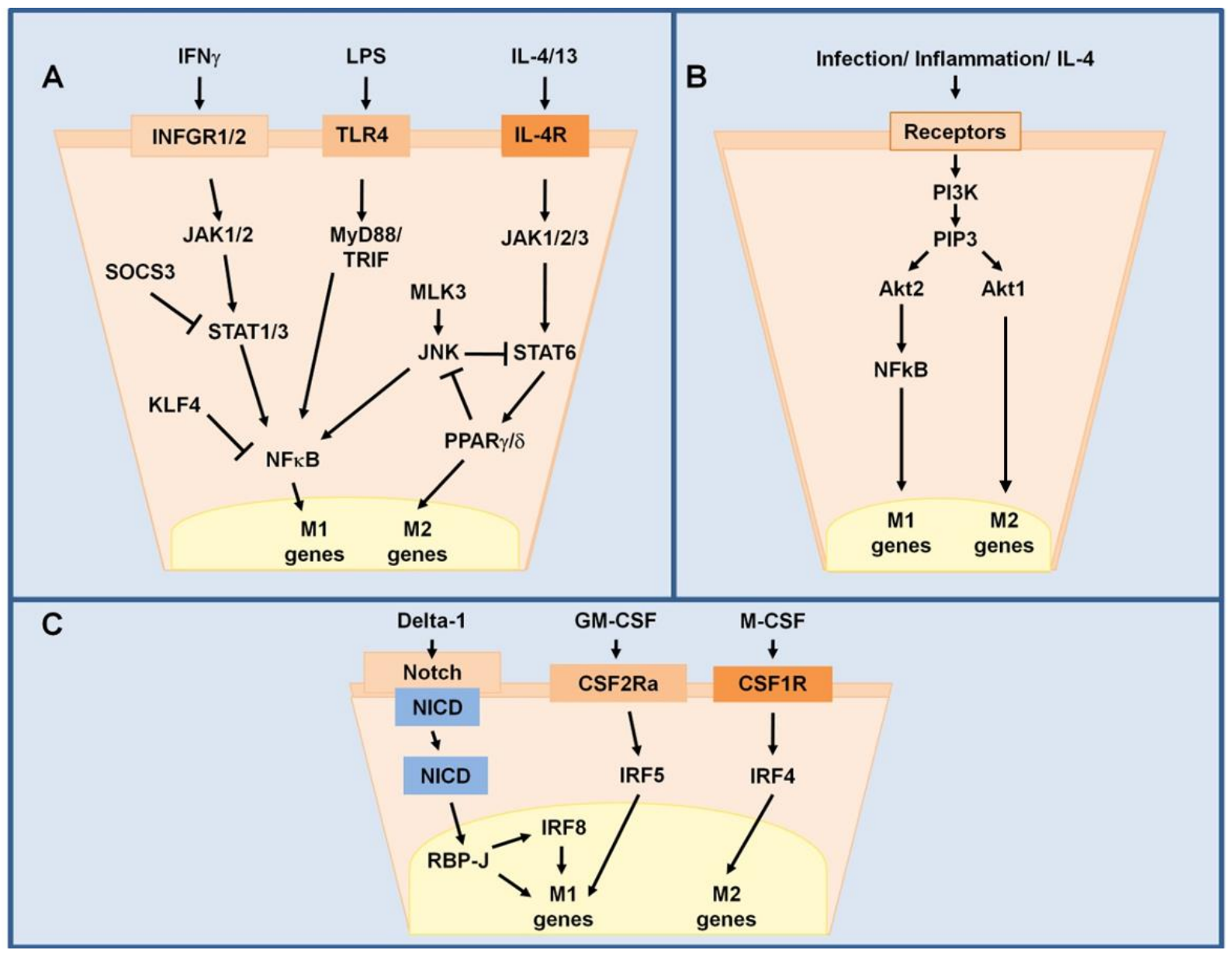


Figure 1.2. Major signaling pathways involved in M1/M2 M $\phi$ polarization. STAT1/3 and STAT6 regulate transcription of M1 and M2 genes following recognition of IFN $\gamma$ or IL-4/13 by their surface receptors and activation of JAKs (A). Differential activation of Akt1 or Akt2 via PI3K and PIP3 leads to either M2 or M1 polarization, respectively (B). Upon activation, the intracellular domain of Notch (NICD) is cleaved and activates IRF8 to promote M1 polarization. GM-CSF triggers M1 polarization via IRF5 while M-CSF induces M2 polarization via IRF4 (C). 


\section{Chapter 2: Rationale and Research Aims}

Hepatitis $\mathrm{C}$ virus (HCV) is known for its ability to establish a persistent infection in hepatocytes, which leads to chronic hepatitis, cirrhosis, and hepatocellular carcinoma. The virus accomplishes this in part by modulating and suppressing a wide variety of immune cell types and signaling pathways. M $\phi$ are important for the activation and direction of innate and adaptive immune responses, but their role in liver infection is particularly poorly understood. This is in part due to the presence of functionally distinct subsets within the population. In addition to the distinction between inflammatory (circulating) and liver resident $\mathrm{M} \phi$ (Kupffer cells), $\mathrm{M} \phi$ can also be directed towards the M1 or M2 phenotypes by classical or alternative activation pathways, respectively. M2 M $\phi$ are anti-inflammatory and immune suppressive, and are characterized in part by increased expression of scavenger receptors.

The scavenger receptor SR-AI is a marker for M2 M $\phi$ and a component of the $\mathrm{HCV}$ receptor complex. Of note, $\mathrm{SR}-\mathrm{AI}$ on $\mathrm{APC}$ s has been shown to inhibit $\mathrm{CD}^{+} \mathrm{T}$ cell function in models of tumor microenvironments. Our preliminary data has shown that hepatotropic viral infection in C57BL/6 mice leads to an increase in M $\phi$ positive for SR-AI. We hypothesize that $\mathrm{M} \phi$ activation in the liver is altered during viral infection, contributing to disease progression. I investigated this hypothesis by using a combination of live mouse and murine cell culture systems to pursue the following aims: 


\section{AIM 1. Investigating the effect of SR-AI receptor expression in controlling hepatic viral infection and progression of disease}

SR-AI is a known marker for alternatively activated, anti-inflammatory $\mathrm{M} \phi$ as well as a suppressor of TLR signaling and T cell activation. The observed increase of SR-AI expression on $\mathrm{M} \phi$ in virally infected livers is likely to be relevant to the pathogenesis of hepatotropic viruses and may even provide insight into the tolerogenic properties of the liver.

Flow cytometry has been used to examine the tempo and duration of SR-AI upregulation on liver $\mathrm{M} \phi$ following viral infection. The $\mathrm{SR}-\mathrm{AI}^{+}$cells generated in this system were characterized by flow staining for M2-specific surface markers and Luminex analysis of cytokines and chemokine production. Cells were further categorized based on which combinations of molecules they express.

I interrogated the suppressive capabilities of SR-AI+ liver $\mathrm{M} \phi$ via flow cytometric analysis of hepatic $\mathrm{T}$ and natural killer (NK) cells to determine if proliferation and activation of these cells was altered in the livers of SR-AI knockout mice. Natural killer (NK) cells were harvested and analyzed for activation and maturity markers as well as Granzyme B (GrB) production.

The functional readout of SR-AI's effect on control of hepatic viral infection and disease was histological examination of tissue health. Furthermore, liver sections from $\mathrm{WT}$ and SR-AI ${ }^{-/-}$ mice were stained for the presence of DNA damage and collagen deposition. 


\section{AIM 2. Characterizing the role of SR-AI in M $\phi$ polarization and its mechanism of action}

The liver is known to be a tolerogenic organ capable of dampening or altering the functions of immune cells during infection. Many aspects of the virally-infected liver, such as high levels of IL-10, have also been shown to contribute to the generation of M2 M $\phi$. I have used a mouse model of adenovirus infection to tease apart the mechanism(s) that contribute to SR-AI upregulation and M2 M $\phi$ activation in vivo.

The effects of SR-AI expression on the regulation of M2-associated surface markers and cytokines were examined by flow cytometry and Luminex analysis of $\mathrm{M} \phi$ isolated from the livers of SR-AI ${ }^{-/-}$mice after viral infection. Furthermore, the impact of SR-AI expression on M $\phi$ functionality was tested by measuring uptake by WT and SR-AI-deficient M $\phi$ of carboxylated latex beads, which approximate the surface charge of apoptotic cell debris.

While many studies have suggested that engagement of SR-AI initiates intracellular signaling, SR-AI contains no identifiable intracellular signaling motifs and therefore the exact mechanism of signal transduction is unknown. I have attempted to confirm other groups' findings that Mertk can associate with SR-AI to transduce signals by probing Mertk phosphorylation in $\mathrm{WT}$ and $\mathrm{SR}-\mathrm{AI}^{-/-}$mice via western blot. 


\title{
Chapter 3: Expression of scavenger receptor-AI promotes alternative activation of macrophages to limit hepatic inflammation and fibrosis
}

\begin{abstract}
The liver maintains an immunologically tolerant environment as a result of continuous exposure to food and bacterial constituents from the digestive tract. Hepatotropic pathogens such as hepatitis $\mathrm{C}$ virus ( $\mathrm{HCV}$ ) can take advantage of this niche and establish lifelong chronic infections causing hepatic fibrosis, and hepatocellular carcinoma. Macrophages $(\mathrm{M} \phi)$ play a critical role in regulation of immune responses to hepatic infection and regeneration of tissue. However, the factors crucial for $\mathrm{M} \phi$ in limiting hepatic inflammation or resolving liver damage have not been fully understood. In this work, we demonstrate that the expression of C-type lectin receptor scavenger receptor-AI (SR-AI) is crucial for promoting M2-like M $\phi$ activation and polarization during hepatic inflammation. Liver M $\phi$ uniquely upregulated SR-AI during hepatotropic viral infection and displayed increased expression of alternative $\mathrm{M} \phi$ activation markers such as YM-1, arginase-1, and IL-10 via the activation of Mertk associated with inhibition of mTOR. The expression of these molecules was reduced on M $\phi$ obtained from the livers of infected mice deficient for the gene encoding SR-AI (msrl). Furthermore, in vitro studies using an SR-AI-deficient M $\phi$ cell line revealed impeded M2 polarization and decreased phagocytic capacity. Direct stimulation with adenovirus was sufficient to activate M2 gene expression in the wild type (WT) cell line but not in the knockdown cell line. Importantly, tissue damage and fibrosis were exacerbated in $\mathrm{SR}-\mathrm{AI}^{-/-}$mice following hepatic infection and adoptive
\end{abstract}


transfer of WT bone marrow derived M $\phi$ conferred protection against fibrosis in these mice.

Taken together, our findings demonstrate that SR-AI expression on liver M $\phi$ promotes recovery from infection-induced tissue damage by mediating a switch to a pro-resolving $\mathrm{M} \phi$ polarization state. 


\section{Introduction}

Due to constant exposure to typically inflammatory stimuli from the gut via the portal vein (i.e. debris from commensal bacteria), the liver has evolved out of necessity to maintain a tolerogenic environment (171). Subsequently, pathogens such as HCV have come to fill this niche and can establish lifelong chronic infections $(172,173)$. While the liver is known to have remarkable regenerative capability, such persistent infections are characterized by liver fibrosis and cirrhosis, potentially leading to the development of hepatocellular carcinoma (174). The phenomenon of liver tolerance has been variously ascribed to dysfunctional activation of several immune cell compartments, including $M \phi(175)$. The specific role of $M \phi$ activation and the factors that control M $\phi$ activation, however, have not yet been well defined. In addition to monocytes and $\mathrm{M} \phi$ circulating throughout the bloodstream, the liver contains a specialized tissue-resident $M \phi$, the Kupffer cell, which is physically integrated into the structure of the sinusoid (176). Liver $\mathrm{M} \phi$ are responsible for the maintenance of healthy tissue through phagocytic clearance of apoptotic cells and foreign materials and through tissue repair and remodeling during wound healing $(13,177)$. Critically, $\mathrm{M} \phi$ are also major regulators of the inflammatory response to disease and infection, monitoring the microenvironment through an array of surface receptors and secreting appropriate cytokines and chemokines (178).

Depending on the inflammatory insults they encounter, $\mathrm{M} \phi$ populations can be directed to distinct phenotypic programs in a process known as $\mathrm{M} \phi$ polarization (179). Classical activation is stimulated by microbial products and proinflammatory cytokines (IFN $\gamma$ and/or LPS or TNF), and the resulting $\mathrm{M} 1 \mathrm{M} \phi$ are characterized by high antigen presentation, high production of IL12 and IL-23, and high production of nitric oxide (NO) and reactive oxygen intermediates (24). By contrast, alternative/M2 activation is mediated by IL-4, IL-10 and IL-13 and is characterized 
by little to no secretion of proinflammatory cytokines, increased secretion of anti-inflammatory cytokines, enhanced scavenging of cellular debris, and promotion of tissue remodeling and repair $(25,34)$. M2 M $\phi$ also upregulate several endocytic surface receptors, including scavenger receptor A (SR-AI/CD204) (24,27).

Scavenger receptors are phagocytic pattern recognition receptors that mediate the clearance of both endogenous (modified host molecules, apoptotic cells) and exogenous (microbes, foreign particles) material (180). Scavenger receptor A exists in two isoforms (I and II) that are co-expressed mainly on $\mathrm{M} \phi$ and have no functional differences; they are typically referred to collectively as SR-AI $(181,182)$. Via its collagenous extracellular domain, SR-AI is capable of binding natural ligands (LTA and LPS) as well as non-physiological ligands (acetylated or oxidized low-density lipoprotein [LDL] and maleylated bovine serum antigen [BSA]) (181). Indeed, scavenger receptor expression and function have been linked to a number of diseases, including atherosclerosis, non-alcoholic steatohepatitis, hepatocellular carcinoma, and transplant rejection $(179,183,184)$.

Many of these diseases may be linked to scavenger receptors via their involvement in $\mathrm{M} \phi$ polarization: SR-AI acts as both a marker and an activator of M2 activation (185). Notably, scavenger receptor function is also linked to $\mathrm{HCV}$ infection in that both SR-AI and SR-B1 can recognize and endocytose $\mathrm{HCV}$ proteins $(186,187)$. The exact function of $\mathrm{SR}-\mathrm{AI}^{+} \mathrm{M} \phi$ in hepatic viral infection, however, remains unknown. In the present study, we investigated the role of SRAI expression by $\mathrm{M} \phi$ in controlling tissue inflammation and repair during hepatic viral infection. This study shows that SR-AI expression on liver M $\phi$ protects against infection-induced tissue damage and fibrosis, possibly via mTOR-mediated modulation of M2 M $\phi$ polarization. These 
results provide insight into new targets for the design of therapeutic agents for chronic liver diseases caused by hepatic viral infections such as HCV. 


\section{Methods and Materials}

\section{Mice}

6-8 week old female C57BL/6 and SR-AI ${ }^{-/-}\left(\mathrm{B} 6 . \mathrm{Cg}-M s r 1^{t m l C s k} / \mathrm{J}\right)$ mice were purchased from Taconic Farms (Hudson, NY) and Jackson Laboratories (Sacramento, CA) respectively. Mice were housed in a pathogen-free facility and routinely tested for mouse hepatitis virus and other pathogens. Animals were handled according to protocols approved by the University of Virginia Institutional Animal Care and Use Committee.

\section{Viral infection}

Replication-defective recombinant adenovirus type 5 expressing ovalbumin (rAd5-OVA) under the human CMV promoter and lacking E1 and E3 genes were purchased from the Iowa Gene Transfer Vector Core (Iowa City, IA). Mice were injected intravenously with 5 x $10^{7} \mathrm{IU}$ AdOVA.

\section{Hepatic and splenic mononuclear cell isolation}

Mononuclear cells were isolated for further experimentation as described previously (188).

Briefly, livers were passed through a metal spleen screen and digested with $0.05 \%$ collagenase

IV (Sigma-Aldrich, St. Louis, MO) and intrahepatic mononuclear cells were purified via Histodenz density gradient centrifugation (Sigma-Aldrich, St. Louis, MO). Spleens were passed through a mesh spleen screen and mononuclear cells were purified by Ficoll gradient. 


\section{Flow cytometry and Luminex assay}

Antibodies against MHC-II, Thy 1.2, F4/80, CD11b (eBioscience, Sand Diego, CA), and SR-AI (R\&D Systems, Minneapolis, MN) were used for surface staining. $1.5 \times 10^{6}$ cells were blocked with anti-CD16/CD32 (2.4G2; University of Virginia, Charlottesville, VA) and incubated with the appropriate antibodies for 30 minutes at $4^{\circ} \mathrm{C}$ in Iscove's Modified Dulbecco's Medium (IMDM) supplemented with $2 \%$ fetal bovine serum (FBS) and $0.1 \% \mathrm{NaN}_{3}$. The cells were then washed and fixed in Cytofix/Cytoperm (BD Biosciences) according to the manufacturer's instructions prior to flow cytometry analysis. For intracellular cytokine staining, cells were incubated in Cytofix/Cytoperm (BD Biosciences) for 20 minutes and washed prior to addition of antibodies. For intracellular T cell IFN $\gamma$ detection, cells were restimulated for $5 \mathrm{~h}$ with $2 \mu \mathrm{g} / \mathrm{mL}$ of SIINFEKL peptide in the presence of monensin immediately after isolation. All samples were run on a BD FACS Canto II (BD Immunocytometry Systems, San Jose, CA) and analyzed using FlowJo software 8.8.6 (Tree Star Inc., Ashland, OR). For Luminex analysis, mononuclear cells were stained as above but in the absence of $\mathrm{NaN}_{3}$ and without fixation. The cells were resuspended in Hank's Buffered Salt Solution (HBSS) containing 1\% fetal calf serum (FCS) and 1mM EDTA and sorted into F4/80 ${ }^{\text {hi }} \mathrm{CD} 11 \mathrm{~b}^{\text {lo }} \mathrm{KC}$ or $\mathrm{F} 4 / 80^{\mathrm{lo}} \mathrm{CD} 11 \mathrm{~b}^{\text {hi }} \mathrm{M} \phi$ using a BD Influx Cell Sorter at the Flow Cytometry Core Facility (University of Virginia, Charlottesville, VA). Sorted

cell populations were cultured overnight in IMDM supplemented with $100 \mathrm{U} / \mathrm{mL}$ Pen Strep, 10\% Hyclone FBS, $2 \mathrm{mM}$ L-glutamine, and $10 \mu \mathrm{M} \beta$-mercaptoethanol. The resulting supernatants were submitted to the Flow Cytometry Core Facility for analysis using the Luminex MAGPIX assay system (Luminex, Austin, TX). 


\section{Fluorescent Microscopy}

Samples were prepared for fluorescent microscopy as described previously (189). In brief, mouse livers were fixed with periodate-lysine-paraformaldehyde (PLP) fixative and mounted in optimal cutting temperature (OCT) medium before being sectioned at $5 \mu \mathrm{m}$, blocked in $2.4 \mathrm{G} 2$ solution, and stained with antibodies from Biolegend, eBioscience, and R\&D Systems. Images were obtained with a Zeiss LSM-700 confocal microscope (Carl Zeiss MicroImaging GmbH, Jena, Germany).

\section{Quantitative Real-time PCR}

Density gradient-isolated mononuclear cell fractions from murine livers were enriched for $\mathrm{M} \phi$ by adherence for 2 hours to Primaria cell culture 6-well plates (Corning Inc., Corning, New York) at $37^{\circ} \mathrm{C}$. Total RNA from enriched cell fractions (or cultured cells in later experiments) was isolated using the RNeasy Plus Mini kit (Qiagen, Hilden, Germany) and reverse transcribed using the High Capacity RNA-to-cDNA kit (Applied Biosystems, Foster City, CA) according to manufacturers' instructions. Quantitative PCR was performed using TaqMan master mix and TaqMan primers for Mus musculus Msr1, Arg1, Chi313, Srebfl, Nos2, and Emr1 on an AB StepOne Plus Real-Time PCR System (all Applied Biosystems).

\section{TUNEL staining}

Liver tissue was fixed, embedded in OCT medium, and sectioned as described above. Sections were stained with TMR red TUNEL reaction mixture (Roche Diagnostics, Basel, Switzerland) according to manufacturer's instructions and imaged using an Olympus BX51 microscope (Olympus, Tokyo, Japan). 


\section{Cell Culture}

RAW 264.7 cells were obtained from ATCC and cultured in Dulbecco's Modified Eagle Medium (DMEM) supplemented with $10 \%$ FBS and $100 \mathrm{U} / \mathrm{mL}$ Pen Strep at $37^{\circ} \mathrm{C}$ and $5 \% \mathrm{CO}_{2}$. RAW cells were polarized by culturing 300,000 cells/well overnight in 24 -well plates before replacing the medium with complete culture medium supplemented with either LPS (300 ng/mL), IL-4/IL-13 (20 ng/mL, $10 \mathrm{ng} / \mathrm{mL})$, or dexamethasone (100 nM) and incubating for 2 hours at $37^{\circ} \mathrm{C}$. For select experiments, RAW cells were cocultured overnight with AdOva in complete culture medium at an MOI of 0.5 or 5.0 PFU AdOVA.

\section{Generation of msr1 Knockdown Cell Line}

A panel of four 29-mer shRNA plasmids targeted against the murine $m s r l$ gene was generated by and obtained from OriGene (Rockville, MD). Each of the four anti-msr 1 shRNA plasmids and the scramble control plasmid were packaged into lentiviral particles and transduced into RAW 264.7 cells following the manufacturer's instructions. The packaging plasmids ENV pCMV-VSVG, pRSV-REV, and Gag/Pol pMDLg/pRRE were kindly provided by Dr. Tim Bender (University of Virginia, Charlottesville, VA), amplified using OneShot TOP10 chemically competent $E$. coli (Invitrogen, Carlsbad, CA), and isolated using an Endotoxin-Free Plasmid Maxi Kit (Qiagen). Transduced RAW cells were isolated via puromycin selection and diluted to a single-cell suspension prior to subculturing.

\section{Western blots}

Cultured cells were lysed in buffer containing $\mathrm{NaF}, \mathrm{Na}_{4} \mathrm{P}_{2} \mathrm{O}_{7}, \mathrm{Na}_{3} \mathrm{VO}_{4}$, and protease inhibitor cocktail V (EMD Millipore, Temecula, CA) to preserve protein phosphorylation. Proteins were 
resolved on Mini-PROTEAN TGX precast gradient gels (BioRad, Berkeley, CA), transferred to PVDF membranes, and incubated with rabbit anti-phospho-mTOR (mAb, Cell Signaling Technology, Danvers, MA), anti-mTOR (mAb, Cell Signaling Technology), anti-phosphoMERTK (pAb, FabGennix, Frisco, TX), or anti-MERTK (pAb, FabGennix). The blots were then incubated with horseradish peroxidase (HRP)-linked anti-rabbit IgG (pAb, Cell Signaling Technology) and HRP-linked goat anti-Actin (Santa Cruz Biotechnology, Santa Cruz, CA) and visualized with an 80/20 mix of SuperSignal West Pico Chemiluminescent Substrate and Femto Chemiluminescent Substrate (Thermo Scientific, Rochester, NY).

\section{In vitro bead phagocytosis assay}

RAW and MSRC2 cells were polarized as described above for 2 hours and washed with serumfree medium. A pre-warmed suspension of PE-conjugated FluoroSphere carboxylated beads (Molecular Probes, Eugene, OR) was added to the cells (500 $\mu \mathrm{L}$ serum-free medium and $1.5 \mu \mathrm{L}$ beads per well) which were incubated for 2 hours at $37^{\circ} \mathrm{C}$. The cells were washed 3 times with PBS and analyzed by flow cytometry. Quantification of internalized beads was determined by gating the PE histogram past the first peak to exclude beads stuck to the cell surface.

\section{Adoptive transfer of BMDMs}

Bone marrow was extracted from the femurs of WT C57BL/6 mice and cultured for 2 hours at $37^{\circ} \mathrm{C}$ in DMEM supplemented with $10 \% \mathrm{FBS}, 100 \mathrm{U} / \mathrm{mL}$ Pen Strep, and $2 \mathrm{mM}$ L-glutamine to adhere resident bone marrow $\mathrm{M} \phi$. The adherent cells were resuspended in culture medium containing 10\% L-292 medium and allowed to differentiate for 7 days. The medium was replaced with fresh differentiation medium every 2 days. Recipient $\mathrm{SR}-\mathrm{AI}^{-/-}$mice were treated 
with $100 \mu \mathrm{L}$ clodronate liposome suspension (Encapsula NanoSciences, Brentwood, TN) via tail vein injection one day prior to transfer of $2 \times 10^{6}$ differentiated BMDMs, also via tail vein injection. Approximately 8 hours following BMDM transfer, the recipients were infected with 5 x $10^{7}$ PFU AdOVA. The mice were sacrificed after 14 days for further experimentation.

\section{Statistical analysis}

Statistical significance was determined using either the two-tailed Student's $t$ test or one-way analysis of variance (ANOVA) where appropriate. Analysis was performed using Prism software (GraphPad Software Inc., La Jolla, CA). Values of $p<0.05$ were regarded as statistically significant. Asterisks $(*, * *$, and $* * *)$ denote $p<0.05, p<0.01$, and $p<0.001$, respectively. 


\section{Results}

\section{SR-AI is upregulated on M $\phi$ following hepatotropic viral infection.}

The expression of SR-AI has been reported to modulate the activation and polarization of M $\phi(185,190)$. To assess the impact of SR-AI expression on regulation of hepatic immune responses to infection and development of tissue damage, we injected 5e7 PFU of OVAexpressing adenovirus (AdOVA) into the tail vein of 6-8 week old C57BL/6 mice. The virus travels along the tail vein to the liver where the large majority is taken up by $\mathrm{M} \phi$ and hepatocytes, establishing a hepatotropic infection. In order to fully examine the phenotype of SR-AI ${ }^{+}$liver M $\phi$, we first determined the tempo and specificity of SR-AI expression in infection. Whole livers were harvested from AdOVA-infected mice and, following homogenization and density gradient centrifugation, liver $\mathrm{M} \phi$ were separately identified as liver-resident Kupffer cells $\left(\mathrm{KC}, \mathrm{F} 4 / 80^{\mathrm{hi}} \mathrm{CD} 11 \mathrm{~b}^{\text {lo }}\right)$ or non-resident circulating $\mathrm{M} \phi\left(\mathrm{F} 4 / 80^{\text {lo }} \mathrm{CD} 11 \mathrm{~b}^{\text {hi }}\right)$ by flow cytometry

(Fig. 3.1A). Increased expression of SR-AI was observed on both $\mathrm{KC}$ and non-resident liver M $\phi$ seven days after AdOVA infection, a time point coinciding with viral clearance and the beginning of tissue repair (Fig. 3.1B, C). In contrast, there was no upregulation of SR-AI on splenic $\mathrm{M} \phi$ following infection (Fig. 3.1B, C), suggesting that the specific upregulation of SR-AI on liver $\mathrm{M} \phi$ was possibly a result of viral recognition at the site of infection. Importantly, fluorescent microscopy of histochemically stained liver sections confirmed upregulation of SRAI detected by flow cytometry and also revealed that $\mathrm{SR}-\mathrm{AI}^{+}$liver $\mathrm{M} \phi$ co-expressed the M2 surface marker YM-1 (Fig. 3.1D). Taken together, these results suggest that SR-AI may trigger signaling involved in alternative activation in liver $\mathrm{M} \phi$ during hepatotropic viral infection. 


\section{SR-AI modulates M $\phi$ activation upon viral insult.}

We next investigated whether the increase in SR-AI expression following infection indeed correlated with a shift in M $\phi$ activation. Luminex analysis of FACS-sorted $\mathrm{KC}$ and circulating $\mathrm{M} \phi$ showed that production of the M2 cytokine IL-10 by both populations was increased on day 7 post-infection (Fig. 3.2A). KC tended to produce higher levels of IL-10 compared to non-resident M $\phi$. Several proinflammatory mediators typical of M1 activation (IL6 , MIP-1 $\alpha$, and MIP-1 $\beta$ ) were also secreted by these cells in both naive and infected conditions, suggesting that liver M $\phi$ may assume an "M2-like" intermediate phenotype with some M1 characteristics (Fig. 3.2A).

Based on the finding that SR-AI+ $\mathrm{M} \phi$ in the liver exhibited M2-like characteristics, we examined the status of $\mathrm{M} \phi$ activation in $\mathrm{WT}$ and $\mathrm{SR}-\mathrm{AI}^{--}$animals to determine whether SR-AI expression contributes to M2 polarization. Indeed, when M $\phi$-enriched mononuclear liver cell fractions from infected animals were analyzed by qPCR, liver $\mathrm{M} \phi$ in $\mathrm{SR}-\mathrm{AI}^{-{ }^{-}}$mice were impaired in their expression of the M2 genes argl, chi313 (YM-1), and il-10 (Fig. 3.2B). Interestingly, expression of the M1 gene nos 2 was also reduced in the cells obtained from SR-AI I- mice compared to WT controls. When sorted SR-AI ${ }^{--} \mathrm{M} \phi$ and $\mathrm{KC}$ were analyzed by Luminex, both populations upregulated IL-10 secretion following infection but to a lesser degree than their WT counterparts (Fig. 3.2C). We next asked whether SR-AI ${ }^{--} \mathrm{M} \phi$ had lost the ability to become alternatively activated by attempting to force M2 polarization via 2-hour stimulation with IL-4 and IL-13. Both the WT and SR-AI ${ }^{-/-} \mathrm{M} \phi$ were capable of upregulating arg 1 expression in the presence of these strong M2 stimuli, but the level of Arg-1 expression by SR-AI ${ }^{-/}$cells was still lower than WT cells (Fig. 3.2D). 


\section{Mice deficient in SR-AI develop exacerbated infection-induced liver tissue damage and} fibrosis.

Given the timing of the appearance of SR-AI' $\mathrm{M} \phi$ in the course of infection and their potential role in wound repair and tissue remodeling following injury and infection, we performed histological examinations on liver sections from $\mathrm{WT}$ and $\mathrm{SR}-\mathrm{AI}^{-/-}$mice to interrogate possible protective qualities of SR-AI expression. Post-infection liver tissue damage appeared dramatically more severe in the absence of SR-AI. H\&E staining of liver tissue sections showed increased inflammatory infiltrates in the $\mathrm{SR}-\mathrm{AI}^{-/-}$mice compared to $\mathrm{WT}$ at 7 and 14 days postinfection (Fig. 3.3A). Infection-induced hepatocyte DNA damage was also increased in the absence of SR-AI as measured by TUNEL staining (Fig. 3.3B). Collagen staining by Trichrome C revealed deposition of extracellular matrix between cells (in blue) in the knockout liver 14 dpi (Fig. 3.3C). No positive staining was observed in the WT liver at day 14 or in either mouse at day 7 post-infection. Together, these data suggest that the expression of SR-AI on liver $\mathrm{M} \phi$ plays a protective role in viral infection. $\mathrm{SR}-\mathrm{AI}^{+}$liver $\mathrm{M} \phi$ may thus comprise an alternatively activated subset involved in wound repair and tissue remodeling.

\section{T cell response to hepatotropic infection is not inhibited by $S R-A I^{+} M \phi$, despite PD-LI coexpression.}

To address the question of how SR-AI expression on liver $\mathrm{M} \phi$ translates to improved tissue health following viral infection we investigated the status of the hepatic $\mathrm{T}$ cell population by flow cytometry. 7 days following infection, the size of the $\mathrm{CD}^{+} \mathrm{T}$ cell population in the SR$\mathrm{AI}^{-/-}$liver tended to be smaller than that of the WT liver, but this difference was not statistically 
significant (Fig. 3.4A, B). The size of the $\mathrm{CD}^{+} \mathrm{T}$ cell population was consistent in spleens from the two animals, as were the $\mathrm{CD}^{+}$populations in both organs. However, comparing IFN $\gamma$ expression across these populations of $\mathrm{CD}^{+} \mathrm{T}$ cells following SIINFEKL restimulation showed no significant effect, demonstrating that the effector function of these liver $\mathrm{CD} 8^{+}$cells was not inhibited in $\mathrm{SR}_{-} \mathrm{AI}^{-/-}$mice (Fig 3.4C, D). To explain the difference in the size of the CD8 ${ }^{+}$ compartment, we hypothesized that liver $\mathrm{M} \phi$ upregulate the programmed death ligand PD-L1 in the absence of SR-AI, but this was not the case. On the contrary, KC and M $\phi$ obtained from SR$\mathrm{AI}^{-/-}$livers expressed less PD-L1 than their WT counterparts (Fig. 3.5). From these data, we concluded that modulation of hepatic T cell function was not the main mechanism by which SR$\mathrm{AI}^{+} \mathrm{M} \phi$ confer protection against virally-induced tissue damage.

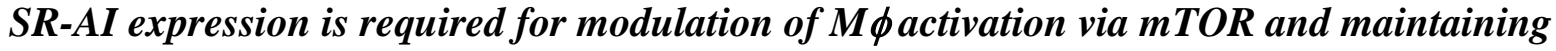 phagocytic ability.}

In order to further investigate a direct effect of SR-AI on $\mathrm{M} \phi$ activation and function, we established a cell line that recapitulated the $\mathrm{SR}-\mathrm{AI}^{-/-}$mice. To accomplish this, plasmids containing shRNA sequences targeted against the $m s r l$ gene were loaded into lentivirus particles via a lentiviral packaging cell line. These lentiviruses were then administered to the RAW 264.7 murine $\mathrm{M} \phi$ cell line, after which individually infected cells were clonally expanded and tested for knockdown efficiency via flow cytometry of SR-AI (Fig. 3.6) and qPCR of msrl. Subclones MSRC1 and MSRC2 showed significant knockdown of msr1 message, but MSRC2 showed more dramatic reduction in SR-AI surface expression than that in MSRC1 (Fig. 3.7A, B). Stable SR-AI knockdown persisted through at least 20 passages in culture, as well as through freeze- 
thaw cycles (data not shown). The RAW 264.7 cell line (hereafter referred to as RAW cells) can be reliably polarized in vitro via stimulation with LPS (M1) or IL-4/IL-13 (M2). We confirmed $\mathrm{M} \phi$ polarization using real-time PCR for the prototypical M1 and M2 genes arginase (arg1) and iNos (nos2) (Fig. 3.8A). Notably, msrl gene expression appeared to track with M2 polarization (Fig. 3.8B). When exposed to M2 stimuli, RAW cells exhibit robust upregulation of arg1 and chi313 (encoding YM1) while MSRC2 cells show minimal upregulation, in agreement with the results obtained from $\mathrm{SR}-\mathrm{AI}^{-/-}$mice (Fig. 3.7C). The lipid metabolism gene srebfl was included as an irrelevant control, and remained unchanged in the knockdown cell line under all stimulation conditions (Fig. 3.7D).

While stimulation with LPS or IL-4/IL-13 are reliable ways to induce specific aspects of $\mathrm{M} \phi$ polarization, we speculated that viral infection represented a unique mode of stimulation via SR-AI-mediated recognition, and therefore we attempted to stimulate RAW and MSRC2 cells by directly adding AdOVA in vitro. Overnight incubation with virus was enough to stimulate upregulation of both $\arg 1$ and nos 2 and the nos 2 effect was dose-dependent with viral MOI (arg1 expression actually decreased slightly at $0.5 \mathrm{MOI}$ when compared to uninfected). Strikingly, Argl expression by MSRC2 cells remained unchanged upon addition of virus, and nos2 upregulation was only observed at 5.0 MOI and to a very small degree when compared to the RAW cell expression (Fig. 3.7E).

We next sought to investigate the mechanism by which SR-AI expression alters M $\phi$ gene expression. While many studies implicate SR-AI signaling in biological processes, the exact mechanism remains unclear. Previous reports that activation of mammalian target of rapamycin (mTOR) regulates scavenger receptor expression lead us to investigate whether mTOR phosphorylation could in turn be regulated by expression of SR-AI $(191,192)$. When analyzed 
by western blot, SR-AI knockdown cells exhibited enhanced mTOR phosphorylation compared to SR-AI sufficient cells under all stimulation conditions (Fig. 3.7F, G). While SR-AI possesses no recognized intracellular signaling motif, it has been suggested that SR-AI associates with Mer receptor tyrosine kinase (Mertk) in order to transduce signals (193). Indeed, western blot analysis revealed Mertk phosphorylation to be impaired in SR-AI knockdown cells stimulated with M1 or M2 cocktails as compared to their WT counterparts (Fig. 3.7F, H). Taken together, these results suggest that the activation of Mertk may lead to inhibition of the mTOR pathway and be involved in SR-AI-mediated alteration of $\mathrm{M} \phi$ activation.

Alternatively activated $\mathrm{M} \phi$ have been reported to participate in wound remodeling and tissue repair $(194,195)$. To determine the contribution of SR-AI to the wound healing process, we analyzed the phagocytic capability of RAW and MSRC2 cells by quantifying internalization of carboxylated fluorescent beads, whose negative surface charge approximates that of an apoptotic cell. Both cell lines exhibited approximately equal phagocytic capability in the absence of virus or when exposed to low doses of virus. Interestingly, RAW cells exhibited decreased phagocytosis with $0.5 \mathrm{MOI}$ of virus compared to uninfected cells but this deficit was absent with 5.0 MOI of virus. However, at a higher dose of virus, bead uptake by MSRC2 cells progressively decreased and MSRC2 cells treated with 5.0 MOI of virus were able to internalize fewer beads than their RAW counterparts (Fig. 3.9A, B). These data indicate that direct stimulation of $\mathrm{M} \phi$ by high doses of virus elicit $\mathrm{M} 2$ polarization, but this response is inhibited in the absence of SR-AI. 
Transfer of SR-AI $I^{+}$M into SR-AI-deficient mice protects against infection-induced tissue damage and fibrosis.

We next investigated whether SR-AI+ $\mathrm{M} \phi$ are able to protect from the development of fibrosis in $\mathrm{SR}-\mathrm{AI}^{-/-}$mice. First, $\mathrm{SR}-\mathrm{AI}^{-/-}$mice were treated with clodronate to deplete the endogenous liver M $\phi$ population before receiving an adoptive transfer of WT BMDMs intravenously (Fig. 3.10A). Transfer of SR-AI ${ }^{+} \mathrm{M} \phi$ derived from WT mice was verified by the presence of SR-AI $I^{+} \mathrm{M} \phi$ in SR-AI ${ }^{-/}$recipient mice (Fig. 3.10C). The animals were then infected with AdOVA for 14 days and the degree of liver fibrosis was assessed by Trichrome $\mathrm{C}$ staining. Remarkably, while the SR-AI ${ }^{--}$mice accumulate a significant degree of fibrosis, knockout mice that received WT BMDMs prior to infection did not develop fibrosis similar to that of WT mice (Fig. 3.10B). These results suggest that manipulation of SR-AI signaling and adoptive transfer of SR-AI ${ }^{+} \mathrm{M} \phi$ may represent potential therapeutic targets for preventing the development of hepatic fibrosis.

\section{Liver NK cell GrB is enhanced in the absence of SR-AI.}

Finally, since hepatic NK cells are known to modulate hepatic fibrosis via interaction with collagen-producing stellate cells, we investigated how NK cell maturation and activation were altered in SR-AI ${ }^{--}$mice. The size of the NK cell population in the knockout liver and the spleen were not significantly different when compared to WT (Fig. 3.11A), and NK cell maturation (as tracked by CD11b/ CD27 co-staining) also appeared comparable between animals (Fig. 3.11B, C). When stained for intracellular $\mathrm{GrB}$, however, $\mathrm{NK}$ cells from $\mathrm{SR}_{-} \mathrm{AI}^{--}$mice displayed enhanced production compared to WT (Fig. 3.11D, E). This result was surprising 
given that enhanced NK cell activation is thought to result in increased killing of activated stellate cells and better control of fibrosis, while our earlier findings demonstrate that ablation of SR-AI leads to more severe tissue damage by all measures. Further experimentation will be required in order to determine what effect NK cell GrB production has on tissue damage in the $\mathrm{SR}-\mathrm{AI}^{-/-}$liver and how SR-AI regulates this process. 


\section{Discussion}

The liver is a highly regenerative organ with a unique immune repertoire that houses over $80 \%$ of the body's macrophages, including liver-resident KC and non-circulating M $\phi$. These M $\phi$ play a unique role in maintaining homeostatic immune tolerance in the liver, and as described in this work, orchestrate inflammatory responses and restore tissue homeostasis following injury. Here, we describe the functional characteristics of SR-AI+ $\mathrm{M} \phi$ and their protective role in fibrosis development during hepatotropic viral infection. SR-AI expression steadily increases at later time points in infection, which parallels the ability of $\mathrm{SR}-\mathrm{AI}^{+} \mathrm{M} \phi$ to produce antiinflammatory mediators, express M2-like markers, perform efficient phagocytosis, and limit the deposition of fibrotic tissue. Collectively, these observations identify SR-AI as a key regulator and potential target in preventing liver fibrosis.

As a scavenger receptor, SR-AI can bind a variety of polyanionic ligands, including LDL, bacterial products, polysaccharides, and nucleic acids. Interestingly, M2-like features were reduced in $\mathrm{SR}-\mathrm{AI}^{--}$mice (both in vivo and under M2-polarizing conditions ex vivo) and in vitro in cultured M $\phi$ with deficient SR-AI expression. Given that each of these conditions is likely to have a different composition of SR-AI ligands, the similarities in M $\phi$ phenotypes indicate that the identity of the ligands might not be crucial for determining the polarizing function of SR-AI. Rather, SR-AI signaling upon engagement with specific ligands may play a pivotal role in influencing M2-like M $\phi$ polarization. However, expression of iNOS (typically associated with $\mathrm{M} 1$ polarization) was decreased in $\mathrm{M} \phi$ from the $\mathrm{SR}-\mathrm{AI}^{-/-}$animals, tracking with the M2-like phenotype exhibited by SR-AI ${ }^{+} \mathrm{M} \phi$. Differences in the quality and quantity of SR-AI ligands may underlie this mosaic polarization phenotype. Furthermore, redundancy in scavenger receptor repertoires and other polarizing factors may be driving these intermediate polarization 
states. Indeed, the loss of M2-like features was more pronounced in cell lines lacking expression of SR-AI when compared to $\mathrm{SR}-\mathrm{AI}^{-/-}$mice, underscoring that $\mathrm{M} \phi$ polarization in vivo includes a spectrum of activation states rather than absolute M1 or M2 phenotypes. Recent reports have also shown that production of pro-inflammatory mediators by $\mathrm{M} 2 \mathrm{M} \phi$ subsets is not uncommon (196-198). It is therefore likely that the polarization state of SR-AI+ liver $\mathrm{M} \phi$ following viral infection represents a crossover M2-like state with some M1 features. Moreover, the inhibition of M2 polarization in SR-AI deficient M $\phi$ RAW cells occurred in the complete absence of potential physiological stimuli such as apoptotic cells or viral particles. This finding indicates that in addition to its role during infection, SR-AI contributes to the M2 polarization signaling pathway even under homeostatic conditions.

Intriguingly, SR-AI was differentially expressed in liver $\mathrm{M} \phi$ and $\mathrm{KC}$ : SR-AI expression peaked in liver $\mathrm{M} \phi$ at day 7 post-infection and returned to basal levels by day 14 . In contrast, $\mathrm{KC}$ expression of SR-AI was maintained at high levels from day 7 to day 21 post-infection. These differences prompt interesting questions regarding distinct functions of these two $\mathrm{M} \phi$ populations. A likely explanation of these differences is that $\mathrm{KC}$ are the predominant M2like cells mediating tissue recovery in hepatotropic viral infection as they continue to express high levels of the M2-promoting marker SR-AI. KC are thought to arise from liver-resident yolk-sac derived precursors; meanwhile, non-resident liver $\mathrm{M} \phi$ are derived from monocyte precursors from the bone marrow. Although there is limited information regarding the expression of SR-AI during M $\phi$ development, it is possible that expression of SR-AI and other M2 effectors are programmed into liver-resident $\mathrm{M} \phi$ precursors. However, deposition of fibrotic tissue was minimized upon transfer of SR-AI+ $\mathrm{BMDMs}^{+}$into $\mathrm{SR}-\mathrm{AI}^{-/-}$mice, suggesting that the local tolerogenic environment may also induce SR-AI and other M2-like properties in M $\phi$ 
originating from extrahepatic sources. Furthermore, the balance of M1 and M2 M $\phi$ at the site of infection is directly related to the development and progression of tissue injury. While proresolving M2 M $\phi$ subsets are responsible for the resolution of inflammation and the clearance and remodeling of scar tissue, M1 M $\phi$ (or even other M2 M $\phi$ subsets) can actively contribute to production of extracellular matrix and further tissue damage. Our studies report that SR-AI liver $\mathrm{M} \phi$ are necessary for optimal recovery from infection, as measured by the presence of inflammatory infiltrates, fibrotic lesions, and hepatocellular DNA damage (Fig. 3A-C).

The molecular and cellular cues that program $\mathrm{M} \phi$ activation thus require further investigation and may have significant implications for the development and function of these cells. Our findings implicate SR-AI expression as a possible driver of alternative $\mathrm{M} \phi$ activation in hepatotropic viral infection. The balance between M1 and M2 M $\phi$ activation (and additional subtypes of $\mathrm{M} 2 \mathrm{M} \phi)$ is a key determinant of recovery from tissue injury and progression to fibrosis. Consequently, the idea that the scavenger receptor SR-AI acts as a switch to turn on resolution of inflammation and repair of tissue injury is a promising avenue to understand $\mathrm{M} \phi$ polarization in the pathogenesis of chronic liver diseases. 
A
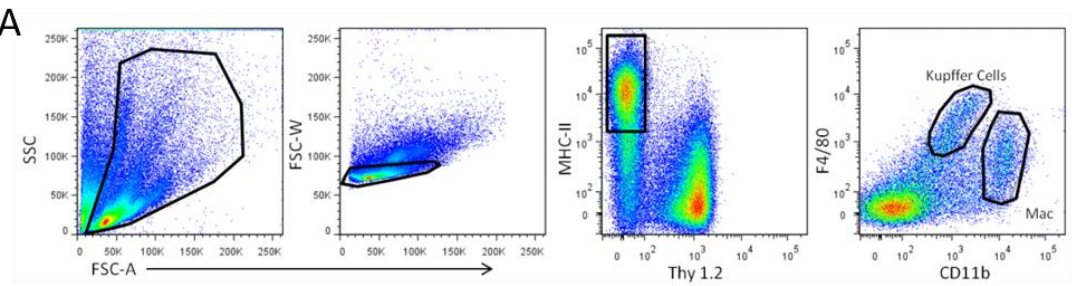

$\star$ Kupffer Cells

$\rightarrow$ Liver $M \phi$

- Spleen M $\phi$
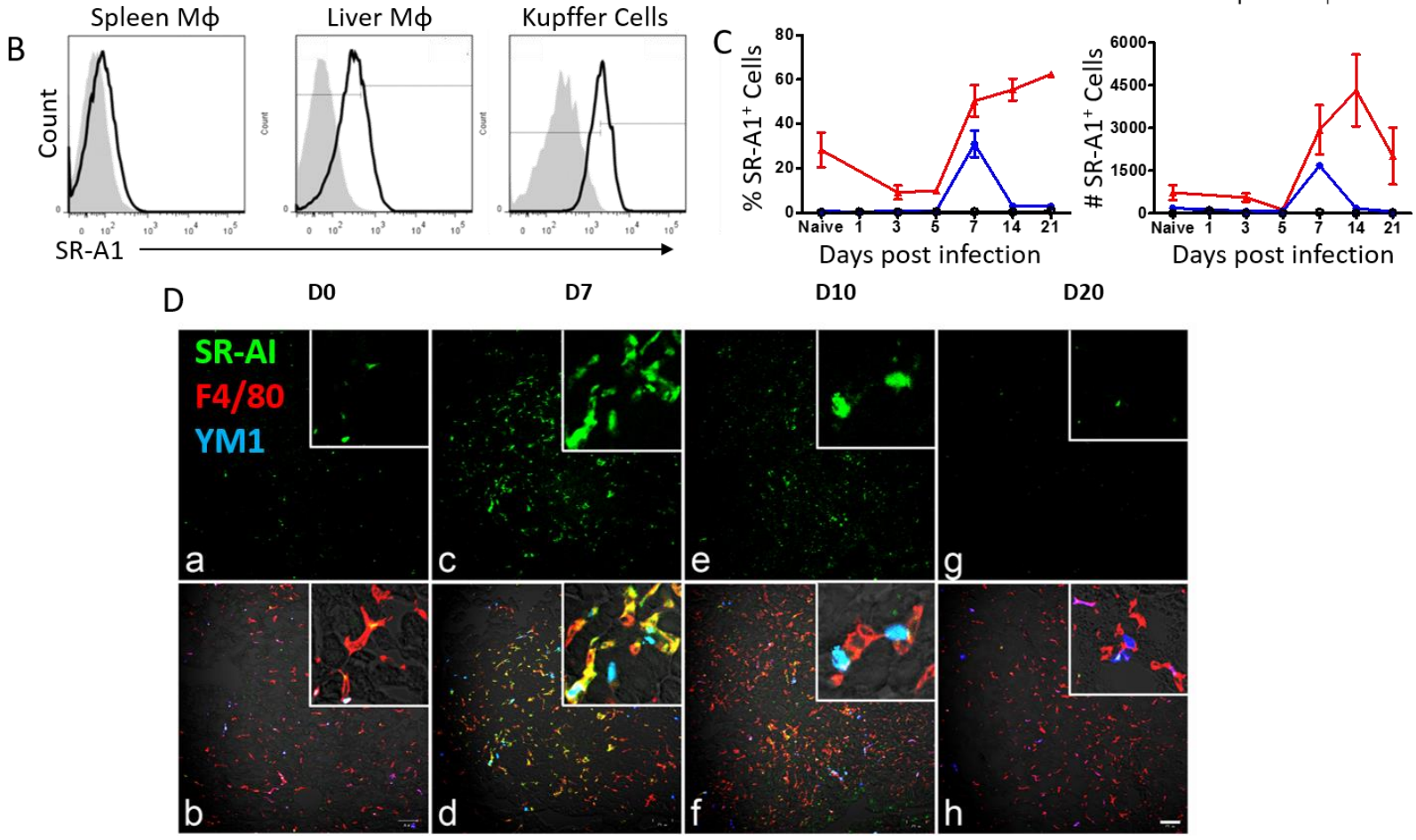
Figure 3.1. SR-AI is upregulated on $\mathrm{M} \phi$ following hepatic viral infection. (A) Flow

cytometry gating strategy for liver macrophages. Mononuclear cells were separated from whole liver homogenate via density gradient centrifugation and live singlets were gated on Thy1.2MHC-II. F4/80 ${ }^{\text {hi }} \mathrm{CD} 11 \mathrm{~b}^{\text {mid }}$ cells were identified as liver resident Kupffer cells and F4/80 ${ }^{\text {mid }} \mathrm{CD} 11 \mathrm{~b}^{\text {hi }}$ cells were identified as nonresident macrophages. (B) SR-AI surface expression (black trace) vs isotype control (gray histogram) in spleen $\mathrm{M} \phi$, liver $\mathrm{M} \phi$, and Kupffer cells at day 7 post infection. (C) Time course of frequency and number of SR-AI ${ }^{+}$cells (determined by gating on isotype control) during AdOVA infection. Data points are mean \pm SEM of $n=3$ mice. (D) Immunofluorescence microscopy of sections from AdLacZ infected mouse liver at $0,7,10$, and 20 days post infection ( x 100 magnification and scale bar $=100 \mu \mathrm{m}$, insert x 200 magnification). Panels a, c, e, and g show SR-AI single surface staining in green; panels b, d, f, and h show merged staining of SR-AI (green), F4/80 (red), and YM1 (blue). 
A
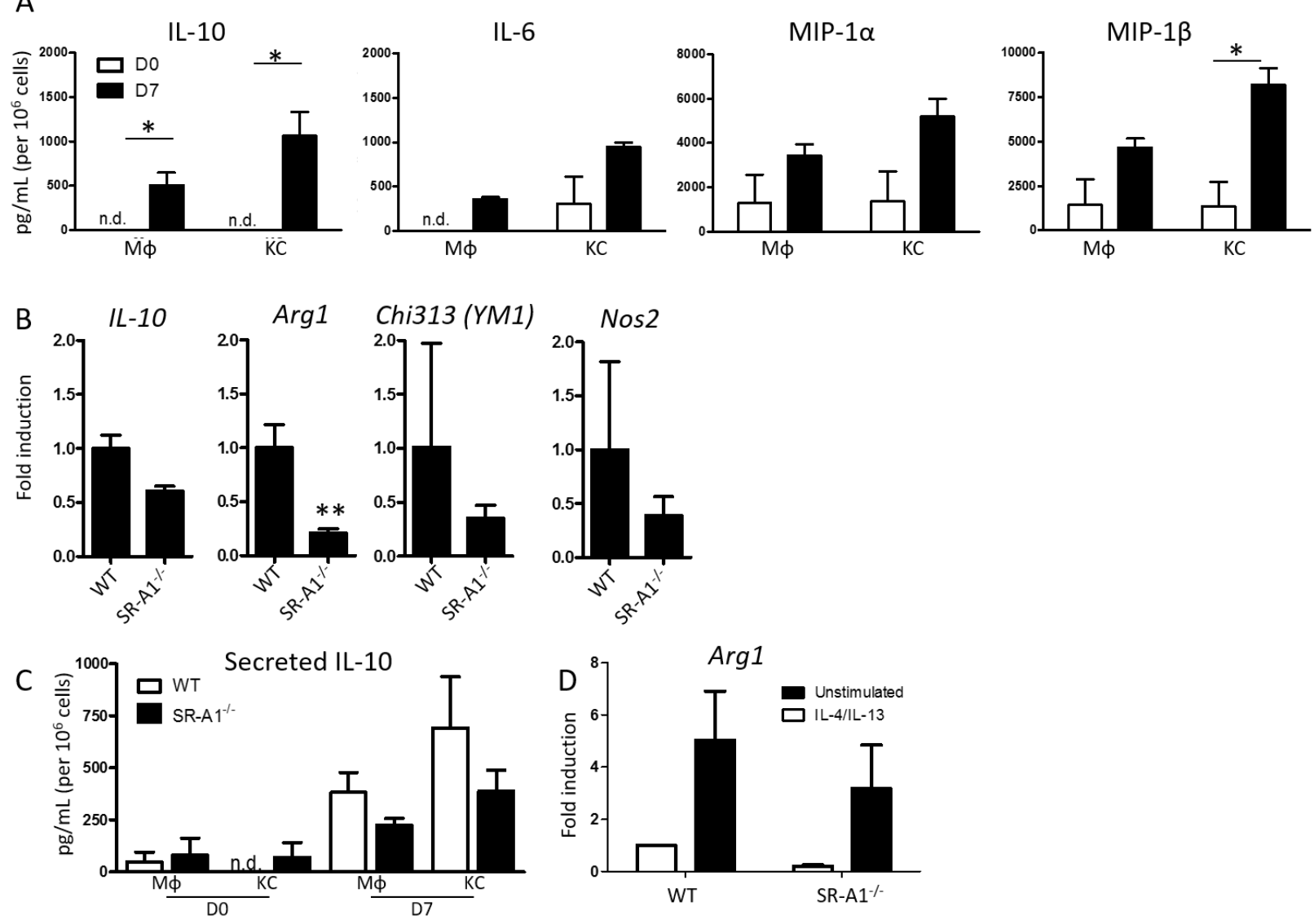
Figure 3.2. SR-AI modulates $M \phi$ activation upon viral insult. (A) Luminex quantification of cytokines and chemokines in supernatants collected from FACS sorted liver KCs and M $\phi$ from infected WT mice following overnight culture. Data are mean \pm SEM of $n=3$ mice. (B) qPCR analysis for expression of M2-related genes in M $\phi$-enriched mononuclear cell fractions from WT and SR-AI ${ }^{-/-}$livers on day 7 post infection. Expression levels were calculated via the ddCT method and normalized to HPRT expression, data are mean \pm SEM for $n=3$ mice. (C) Luminex data of IL-10 levels in supernatants from sorted $\mathrm{M} \phi$ or $\mathrm{KC}$ from WT and SR-AI ${ }^{-/-}$mice at day 7 post infection. Data are mean \pm SEM for $n=3$ mice. (D) Arginase 1 qPCR analysis of $M \phi$ from infected WT or SR-AI ${ }^{-/-}$livers cultured for $2 \mathrm{~h}$ in either plain media or media with IL-4 and IL-13 to induce M2 polarization. Expression levels were calculated as in $\mathbf{A}$, data are mean \pm SEM for $\mathrm{n}=3$ mice. 

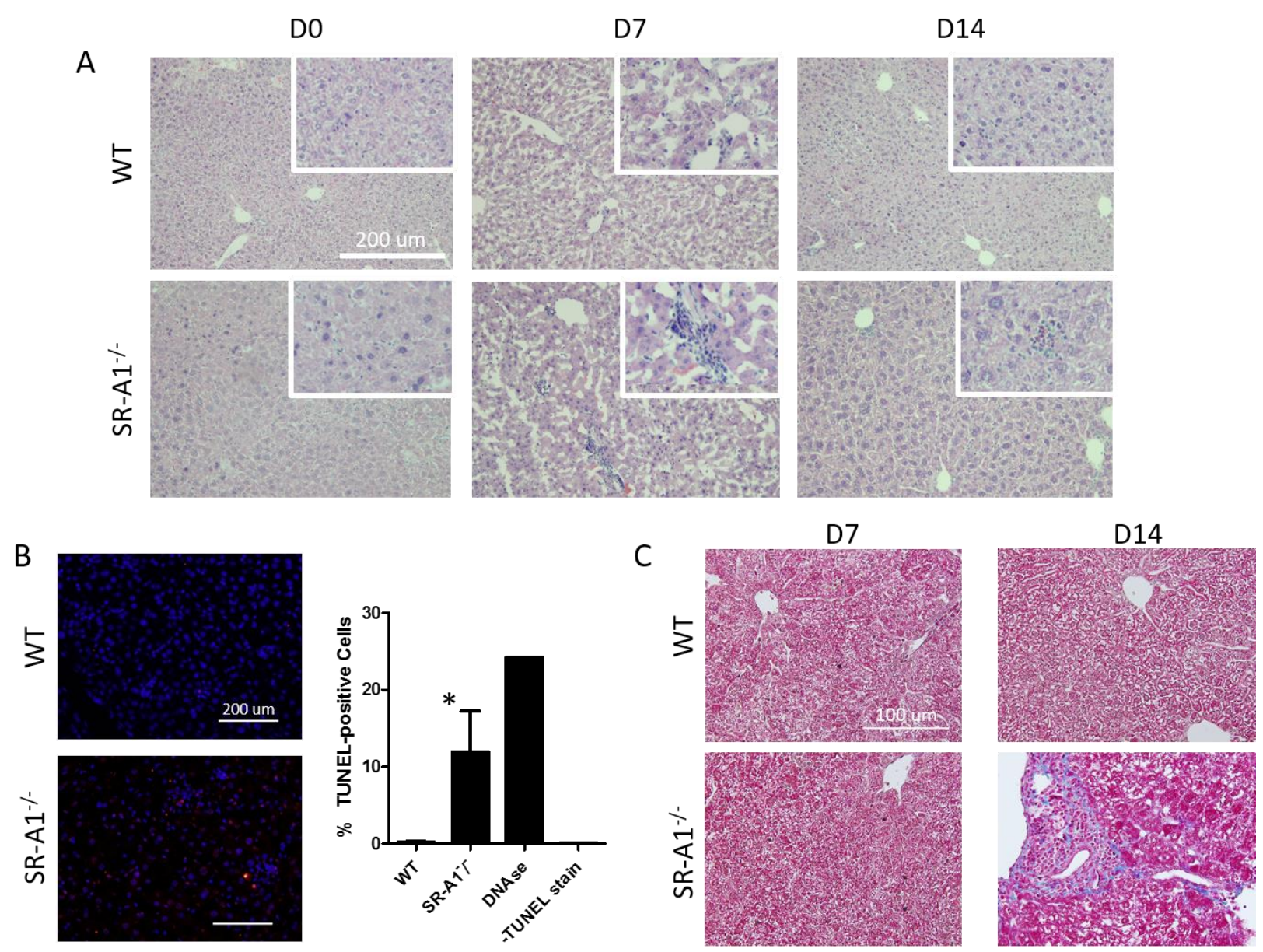
Figure 3.3. Infection-induced tissue damage is more severe in the absence of SR-AI. (A) $\mathrm{H} \& \mathrm{E}$ staining of liver sections obtained from $\mathrm{WT}$ and $\mathrm{SR}-\mathrm{AI}^{-/-}$mice 0,7 , or 14 days after tail vein injection of 5e7 PFU of AdOVA (x 100 magnification and scale bars $=200 \mu \mathrm{m}$, insert x 200 magnification). Images are representative of 3 independent experiments. (B) Visualization of cell damage by TUNEL staining of WT and SR-AI ${ }^{-/-}$liver sections 7 days post infection (x 100 magnification and scale bars $=200 \mu \mathrm{m}$, insert x 200 magnification). Staining was quantified by dividing the number of positive red stained cells by the total number of blue counter stained cells. Data are mean \pm SEM, $* \mathrm{P}<0.05$ vs WT mice. (C) Trichrome staining for collagen in liver sections from WT and SR-AI ${ }^{-/-}$mice 7 and 14 days post infection (x100 magnification and scale bars $=200 \mu \mathrm{m})$. Images are representative of 3 independent experiments. 
A

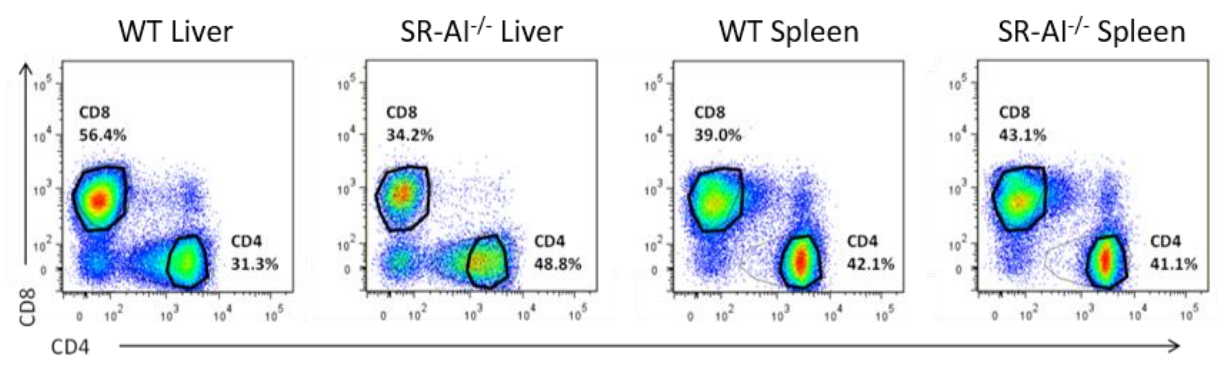

B
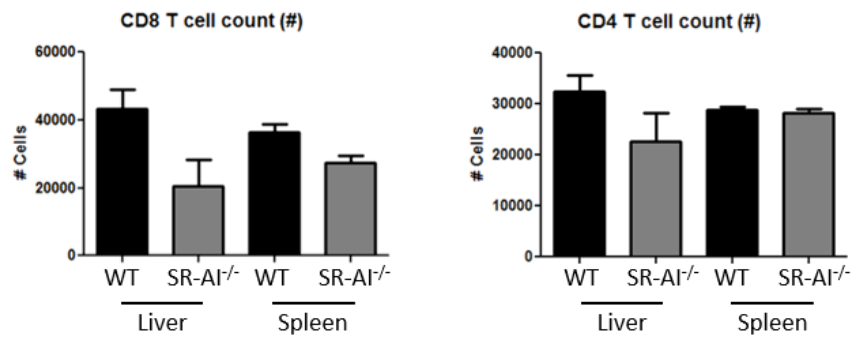

C
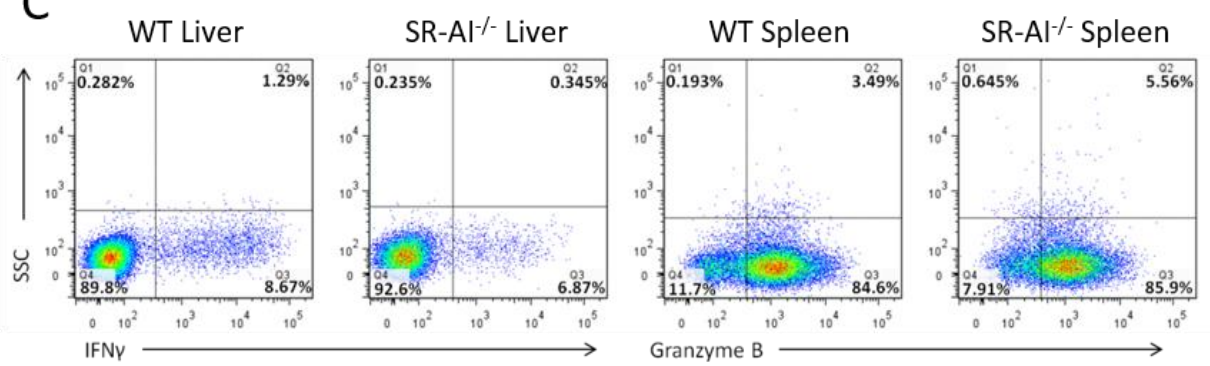

D
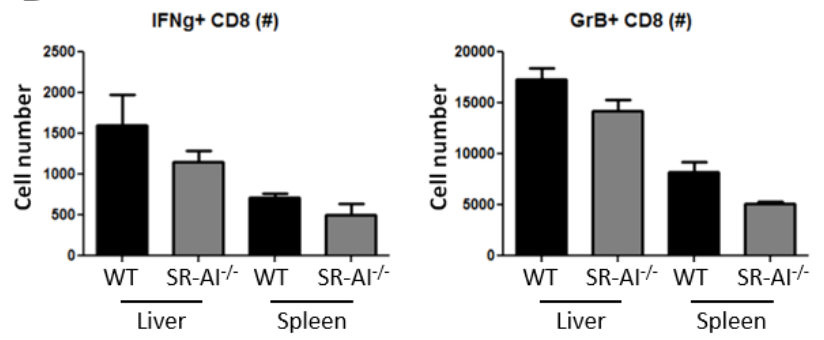
Figure 3.4. $T$ cell response to hepatotropic infection is not inhibited by SR-AI. (A) Flow cytometry analysis of hepatic $\mathrm{CD} 4^{+}$and $\mathrm{CD} 8^{+} \mathrm{T}$ cell populations in $\mathrm{WT}$ and $\mathrm{SR}-\mathrm{AI}^{-/-}$mice 7 days after tail vein injection of 5e7 PFU of AdOVA. Numbers adjacent to gates show subset frequency of total T cell population. Data show one representative mouse per group $(n=3)$.

Quantification of the absolute number of cells in the populations shown in (A). Data are presented as mean \pm SEM. (C) Intracellular cytokine staining of IFN $\gamma$ production by restimulated $\mathrm{CD}^{+} \mathrm{T}$ cells isolated 7 days after infection. Numbers in bottom right gates show frequency of IFN $\gamma^{+} \mathrm{CD}^{+} \mathrm{T}$ cells. Data show one representative mouse per group ( $\mathrm{n}=3$ ). (D) Quantification of the absolute number of IFN $\gamma^{+} \mathrm{CD}^{+} \mathrm{T}$ cells shown in $(\mathbf{C})$. Data are presented as mean \pm SEM. 

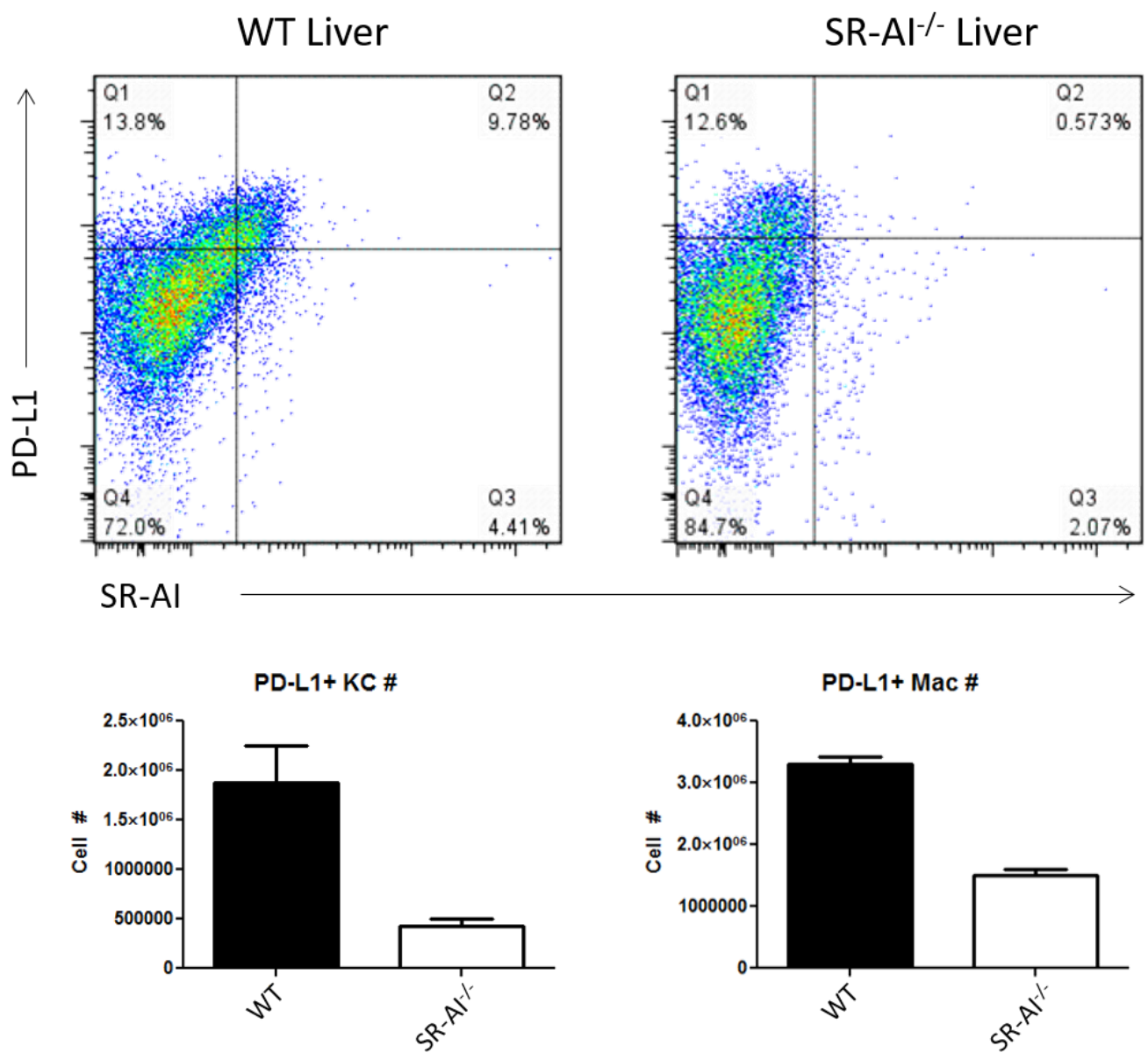
Figure 3.5. Mф PD-L1 expression is decreased in the absence of SR-AI. (A) Flow cytometry analysis of PD-L1 and SR-AI expression by $\mathrm{KC}$ obtained from $\mathrm{WT}$ and $\mathrm{SR}-\mathrm{AI}^{-/-}$mice 7 days after tail vein injection of 5e7 PFU of AdOVA. Numbers in each quadrant show subset frequency of total KC cell population. Data show one representative mouse per group $(n=3)$. (B) Quantification of the absolute number of $\mathrm{PD}-\mathrm{L}^{+}{ }^{+} \mathrm{KC}$ and $\mathrm{M} \phi$ in $\mathrm{WT}$ and $\mathrm{SR}-\mathrm{AI}^{-/-}$mice. Data are presented as mean \pm SEM. 
A

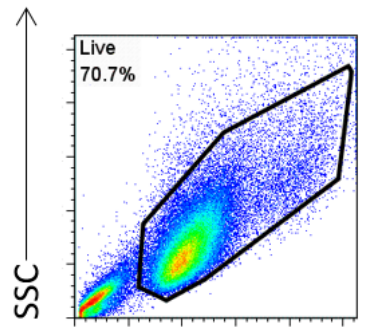

FSC
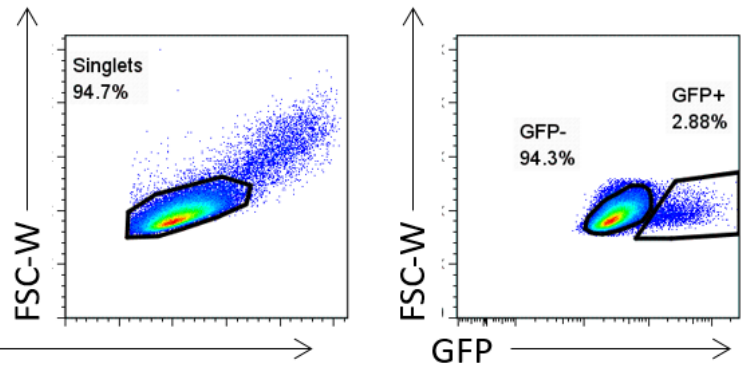

B
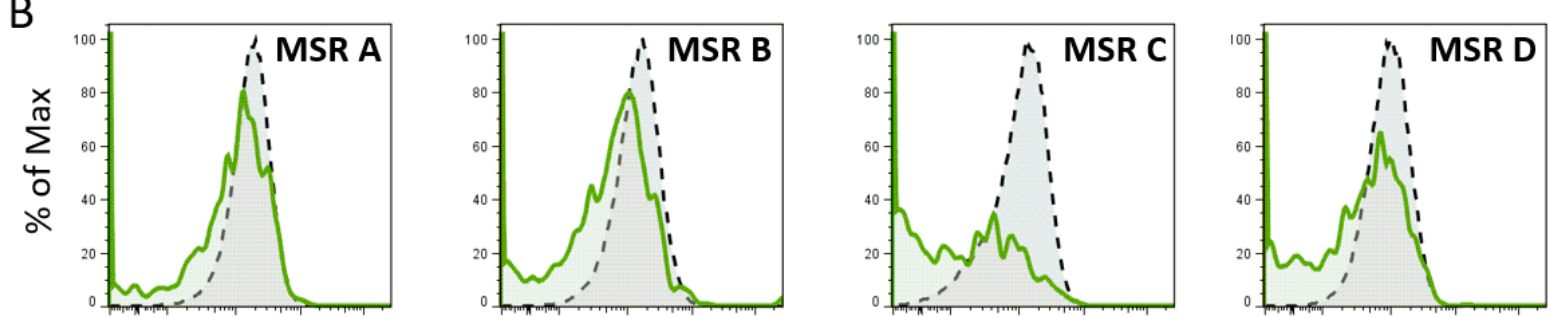

SR-AI

msr1 Scramble

C
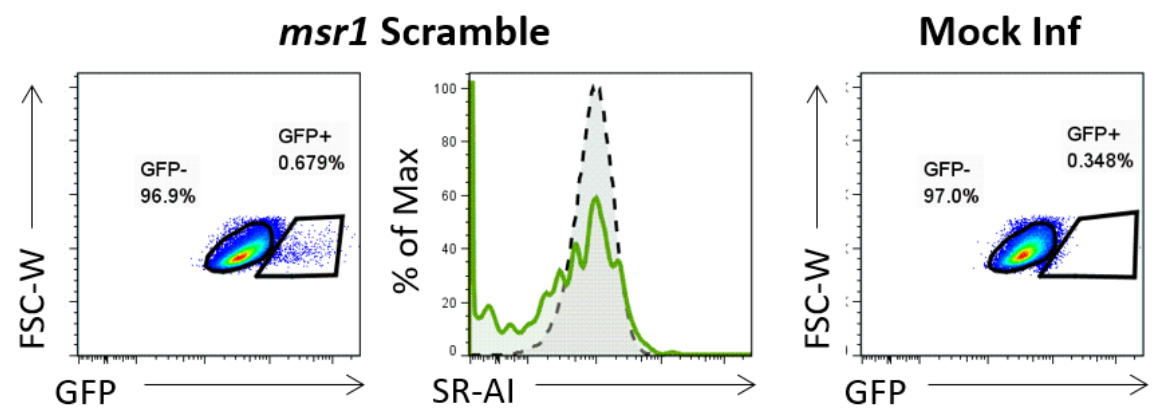
Figure 3.6. Generation of a stable MSR knockdown cell line. (A) Flow cytometric identification of successfully transduced cells by detection of included selection marker GFP. (B) Histograms comparing SR-AI surface expression of non-transduced (GFP', black trace) and transduced $\left(\mathrm{GFP}^{+}\right.$, green trace) RAW cells for each of the four anti-msrl shRNA variants provided by OriGene, as measured by flow cytometry. (C) Flow cytometric analysis of transduction efficiency and SR-AI expression in control scramble shRNA and mock infection. 

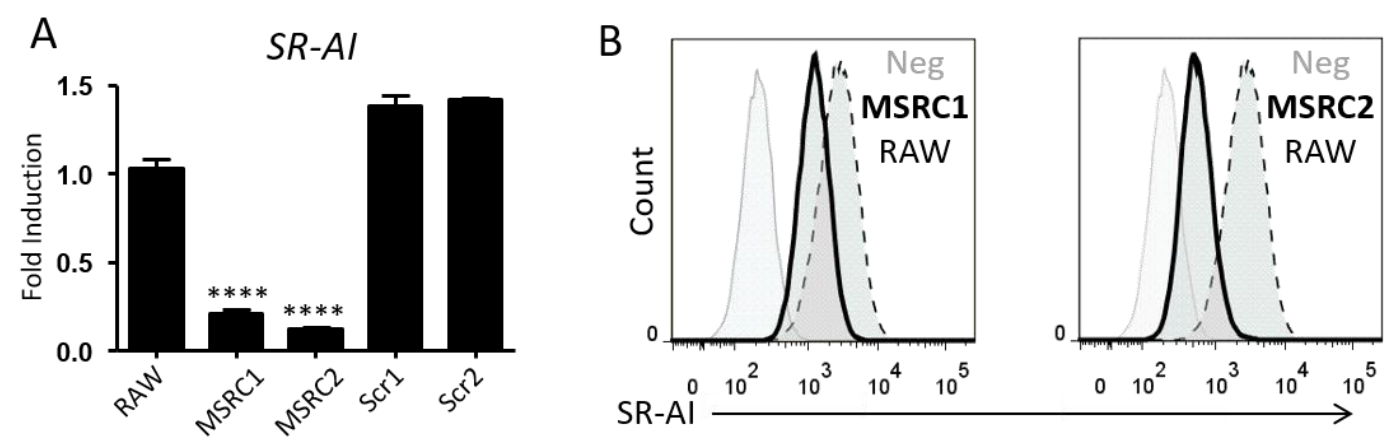

C
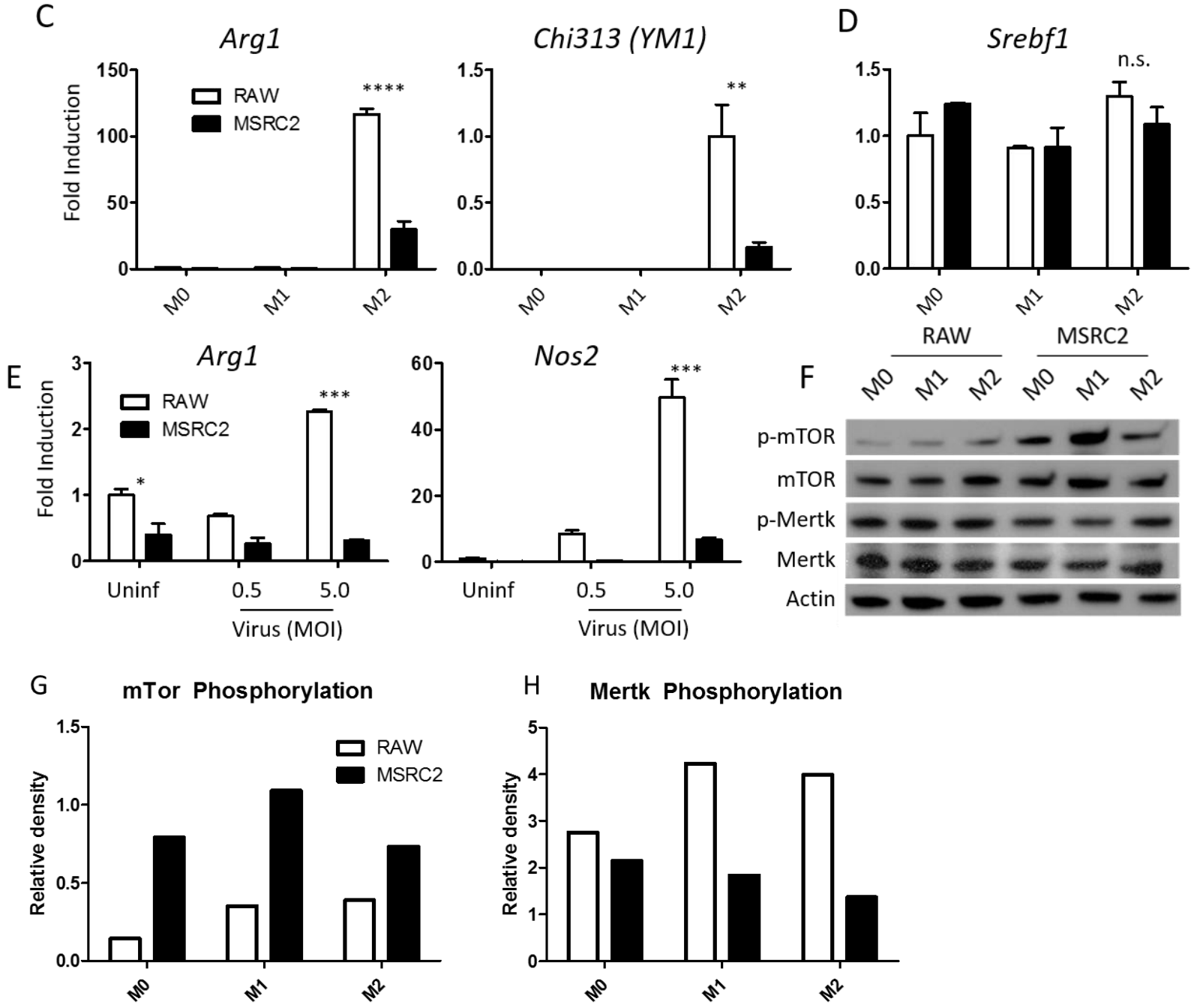
Figure 3.7. SR-AI expression is required for modulation of M $\phi$ activation via mTOR. (A) qPCR analysis of relative $M s r l$ expression in two subcultures of siRNA-transfected cells and two subcultures transfected with scrambled control plasmids. Expression levels were calculated via the ddCT method and normalized to HPRT expression, then normalized to expression of untransfected RAW cells. Data are mean \pm SEM for $n=3$, $* * * * \mathrm{P}<0.00005$. (B) Flow analysis of SR-AI expression after transfection with lentivirally-packaged anti-Msrl siRNA. The bold trace represents transfected RAW cell subclones while the dotted trace represents WT RAW cells. (C, D) qPCR analysis comparing arg1, chi313, and srebfl expression by stable knockdown MSRC2 cells to that of untransfected RAW cells cells incubated for 2 hours in either plain media (M0), LPS (M1), or IL-4 and IL-13 (M2). Expression levels were calculated as in A. Data are mean \pm SEM for $\mathrm{n}=3$; $* * \mathrm{P}<0.005, * * * * \mathrm{P}<0.00005$. (E) Arg 1 and Nos 2 gene expression of MSRC2 and untransfected RAW cells following overnight coculture with 0, 0.5 MOI, or 5.0 MOI of AdOVA in complete media. Expression levels were calculated as in A, data are mean \pm SEM for $n=3$. (F) Western blot of phosphorylated and total mTOR and Mertk from whole cell lysates of RAW or MSRC2 cells incubated for 2 hours in either plain media (M0), LPS (M1), or IL-4 and IL-13 (M2). Images are representative of 3 independent experiments. (G, H) Densitometry analysis of phosphorylated mTOR and Mertk protein in RAW and MSRC2 cells cultured for $2 \mathrm{~h}$ in either plain media (M0), LPS (M1), or IL-4 and IL-13 (M2). Data are presented as the ratio of intensity of the phospho-mTOR or phospho-Mertk bands divided by the total mTOR or total Mertk bands respectively, normalized to the expression of actin. 


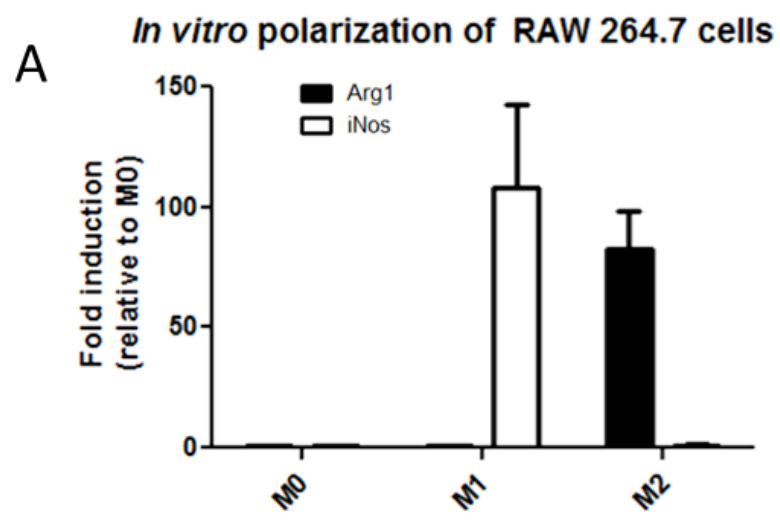

B
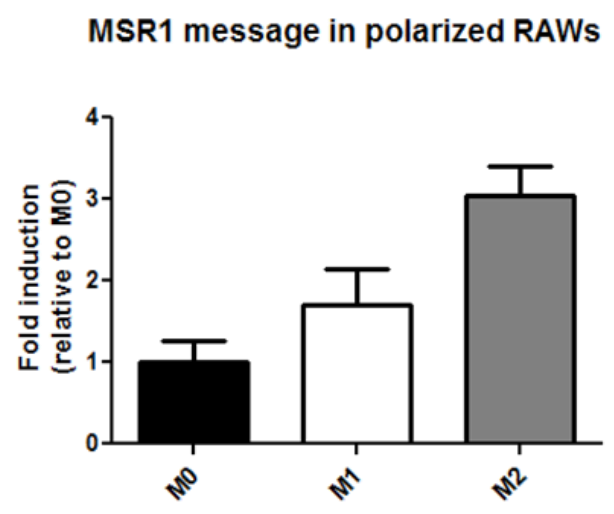

C

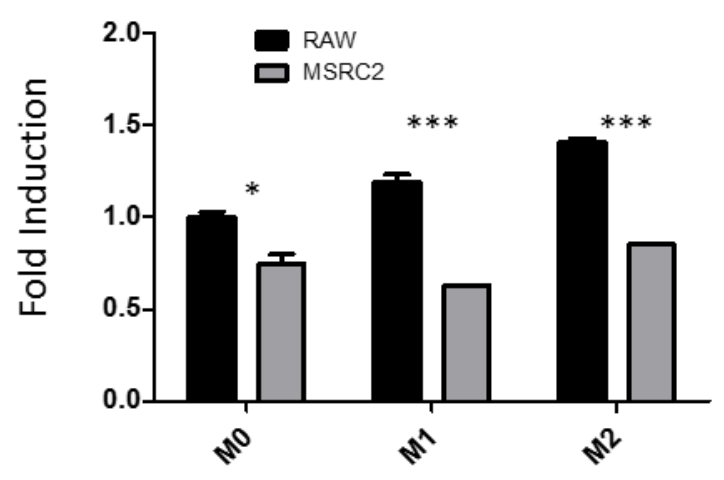


Figure 3.8. Gene expression by differentially polarized RAW and MSRC2 cells. (A) qPCR analysis of polarization-related genes arg1 (arginase) and nos2 (iNOS) in RAW 264.7 cells cultured for $2 \mathrm{~h}$ in either plain media (M0), LPS (M1), or IL-4 and IL-13 (M2). Expression levels were calculated via the ddCT method and normalized to HPRT expression, then normalized to expression of M0 stimulated RAW cells. Data are mean \pm SEM for $n=3$. (B) $q P C R$ analysis of msrl (SR-AI) gene expression by RAW cells cultured for $2 \mathrm{~h}$ in either plain media (M0), LPS (M1), or IL-4 and IL-13 (M2). Expression levels were calculated as in A, data are mean \pm SEM for $\mathrm{n}=3$. (C) qPCR analysis of emrl (F4/80) expression by RAW and MSRC2 cells cultured for 2h in either plain media (M0), LPS (M1), or IL-4 and IL-13 (M2). Expression levels were calculated as in $\mathbf{A}$, data are mean $\pm \mathrm{SEM}$ for $\mathrm{n}=3 ; * \mathrm{P}<0.05, * * * \mathrm{P}<0.0005$. 

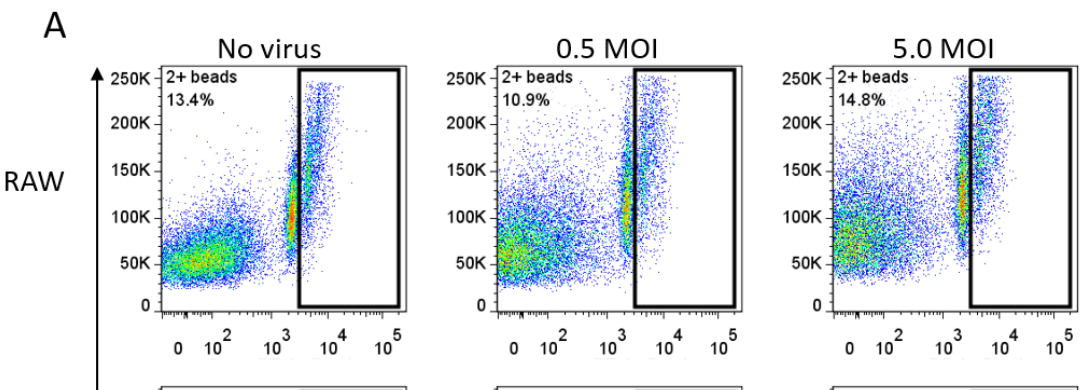

B
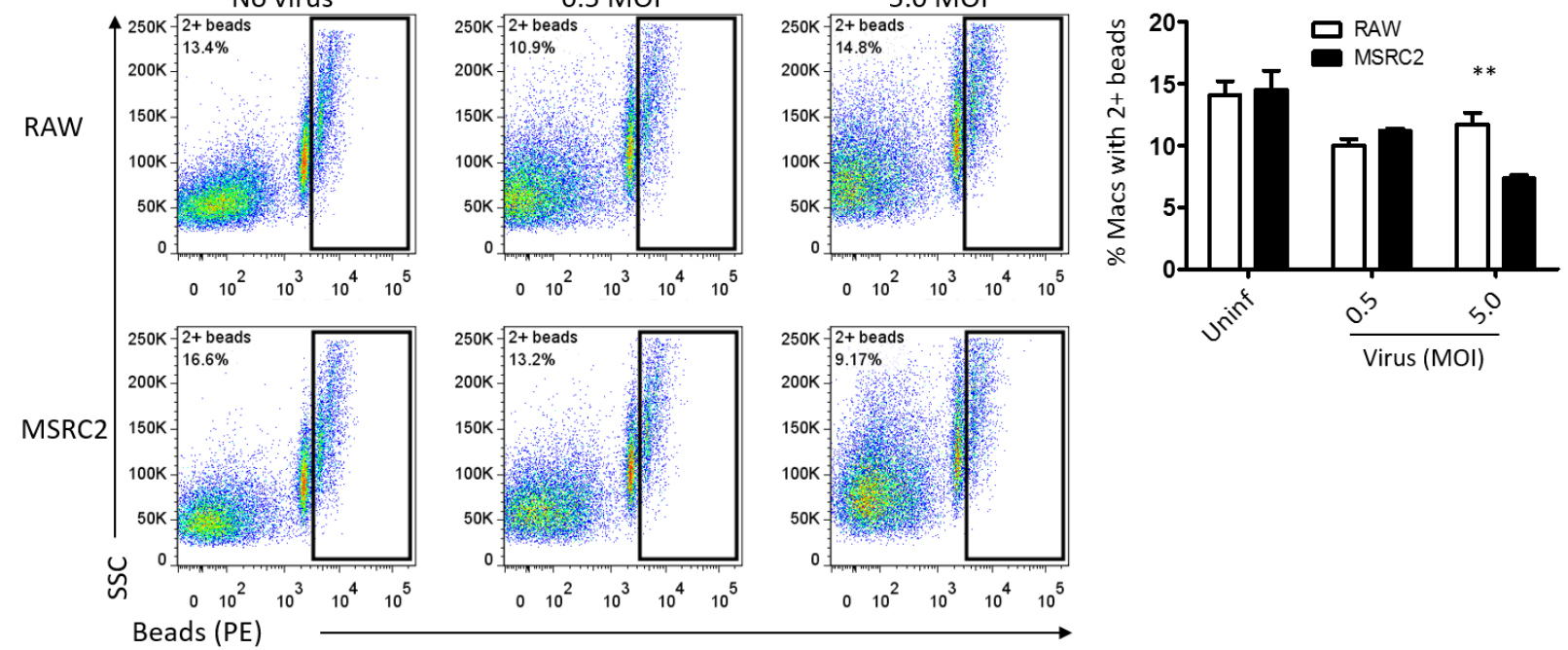

Beads (PE) 
Figure 3.9. RAW cells, but not MSRC2 cells, exhibit a phagocytosis profile consistent with M2 polarization. (A) Flow staining of MSRC2 and WT RAW cells following exposure to AdOVA and incubation with PE-stained carboxy-modified beads. Macrophages were gated as live singlets with positive CFSE uptake, images are representative of 3 independent experiments. (B) Quantification of A, showing the percent of cells containing fluorescence corresponding to the presence of $2+$ beads as mean \pm SEM for $n=3$ replicates, $* * \mathrm{P}<0.005$. 

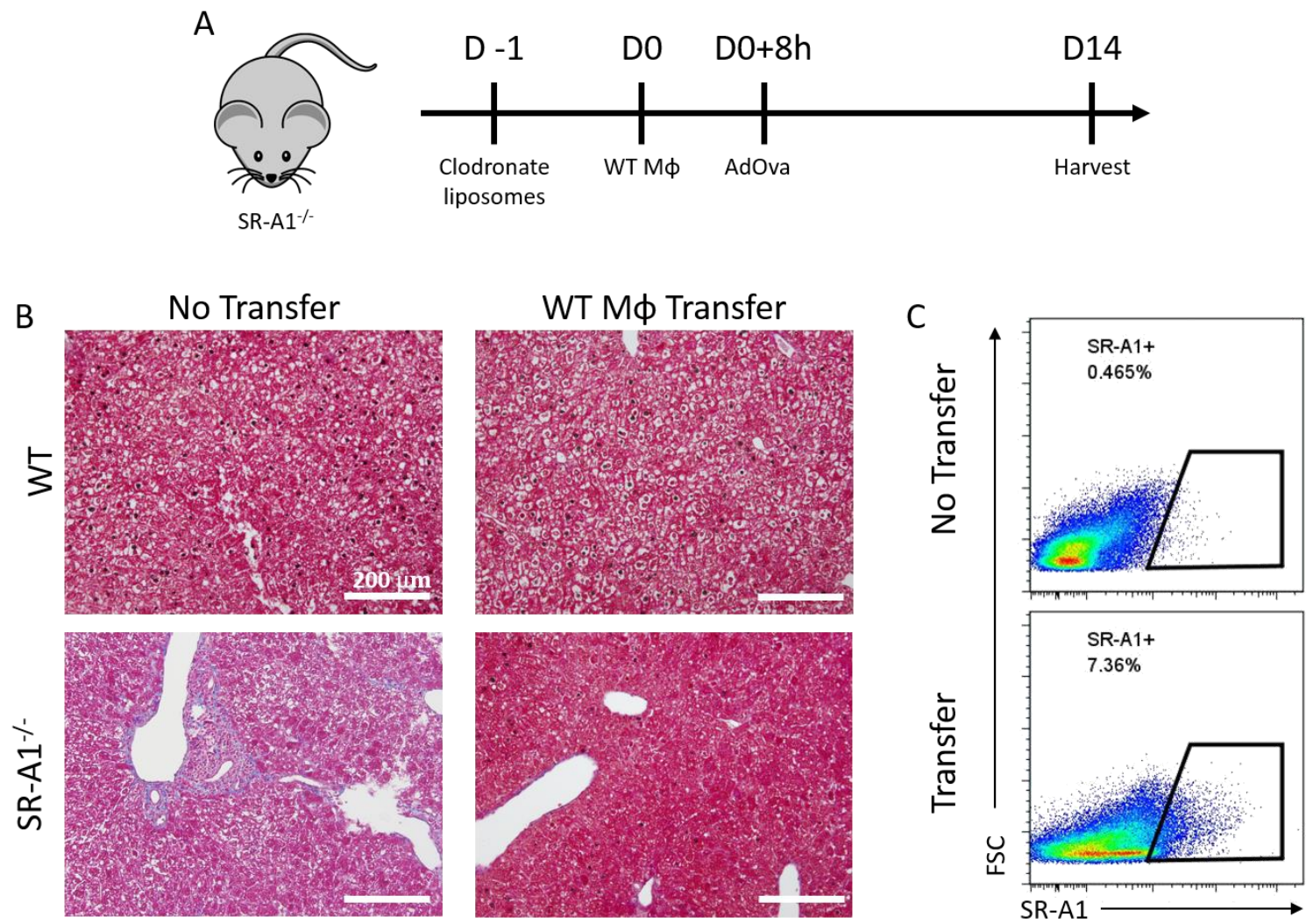
Figure 3.10. Transfer of SR-AI+ M protects against infection-induced tissue damage. (A) Experimental design for adoptive BMDM transfer and infection. (B) Trichrome staining for collagen in liver sections from WT and SR-AI ${ }^{-/-}$mice 14 days post infection (x 100 magnification and scale bars $=200 \mu \mathrm{m})$. Images representative of 3 mice. $(\mathbf{C})$ Confirmation of successful transfer of SR-AI+ BMDMs into SR-AI ${ }^{-/-}$mice by flow cytometry. 

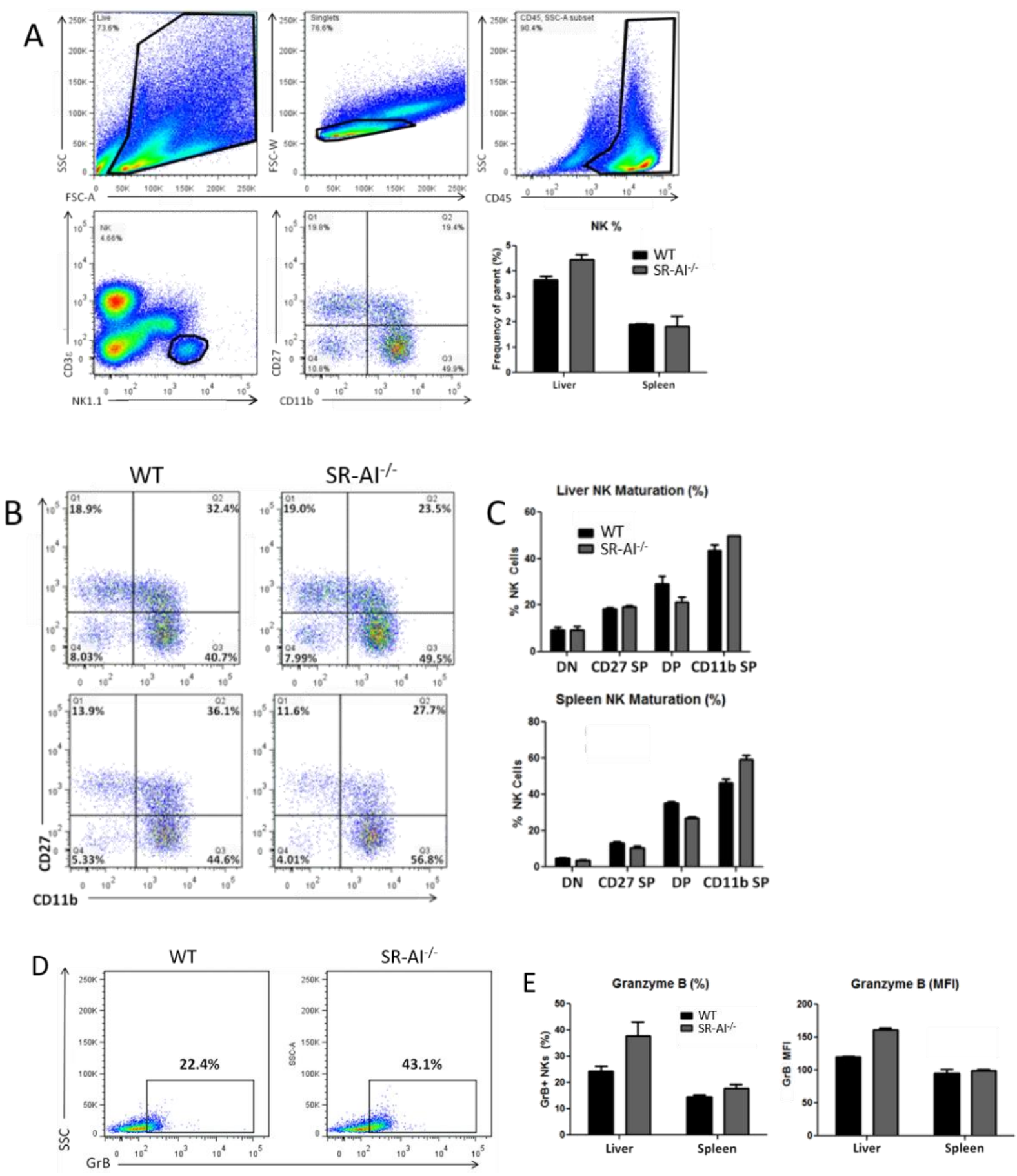
Figure 3.11. Liver NK cell GrB is enhanced in the absence of SR-AI. (A) Gating strategy for identifying NK cell populations and flow cytometric analysis of hepatic and splenic NK cellularity in $\mathrm{WT}$ and $\mathrm{SR}-\mathrm{AI}^{-/-}$mice 7 days after tail vein injection of $5 \mathrm{e} 7 \mathrm{PFU}$ of AdOVA. Data are mean \pm SEM for $n=3$ mice. (B) Method of CD11b/CD27 breakdown of NK cell maturity in $\mathrm{WT}$ and $\mathrm{SR}-\mathrm{AI}^{-/-}$mice by flow cytometry. Images are representative of one liver (top panels) or spleen (bottom panels) per group $(n=3)$. (C) Quantification of $(\mathbf{B})$, data are mean \pm SEM for $n=3$. (D) Intracellular staining of $\mathrm{GrB}$ in hepatic $\mathrm{NK}$ cells from $\mathrm{WT}$ and $\mathrm{SR}-\mathrm{AI}^{-/-}$mice 7 days post infection. Numbers above gates represent the frequency of $\mathrm{GrB}^{+} \mathrm{NKs}$. Images are representative of one WT and one knockout liver (n=3). (E) Quantification of GrB MFI and $\mathrm{GrB}^{+} \mathrm{NK}$ frequency from hepatic and splenic NK cells 7 days post infection, data are mean \pm SEM for $n=3$. 


\section{Chapter 4: Conclusions and future directions}

\section{Main Findings}

In this work we describe the importance of the scavenger receptor SR-AI on hepatic M $\phi$ in the context of viral infection, and characterize the phenotype of $\mathrm{M} \phi$ that upregulate SR-AI expression during the resolution and repair phase of infection. Contrary to our early working hypothesis that SR-AI would be critical for M $\phi$ polarization immediately after virus exposure and therefore have a primary role in determining the quality of the adaptive immune response, we found that this receptor is instead crucial for optimal recovery from infection and long term liver tissue damage. In the absence of SR-AI expression, virally infected murine livers accrue considerable DNA damage and collagen deposition. This infection-induced fibrosis, however, can be prevented by adoptive transfer of SR-AI-sufficient $\mathrm{M} \phi$ into an $\mathrm{SR}^{-\mathrm{AI}^{-/}}$animal, suggesting that $\mathrm{SR}-\mathrm{AI}^{+} \mathrm{M} \phi$ are capable of controlling this damage.

It is worthwhile to point out that the late timing of induction of SR-AI expression (7 dpi) in both the resident $\mathrm{F} 4 / 80^{\text {hi }} \mathrm{CD} 11 \mathrm{~b}^{\text {lo }} \mathrm{KC}$ cell population and the nonresident $\mathrm{F} 4 / 80^{\mathrm{lo}} \mathrm{CD} 11 \mathrm{~b}^{\text {hi }}$ circulating $\mathrm{M} \phi$ population correlates with resolution and tissue repair after viral clearance. Furthermore, in naïve animals, SR-AI expression was detectable at much higher levels on KCs than circulating $\mathrm{M} \phi$, consistent with reports that tissue-resident $\mathrm{M} \phi$ from many organs express elevated levels of SR-AI compared to their nonresident counterparts. Consequently, the magnitude of the increased SR-AI expression and the duration of sustained expression following infection were both greater in KCs than nonresident $\mathrm{M} \phi$. This suggests a possibility for a predisposition of liver resident $\mathrm{M} \phi$ to become alternatively activated under stress, contributing to the tolerogenic and regenerative nature of the liver. 
Our findings that YM-1 co-localized with SR-AI in total liver M $\phi$ that also produced elevated amounts of IL-10 reinforce the M2 characteristics of hepatic M $\phi$ following exposure to virus. Unexpectedly, the secretion of pro-inflammatory chemokines MIP- $1 \alpha$ and MIP-1 $\beta$ by both $\mathrm{KC}$ and circulating $\mathrm{M} \phi$ were increased following viral infection, and expression of iNOS (typically associated with M1 polarization) was decreased in $\mathrm{M} \phi$ from the $\mathrm{SR}-\mathrm{AI}^{-/-}$animals, apparently tracking with the M2-like phenotype exhibited by SR-AI+ $\mathrm{M} \phi$. We believe that the polarization state of $\mathrm{SR}-\mathrm{AI}^{+}$liver $\mathrm{M} \phi$ following viral infection represents a crossover M2-like state with some M1 aspects.

As expected, expression of the M2 genes argl and chi313 was elevated in cultured M $\phi$ treated with canonical M2 stimuli and the expression of these genes was significantly reduced in the MSRC2 cell line as compared to the WT RAW cells. These findings were further verified by in vitro co-culture studies of RAW and MSRC2 cells with AdOva. Intriguingly, direct stimulation with the virus was sufficient to induce M2 polarization in RAW cells as measured by arg 1 expression, but MSRC2 cells showed no change, confirming the ex vivo findings. It is of interest to note that following direct viral stimulation of a clonally identical cultured M $\phi$ population, iNOS expression was observed alongside arg 1 expression. It is more likely, therefore, that in both cases the M2-like M $\phi$ observed are indeed the same population found to express some M1 mediators.

The balance of polarized $\mathrm{M} \phi$ at the site of damaged tissue is directly related to the progression of fibrosis following infection or injury. While pro-resolving M2 M $\phi$ subsets are responsible for the resolution of inflammation and the clearance and remodeling of scar tissue, M1 M $\phi$ (or even other M2 M $\phi$ subsets) can actively contribute to production of extracellular 
matrix and further tissue damage. Our studies report that SR-AI+ liver $\mathrm{M} \phi$ are necessary for optimal recovery from infection, as measured by the presence of inflammatory infiltrates, fibrotic lesions, and hepatocellular DNA damage. Furthermore, phagocytosis of carboxylated beads, an analogue of apoptotic cell recognition and uptake, was used as a functional readout of M2 polarization. At a dose of virus stimulation sufficient to induce argl expression, bead uptake by SR-AI knockdown MSRC2 cells was impaired compared to RAW cells. This effect was not due to direct recognition and endocytosis of beads by SR-AI, however, as bead uptake levels remained consistent between the two cell culture variants in other conditions. It is probable, then, that the role of SR-AI on liver $\mathrm{M} \phi$ is to promote a transition to a pro-resolving $\mathrm{M} 2$ subset in order to effectively address the insult and any damage that results.

\section{Implications and Future Directions}

\section{Targeted therapeutic modulation of SR-AI}

While similar protective roles for $\mathrm{SR}-\mathrm{AI}^{+} \mathrm{M} \phi$ have been demonstrated in models of chemically-induced liver tissue damage (such as treatment with concanavalin A), it has not previously been shown in models of hepatotropic viral infection. These findings introduce SR$\mathrm{AI}$ as an attractive target for drug design for the treatment of hepatotropic infection and concomitant liver fibrosis. The type of SR-AI modulation needed would vary in a biphasic manner correlating with the progression of the infection: SR-AI agonists administered in the late stages of infection would encourage SR-AI-mediated protection against fibrosis, while SR-AI inhibitors would be desirable in the early stages of infection in order to dampen M2 polarization and encourage the development of productive immune responses. No highly effective agonists, 
small molecule inhibitors, or blocking antibodies are currently available, and the development and testing of these compounds may provide fertile ground for future studies. It would therefore be of great interest to coordinate with the Antibody Engineering and Technology Core to generate and test monoclonal anti-SR-AI antibodies via their phage-yeast display and hybridoma selection services. Potential biologics resulting from these studies may also be widely applicable to the control of inflammatory diseases that occur in tissues with a resident $\mathrm{M} \phi$ population, as they often express elevated levels of SR-AI and may be similarly protective as $\mathrm{SR}-\mathrm{AI}^{+} \mathrm{KC}$.

\section{SR-AI-mediated signal propagation}

The participants of the signaling transduction pathway induced by SR-AI may also provide targets for future intervention studies, but despite the findings presented here remain poorly understood. While cooperative association between SR-AI and Mertk has been suggested by others to propagate intracellular signals following SR-AI engagement, we have not definitely shown this physical interaction in our model. Techniques such as FRET or electron microscopy in combination with immunogold labeling would confirm the association suggested by the results of the western blot phosphorylation experiments. The mechanism by which SR-AI or Mertk signaling may inhibit mTOR phosphorylation and activation also remains unclear. Possibilities include physical binding of SR-AI or Mertk (or another signaling molecule downstream of Mertk) to mTOR, redirection of phosphorylated mTOR to the proteasome, or the prevention of mTOR phosphorylation via SR-AI/Mertk-mediated interference with S6 kinase. Similarly, the method of SR-AI activation in our model also has multiple possible explanations. Experiments investigating RAW and MSRC2 cell activation following treatment with apoptotic cells, lipid particles (LDL/HDL), or viral components (adenovirus capsid or DNA) will reveal whether 
some or all of these mediators are essential for inducing the anti-fibrotic properties of polarized M $\phi$. Antibodies generated through the studies detailed above may also prove useful in these studies if they are found to have agonistic effects on SR-AI as evidenced by increased activation of Mertk and inhibition of mTOR.

\section{Comprehensive analysis of polarized $M \phi$ using next-generation techniques}

Although the findings presented here begin to answer the question of what the polarization state of $\mathrm{SR}-\mathrm{AI}^{+}$liver $\mathrm{M} \phi$ looks like, they also reveal that $\mathrm{M} \phi$ polarization is a nuanced and complicated process. Too often, descriptions of $\mathrm{M} \phi$ polarization in the scientific literature present a very clear delineation between the expression of either canonically identified M1 markers or M2 markers. These profiles are also frequently superficial, only presenting one or two choice identifiers and showing them in stark contrast under different experimental conditions. However, as the study of $\mathrm{M} \phi$ polarization has developed, it has been stressed by many leaders in the field that M1 and M2 are merely the extreme ends of what exists in nature as a spectrum of activation states. It seems that the best approach to take when attempting to access

the true nature of a particular $\mathrm{M} \phi$ population is "the more markers, the better." While it will be a time consuming and resource-intensive process, eventually the biggest breakthroughs will be made by taking advantage of Big Data techniques, compiling comprehensive profiles of CyTOF or RNA-Seq data to fully characterize polarized $\mathrm{M} \phi$ in different tissues at homeostasis and during disease. 


\section{Interactions of $\mathrm{SR}-\mathrm{AI}^{+} \mathrm{M} \phi$ with other hepatic immune cell types to orchestrate fibrosis}

Our findings also raise the question of how these polarized $\mathrm{M} \phi$ interact with other hepatic immune cells to control the accumulation of liver tissue damage and fibrosis. While we found no clear effect of SR-AI expression on hepatic T cell recruitment or effector function, liver NK cell production of GrB was decreased in the absence of SR-AI. It remains unclear how this phenotype may relate to the effect of SR-AI expression on post-infection tissue damage. The current understanding of how NK cells interact with liver fibrosis in the liver is that activated NK cells can in turn kill activated hepatic stellate cells, which are otherwise free to deposit large amounts of collagen. Therefore, in an SR-AI-deficient animal, higher GrB production by NK cells should correlate with increased stellate cell killing and better control of fibrosis - however, we observe the opposite effect. One possible explanation is that NK cells may have multiple modes of target cell killing that they switch between depending on the activating signals they receive. NK cells have been found to kill activated stellate cells using surface interactions with NKG2D and TNF-related apoptosis-inducing ligand (TRAIL) (199). It may be that the presence or absence of SR-AI on liver M $\phi$ mediates a switch between NK cell activation programs that either favor NKG2D/TRAIL or GrB upregulation, respectively. Alternatively, it has also been shown that NK cells preferentially kill previously-activated senescent stellate cells to resolve fibrosis (200). SR-AI ${ }^{+} \mathrm{M} \phi$ may regulate this senescent program, rendering NK cells less effective in its absence. Further experiments that make use of NK-depleting anti-asialo GM1 antibodies, SR-AI knockout mice, and the combination of cultured NK cells with our SR-AI knockdown M $\phi$ cell line will be necessary to tease apart the interactions between these three cell types and how they work together to promote or resolve fibrosis. 


\section{SR-AI in liver regeneration}

The liver is unique in that it possesses a remarkable capacity to regenerate after partial resection or transplant, unlike any other organ. The role of $\mathrm{SR}-\mathrm{AI}^{+} \mathrm{M} \phi$ in maintaining healthy, non-fibrotic liver tissue following viral infection raises the question of whether these $\mathrm{M} \phi$ can also contribute to liver regeneration. To date, no investigations assessing the impact of SR-AI expression on liver regeneration have been carried out. Partial hepatectomy and transplant experiments in $\mathrm{WT}$ and $\mathrm{SR}-\mathrm{AI}^{-/-}$mice would provide fascinating insight into the interactions of liver $\mathrm{M} \phi$ and hepatocytes. Findings from these experiments and adoptive transfer experiments would potentially have translational applications in the field of liver surgery and transplantation, and may even have exciting implications for stimulating regeneration in other damaged organs.

In summary, my thesis work shows that $\mathrm{SR}-\mathrm{AI}^{+} \mathrm{M} \phi$ comprise a crucial component of the machinery employed by the liver to fight injury and maintain homeostasis, despite its vulnerable nature as an intrinsically immunotolerant organ. In the face of infection, liver $\mathrm{M} \phi$ upregulate SR-AI which in turn promotes their transition to an M2-like activation state that promotes injury resolution and tissue repair. Furthermore, we show that this transition may be mediated via modulation of the mTOR and Mertk signaling pathways. These findings help us to better understand how the liver's considerable immune compartment contribute to its function (and dysfunction), as well as provide several starting points for the development of therapeutic agents to aid in the treatment of hepatotropic infections and amelioration of debilitating liver damage and fibrosis. 


\section{References}

1. Long CA, Zavala F. Malaria vaccines and human immune responses. Curr. Opin. Microbiol. 2016;32:96-102.

2. Cwiklinski K, O’Neill SM, Donnelly S, Dalton JP. A prospective view of animal and human Fasciolosis. Parasite Immunol. 2016;

3. Nakada-Tsukui K, Nozaki T. Immune Response of Amebiasis and Immune Evasion by Entamoeba histolytica. Front. Immunol. 2016;7:175.

4. Lardière-Deguelte S, Ragot E, Amroun K, Piardi T, Dokmak S, Bruno O, et al. Hepatic abscess: Diagnosis and management. J. Visc. Surg. 2015;152:231-243.

5. Rosen HR. Chronic Hepatitis C Infection. N. Engl. J. Med. 2011;364:2429-2438.

6. Peery AF, Crockett SD, Barritt AS, Dellon ES, Eluri S, Gangarosa LM, et al. Burden of Gastrointestinal, Liver, and Pancreatic Diseases in the United States. Gastroenterology. 2015;149:1731-1741.e3.

7. Iyengar S, Tay-Teo K, Vogler S, Beyer P, Wiktor S, de Joncheere K, et al. Prices, Costs, and Affordability of New Medicines for Hepatitis C in 30 Countries: An Economic Analysis. PLoS Med. 2016;13:e1002032.

8. Thomson AW, Knolle PA. Antigen-presenting cell function in the tolerogenic liver environment. Nat. Rev. Immunol. 2010;10:753-766.

9. Ishibashi H, Nakamura M, Komori A, Migita K, Shimoda S. Liver architecture, cell function, and disease. Semin. Immunopathol. 2009;31:399-409. 
10. Hume D a. Differentiation and heterogeneity in the mononuclear phagocyte system. Mucosal Immunol. 2008;1:432-41.

11. Davies LC, Jenkins SJ, Allen JE, Taylor PR. Tissue-resident macrophages. Nat. Immunol. 2013;14:986-95.

12. Ji W-J, Ma Y-Q, Zhou X, Zhang Y-D, Lu R-Y, Sun H-Y, et al. Temporal and Spatial Characterization of Mononuclear Phagocytes in Circulating, Lung Alveolar and Interstitial Compartments in a Mouse Model of Bleomycin-Induced Pulmonary Injury. J. Immunol. Methods. 2013;1-10.

13. You Q, Holt M, Yin H, Li G, Hu C-J, Ju C. Role of hepatic resident and infiltrating macrophages in liver repair after acute injury. Biochem. Pharmacol. 2013;86:836-43.

14. Gautier EL, Shay T, Miller J, Greter M, Jakubzick C, Ivanov S, et al. Gene-expression profiles and transcriptional regulatory pathways that underlie the identity and diversity of mouse tissue macrophages. Nat. Immunol. 2012;13:1118-28.

15. Gomez Perdiguero E, Geissmann F. Myb-Independent Macrophages: A Family of Cells That Develops with Their Tissue of Residence and Is Involved in Its Homeostasis. Cold Spring Harb. Symp. Quant. Biol. 2013;

16. Schulz C, Gomez Perdiguero E, Chorro L, Szabo-Rogers H, Cagnard N, Kierdorf K, et al. A Lineage of Myeloid Cells Independent of Myb and Hematopoietic Stem Cells. Science. $2012 ; 1-7$.

17. Mantovani A, Biswas SK, Galdiero MR, Sica A, Locati M. Macrophage plasticity and polarization in tissue repair and remodelling. J. Pathol. 2013;229:176-85. 
18. Duffield J. Selective depletion of macrophages reveals distinct, opposing roles during liver injury and repair. J. Clin. .... 2005;115.

19. Majai G, Kiss E, Tarr T, Zahuczky G, Hartman Z, Szegedi G, et al. Decreased apoptophagocytic gene expression in the macrophages of systemic lupus erythematosus patients. Lupus. 2013;

20. Ghavami S, Shojaei S, Yeganeh B. Autophagy and apoptosis dysfunction in neurodegenerative disorders. Prog. .... 2013;

21. Heydtmann M. Macrophages in hepatitis B and hepatitis C virus infections. J. Virol. 2009;83:2796-802.

22. Schwabe RF, Seki E, Brenner D a. Toll-like receptor signaling in the liver. Gastroenterology. 2006;130:1886-900.

23. Murray PJ, Wynn T a. Protective and pathogenic functions of macrophage subsets. Nat. Rev. Immunol. 2011;11:723-37.

24. Mantovani A, Sica A, Sozzani S, Allavena P, Vecchi A, Locati M. The chemokine system in diverse forms of macrophage activation and polarization. Trends Immunol. 2004;25:677-86.

25. Martinez FO, Helming L, Gordon S. Alternative activation of macrophages: an immunologic functional perspective. Annu. Rev. Immunol. 2009;27:451-83.

26. Sica A, Invernizzi P, Mantovani A. Macrophage plasticity and polarization in liver homeostasis and pathology. Hepatology. 2013;1-44.

27. Gordon S. Alternative activation of macrophages. Nat. Rev. Immunol. 2003;3:23-35. 
28. Mills CD, Kincaid K, Alt JM, Heilman MJ, Hill AM. M-1/M-2 macrophages and the Th1/Th2 paradigm. J. Immunol. 2000;164:6166-6173.

29. Verreck FAW, Boer T De, Langenberg DML, Hoeve MA, Kramer M, Ottenhoff THM, et al. Human IL-23-producing type 1 macrophages promote but IL-10-producing type 2 macrophages subvert immunity to ( myco ) bacteria. 2004;101.

30. Mantovani A. Macrophage diversity and polarization: in vivo veritas. Blood. 2006;108:408-409.

31. Mosser D. The many faces of macrophage activation. J. Leukoc. Biol. 2003;73:209-212.

32. Raes G, Baetselier P De, Noe W, Beschin A, Brombacher F. Differential expression of FIZZ1 and Ym1 in alternatively versus classically activated macrophages Abstract: Alternatively activated macrophages. 2002;71:597-602.

33. Raes G, Baetselier P De, Ghassabeh GH, Alerts E. Arginase-1 and Ym1 Are Markers for Murine, but Not Human, Alternatively Activated Myeloid Cells. J. Immunol. 2005;174:6561-6562.

34. Alfano M, Graziano F, Genovese L, Poli G. Macrophage Polarization at the Crossroad Between HIV-1 Infection and Cancer Development. Arterioscler. Thromb. Vasc. Biol. 2013;33:1145-52.

35. López-Vicario C, Clária J, García-Alonso V, Rius B, González-Périz A, Titos E, et al. Resolution of inflammation in obesity-induced liver disease. Front. Immunol. 2012;3.

36. Martinez FO, Sica A, Mantovani A, Locati M. Macrophage activation and polarization. Front. Biosci. 2008;13:453-461. 
37. Mosser DM, Edwards JP. Exploring the full spectrum of macrophage activation. Nat. Rev. Immunol. 2008;8:958-969.

38. Kadl A, Meher AK, Sharma PR, Lee MY, Doran AC, Johnstone SR, et al. Identification of a novel macrophage phenotype that develops in response to atherogenic phospholipids via Nrf2. Circ. Res. 2010;107:737-746.

39. Umemura N, Saio M, Suwa T, Kitoh Y, Bai J, Nonaka K, et al. Tumor-infiltrating myeloid-derived suppressor cells are pleiotropic-inflamed monocytes/macrophages that bear M1- and M2-type characteristics. J. Leukoc. Biol. 2008;83:1136-44.

40. Biswas SK, Sica A, Lewis CE. Plasticity of macrophage function during tumor progression: regulation by distinct molecular mechanisms. J. Immunol. 2008;180:20112017.

41. Stout RD, Suttles J. Functional plasticity of macrophages: reversible adaptation to changing microenvironments. J. Leukoc. Biol. 2004;76:509-513.

42. Biswas SK, Mantovani A. Macrophage plasticity and interaction with lymphocyte subsets: cancer as a paradigm. Nat. Immunol. 2010;11:889-896.

43. Mylonas KJ, Nair MG, Prieto-Lafuente L, Paape D, Allen JE. Alternatively activated macrophages elicited by helminth infection can be reprogrammed to enable microbial killing. J. Immunol. 2009;182:3084-3094.

44. Stout RD, Jiang C, Matta B, Tietzel I, Watkins SK, Suttles J. Macrophages sequentially change their functional phenotype in response to changes in microenvironmental influences. J. Immunol. 2005;175:342-349. 
45. Chang NC, Hung SI, Hwa KY, Kato I, Chen JE, Liu CH, et al. A macrophage protein, Ym1, transiently expressed during inflammation is a novel mammalian lectin. J. Biol. Chem. 2001;276:17497-17506.

46. Raes G, De Baetselier P, Noël W, Beschin A, Brombacher F, Hassanzadeh Gh G. Differential expression of FIZZ1 and Ym1 in alternatively versus classically activated macrophages. J. Leukoc. Biol. 2002;71:597-602.

47. Leitinger N, Schulman IG. Phenotypic polarization of macrophages in atherosclerosis. Arterioscler. Thromb. Vasc. Biol. 2013;33:1120-6.

48. Fenyo IM, Gafencu AV. The involvement of the monocytes/macrophages in chronic inflammation associated with atherosclerosis. Immunobiology. 2013;218:1376-84.

49. Rawlings JS, Rosler KM, Harrison D a. The JAK/STAT signaling pathway. J. Cell Sci. 2004;117:1281-3.

50. Hu X, Chen J, Wang L, Ivashkiv LB. Crosstalk among Jak-STAT, Toll-like receptor, and ITAM-dependent pathways in macrophage activation. J. Leukoc. Biol. 2007;82:237-43.

51. Rauch I, Müller M, Decker T. The regulation of inflammation by interferons and their STATs. Jak-Stat. 2013;2:e23820.

52. Qin H, Holdbrooks AT, Liu Y, Reynolds SL, Yanagisawa LL, Benveniste EN. SOCS3 deficiency promotes M1 macrophage polarization and inflammation. J. Immunol. 2012;189:3439-48.

53. Qin H, Yeh W. Signal transducer and activator of transcription-3/suppressor of cytokine signaling-3 (STAT3/SOCS3) axis in myeloid cells regulates neuroinflammation. Proc. .... 
2012;3:1-6.

54. Daley JM, Brancato SK, Thomay a. a., Reichner JS, Albina JE. The phenotype of murine wound macrophages. J. Leukoc. Biol. 2009;87:59-67.

55. Moreno JL, Kaczmarek M, Keegan AD, Tondravi M. IL-4 suppresses osteoclast development and mature osteoclast function by a STAT6-dependent mechanism: irreversible inhibition of the differentiation program activated by RANKL. Blood. 2003;102:1078-86.

56. Stolfi C, Caruso R, Franzè E, Sarra M, De Nitto D, Rizzo A, et al. Interleukin-25 fails to activate STAT6 and induce alternatively activated macrophages. Immunology. 2011;132:66-77.

57. Zhou D, Huang C, Lin Z, Zhan S, Kong L, Fang C, et al. Macrophage polarization and function with emphasis on the evolving roles of coordinated regulation of cellular signaling pathways. Cell. Signal. 2013;

58. Shirakawa T, Kawazoe Y, Tsujikawa T, Jung D, Sato S, Uesugi M. Deactivation of STAT6 through serine 707 phosphorylation by JNK. J. Biol. Chem. 2011;286:4003-10.

59. Gadang V, Kohli R, Myronovych A, Hui DY, Perez-Tilve D, Jaeschke A. MLK3 promotes metabolic dysfunction induced by saturated fatty acid-enriched diet. Am. J. Physiol. Endocrinol. Metab. 2013;305:E549-56.

60. Kang K, Reilly SM, Karabacak V, Gangl MR, Fitzgerald K, Hatano B, et al. Adipocytederived Th2 cytokines and myeloid PPARdelta regulate macrophage polarization and insulin sensitivity. Cell Metab. 2008;7:485-95. 
61. Odegaard JI, Ricardo-Gonzalez RR, Goforth MH, Morel CR, Subramanian V, Mukundan L, et al. Macrophage-specific PPARgamma controls alternative activation and improves insulin resistance. Nature. 2007;447:1116-20.

62. Liao X, Sharma N, Kapadia F. Krüppel-like factor 4 regulates macrophage polarization. J. Clin. .... 2011;121.

63. Liu H, Perlman H, Pagliari LJ, Pope RM. Constitutively activated Akt-1 is vital for the survival of human monocyte-differentiated macrophages. Role of Mcl-1, independent of nuclear factor (NF)-kappaB, Bad, or caspase activation. J. Exp. Med. 2001;194:113-126.

64. Luyendyk J, Schabbauer G. Genetic analysis of the role of the PI3K-Akt pathway in lipopolysaccharide-induced cytokine and tissue factor gene expression in monocytes/macrophages. J. .... 2008;180:4218-4226.

65. Arranz A, Doxaki C, Vergadi E, Martinez de la Torre Y, Vaporidi K, Lagoudaki ED, et al. Akt1 and Akt2 protein kinases differentially contribute to macrophage polarization. Proc. Natl. Acad. Sci. U. S. A. 2012;109:9517-22.

66. Byles V, Covarrubias A. The TSC-mTOR pathway regulates macrophage polarization. Nat. .... 2013;4:2834.

67. Weichhart T, Säemann MD. The PI3K/Akt/mTOR pathway in innate immune cells: emerging therapeutic applications. Ann. Rheum. Dis. 2008;67 Suppl 3:iii70-4.

68. Mercalli A, Calavita I, Dugnani E, Citro A, Cantarelli E, Nano R, et al. Rapamycin unbalances the polarization of human macrophages to M1. Immunology. 2013;140:17990. 
69. Krausgruber T, Blazek K, Smallie T, Alzabin S, Lockstone H, Sahgal N, et al. IRF5 promotes inflammatory macrophage polarization and TH1-TH17 responses. Nat. Immunol. 2011;12:231-8.

70. Xu H, Zhu J, Smith S, Foldi J, Zhao B, Chung AY, et al. Notch-RBP-J signaling regulates the transcription factor IRF8 to promote inflammatory macrophage polarization. Nat. Immunol. 2012;advance on.

71. Eguchi J, Kong X, Tenta M, Wang X, Kang S, Rosen ED. Interferon regulatory factor 4 regulates obesity-induced inflammation through regulation of adipose tissue macrophage polarization. Diabetes. 2013;62:3394-403.

72. Lawrence T, Natoli G. Transcriptional regulation of macrophage polarization: enabling diversity with identity. Nat. Rev. Immunol. 2011;11:750-61.

73. Jenner RG, Young R a. Insights into host responses against pathogens from transcriptional profiling. Nat. Rev. Microbiol. 2005;3:281-94.

74. Nau GJ, Richmond JFL, Schlesinger A, Jennings EG, Lander ES, Young R a. Human macrophage activation programs induced by bacterial pathogens. Proc. Natl. Acad. Sci. U. S. A. 2002;99:1503-8.

75. Benoit M, Desnues B, Mege J-L. Macrophage polarization in bacterial infections. J. Immunol. 2008;181:3733-9.

76. Jouanguy E, Döffinger R, Dupuis S. IL-12 and IFN- $\gamma$ in host defense against mycobacteria and salmonella in mice and men. Curr. Opin. .... 1999;346-351.

77. Shaughnessy LM, Swanson JA. The role of the activated macrophage in clearing Listeria 
monocytogenes infection. Front. Biosci. 2007;12:2683-2692.

78. Kiszewski a E, Becerril E, Aguilar LD, Kader IT a, Myers W, Portaels F, et al. The local immune response in ulcerative lesions of Buruli disease. Clin. Exp. Immunol. 2006;143:445-51.

79. Chacón- Salinas R. Differential pattern of cytokine expression by macrophages infected in vitro with different Mycobacterium tuberculosis genotypes. Clin. ... 2005;140:443-9.

80. Rottenberg ME, Gigliotti-Rothfuchs A, Wigzell H. The role of IFN-gamma in the outcome of chlamydial infection. Curr. Opin. Immunol. 2002;14:444-51.

81. Paciello I, Silipo A, Lembo-fazio L, Zumsteg A, Noël G, Ciancarella V, et al. Intracellular Shigella remodels its LPS to dampen the innate immune recognition and evade inflammasome activation. Proc. Natl. Acad. Sci. U. S. A. 2013;

82. Xu F, Kang Y, Zhang H, Piao Z, Yin H, Diao R, et al. Akt1-mediated regulation of macrophage polarization in a murine model of Staphylococcus aureus pulmonary infection. J. Infect. Dis. 2013;208:528-38.

83. Lugo-Villarino G. Macrophage polarization: convergence point targeted by Mycobacterium tuberculosis and HIV. Front. Immunol. 2011;2.

84. Schaale K, Brandenburg J, Kispert A, Leitges M, Ehlers S, Reiling N. Wnt6 Is Expressed in Granulomatous Lesions of Mycobacterium tuberculosis-Infected Mice and Is Involved in Macrophage Differentiation and Proliferation. J. Immunol. 2013;191:5182-95.

85. Thurlow LR, Hanke ML, Fritz T, Angle A, Aldrich A, Williams SH, et al. Staphylococcus aureus biofilms prevent macrophage phagocytosis and attenuate inflammation in vivo. J. 
Immunol. 2011;186:6585-96.

86. Eisele N a, Ruby T, Jacobson A, Manzanillo PS, Cox JS, Lam L, et al. Salmonella require the fatty acid regulator PPAR $\delta$ for the establishment of a metabolic environment essential for long-term persistence. Cell Host Microbe. 2013;14:171-82.

87. Lavanchy D. Evolving epidemiology of hepatitis C virus. Clin. Microbiol. Infect. 2011;17:107-15.

88. Hajizadeh MR, Mokarram P, Kamali Sarvestani E, Bolhassani A, Mostafavi Pour Z. Recombinant Nonstructural 3 Protein, rNS3, of Hepatitis C Virus Along With Recombinant GP96 Induce IL-12, TNF $\alpha$ and $\alpha 5$ integrin Expression in Antigen Presenting Cells. Hepat. Mon. 2013;13:e8104.

89. Fletcher N, Sutaria R, Jo J, Barnes A. Activated macrophages promote hepatitis C virus entry in a tumor necrosis factor- dependent manner. Hepatology. 2013;1-31.

90. Sun H, Sun Y, Pu J, Zhang Y, Zhu Q, Li J, et al. Comparative virus replication and host innate response in human cells infected with 3 prevalent clades $(2.3 .4,2.3 .2$ and 7$)$ of highly pathogenic avian influenza H5N1 viruses. J. Virol. 2013;

91. Wang J, Li F, Sun R, Gao X, Wei H, Li L-J, et al. Bacterial colonization dampens influenza-mediated acute lung injury via induction of M2 alveolar macrophages. Nat. Commun. 2013;4:2106.

92. Peiris JSM, Chu CM, Cheng VCC, Chan KS, Hung IFN, Poon LLM, et al. Clinical progression and viral load in a community outbreak of coronavirus-associated SARS pneumonia: a prospective study. Lancet. 2003;361:1767-72. 
93. Franks TJ, Chong PY, Chui P, Galvin JR, Lourens RM, Reid AH, et al. Lung pathology of severe acute respiratory syndrome (SARS): a study of 8 autopsy cases from Singapore. Hum. Pathol. 2003;34:743-748.

94. Page C, Goicochea L, Matthews K, Zhang Y, Klover P, Holtzman MJ, et al. Induction of alternatively activated macrophages enhances pathogenesis during severe acute respiratory syndrome coronavirus infection. J. Virol. 2012;86:13334-49.

95. Avdic S, Cao JZ, McSharry BP, Clancy LE, Brown R, Steain M, et al. Human Cytomegalovirus Interleukin-10 Polarizes Monocytes toward a Deactivated M2c Phenotype To Repress Host Immune Responses. J. Virol. 2013;87:10273-82.

96. Poglitsch M, Weichhart T, Hecking M, Werzowa J, Katholnig K, Antlanger M, et al. CMV late phase-induced mTOR activation is essential for efficient virus replication in polarized human macrophages. Am. J. Transplant. 2012;12:1458-68.

97. Chan G, Bivins-Smith ER, Smith MS, Smith PM, Yurochko AD. Transcriptome analysis reveals human cytomegalovirus reprograms monocyte differentiation toward an M1 macrophage. J. Immunol. 2008;181:698-711.

98. Cassetta L, Kajaste-Rudnitski A, Coradin T. M1 polarization of human monocyte-derived macrophages restricts pre-and post-integration steps of HIV-1 replication. AIDS. 2013;27:1847-56.

99. Cassol E, Cassetta L, Rizzi C, Gabuzda D, Alfano M, Poli G. Dendritic cell-specific intercellular adhesion molecule-3 grabbing nonintegrin mediates HIV-1 infection of and transmission by M2a-polarized macrophages in vitro. AIDS. 2013;27:707-16. 
100. Cassol E, Cassetta L, Alfano M, Poli G. Macrophage polarization and HIV-1 infection. J. Leukoc. Biol. 2010;87:599-608.

101. Gobeil L-A, Lodge R, Tremblay MJ. Differential HIV-1 endocytosis and susceptibility to virus infection in human macrophages correlate with cell activation status. J. Virol. 2012;86:10399-407.

102. Chihara T, Hashimoto M. HIV-1 proteins preferentially activate anti-inflammatory M2type macrophages. J. .... 2012;188:3620-7.

103. Smith M, Bentz G. Human cytomegalovirus induces monocyte differentiation and migration as a strategy for dissemination and persistence. J. Virol. 2004;

104. Smith M, Bentz G. HCMV activates PI (3) K in monocytes and promotes monocyte motility and transendothelial migration in a PI (3) K-dependent manner. J. Leukoc. .... $2004 ; 76: 65-76$.

105. Bradshaw EM, Raddassi K, Elyaman W, Orban T, Gottlieb PA, Kent SC, et al. Monocytes from Patients with Type 1 Diabetes Spontaneously Secrete Proinflammatory Cytokines Inducing Th17 Cells. J. Immunol. 2009;183:4432-4439.

106. Devaraj S, Glaser N, Griffen S, Wang-Polagruto J, Miguelino E, Jialal I. Increased monocytic activity and biomarkers of inflammation in patients with type 1 diabetes. Diabetes. 2006;55:774-779.

107. Shanmugam N, Gaw Gonzalo IT, Natarajan R. Molecular mechanisms of high glucoseinduced cyclooxygenase-2 expression in monocytes. Diabetes. 2004;53:795-802.

108. Henao-Mejia J, Elinav E, Thaiss C a, Flavell R a. Inflammasomes and Metabolic Disease. 
Annu. Rev. Physiol. 2013;1-22.

109. Burke A, Kolodgie F. Morphologic findings of coronary atherosclerotic plaques in diabetics a postmortem study. ..., Vasc. Biol. 2004;24:1266-1271.

110. Villares R, Kakabadse D, Juarranz Y, Gomariz RP, Martínez-A C, Mellado M. Growth hormone prevents the development of autoimmune diabetes. Proc. Natl. Acad. Sci. U. S. A. 2013;4619-4627.

111. Goh YPS, Chawla A, Nguyen KD. Macrophage-mediated inflammation in metabolic disease. Nat. Rev. Immunol. 2011;11:738-749.

112. Hotamisligil GS. Inflammation and metabolic disorders. Nature. 2006;444:860-7.

113. Kanneganti T-D, Dixit VD. Immunological complications of obesity. Nat. Immunol. 2012;13:707-712.

114. Sun K, Kusminski CM, Scherer PE. Adipose tissue remodeling and obesity. J. Clin. Invest. 2011;121:2094-2101.

115. Tateya S, Kim F, Tamori Y. Recent advances in obesity-induced inflammation and insulin resistance. Front. Endocrinol. (Lausanne). 2013;4:93.

116. Lumeng CN, Bodzin JL, Saltiel AR. Obesity induces a phenotypic switch in adipose tissue macrophage polarization. J. Clin. Invest. 2007;117:175-184.

117. Lumeng C, DeYoung S, Bodzin J, Saltiel A. Increased inflammatory properties of adipose tissue macrophages recruited during diet-induced obesity. Diabetes. 2007;56:16-23.

118. Wynn T a, Chawla A, Pollard JW. Macrophage biology in development, homeostasis and disease. Nature. 2013;496:445-55. 
119. Weisberg SP, Hunter D, Huber R, Lemieux J, Slaymaker S, Vaddi K, et al. CCR2 modulates inflammatory and metabolic effects of high-fat feeding. J. Clin. Invest. 2006;116:115-124.

120. Cinti S, Mitchell G, Barbatelli G, Murano I. Adipocyte death defines macrophage localization and function in adipose tissue of obese mice and humans. J. lipid .... 2005;46:2347-2355.

121. Olefsky JM, Glass CK. Macrophages, inflammation, and insulin resistance. Annu. Rev. Physiol. 2010;72:219-246.

122. Weisberg SP, McCann D, Desai M, Rosenbaum M, Leibel RL, Ferrante AW. Obesity is associated with macrophage accumulation in adipose tissue. J. Clin. Invest. 2003;112:1796-1808.

123. Day CP, James OF. Steatohepatitis: a tale of two "hits"? Gastroenterology. 1998;114:8425.

124. Racanelli V, Rehermann B. The liver as an immunological organ. Hepatology. 2006;43:S54-S62.

125. Tilg H, Moschen AR. Evolution of inflammation in nonalcoholic fatty liver disease: the multiple parallel hits hypothesis. Hepatology. 2010;52:1836-1846.

126. Tosello-Trampont A-C, Landes SG, Nguyen V, Novobrantseva TI, Hahn YS. Kuppfer cells trigger nonalcoholic steatohepatitis development in diet-induced mouse model through tumor necrosis factor- $\alpha$ production. J. Biol. Chem. 2012;287:40161-72.

127. Karlmark K, Weiskirchen R. Hepatic recruitment of the inflammatory Gr1+ monocyte 
subset upon liver injury promotes hepatic fibrosis. .... 2009;50:261-274.

128. Klein I, Cornejo J, Polakos N. Kupffer cell heterogeneity: functional properties of bone marrow-derived and sessile hepatic macrophages. .... 2007;110:4077-4085.

129. Seki E, Ohnishi H, van Rooijen N, Yang L, Miura K. Hepatic recruitment of macrophages promotes nonalcoholic steatohepatitis through CCR2. AJP Gastrointest. Liver Physiol. 2012;302:G1310-G1321.

130. Obstfeld AE, Sugaru E, Thearle M, Francisco A-M, Gayet C, Ginsberg HN, et al. C-C chemokine receptor 2 (CCR2) regulates the hepatic recruitment of myeloid cells that promote obesity-induced hepatic steatosis. Diabetes. 2010;59:916-925.

131. Schwabe RF, Brenner DA. Mechanisms of Liver Injury. I. TNF-alpha-induced liver injury: role of IKK, JNK, and ROS pathways. Am. J. Physiol. Gastrointest. Liver Physiol. 2006;290:G583-G589.

132. Bieghs V, Wouters K, Gorp P Van. Role of scavenger receptor A and CD36 in dietinduced nonalcoholic steatohepatitis in hyperlipidemic mice. Gastroenterology. 2010;138:2477-2486, 2486.e1-e3.

133. Miura K, Kodama Y, Inokuchi S, Schnabl B, Aoyama T, Ohnishi H, et al. Toll-Like Receptor 9 Promotes Steatohepatitis by Induction of Interleukin-1 beta in Mice. Gastroenterology. 2010;139:323-U453.

134. Miura K, Yang L, van Rooijen N, Brenner D a, Ohnishi H, Seki E. Toll-like receptor 2 and palmitic acid cooperatively contribute to the development of nonalcoholic steatohepatitis through inflammasome activation in mice. Hepatology. 2013;57:577-89. 
135. Farrell GC, Chitturi S, Gan L, van Rooyen D. NASH is an Inflammatory Disorder: Pathogenic, Prognostic and Therapeutic Implications. Gut Liver. 2012;6:149.

136. Roh YS, Seki E. Toll-like receptors in alcoholic liver disease, non-alcoholic steatohepatitis and carcinogenesis. J. Gastroenterol. Hepatol. 2013;28 Suppl 1:38-42.

137. Zhu L, Baker SS, Gill C, Liu W, Alkhouri R, Baker RD, et al. Characterization of gut microbiomes in nonalcoholic steatohepatitis (NASH) patients: a connection between endogenous alcohol and NASH. Hepatology. 2013;57:601-9.

138. Csak T, Ganz M, Pespisa J, Kodys K, Dolganiuc A, Szabo G. Fatty acid and endotoxin activate inflammasomes in mouse hepatocytes that release danger signals to stimulate immune cells. Hepatology. 2011;54:133-144.

139. Henao-Mejia J, Elinav E, Jin C, Hao L. Inflammasome-mediated dysbiosis regulates progression of NAFLD and obesity. Nature. 2012;

140. Cassetta L, Cassol E, Poli G. Macrophage polarization in health and disease. ScientificWorldJournal. 2011;11:2391-402.

141. Zhou Q, Peng R-Q, Wu X-J, Xia Q, Hou J-H, Ding Y, et al. The density of macrophages in the invasive front is inversely correlated to liver metastasis in colon cancer. J. Transl. Med. 2010;8:13.

142. Öberg Å, Samii S, Stenling R, Lindmark G. Different occurrence of CD8+, CD45R0+, and CD68+ immune cells in regional lymph node metastases from colorectal cancer as potential prognostic predictors. J. Color. Dis. 2002;17:25-29.

143. Dumont P, Berton A, Nagy N, Sandras F, Tinton S, Demetter P, et al. Expression of 
galectin-3 in the tumor immune response in colon cancer. Lab. Invest. 2008;88:896-906.

144. Klimp a H, de Vries EGE, Scherphof GL, Daemen T. A potential role of macrophage activation in the treatment of cancer. Crit. Rev. Oncol. Hematol. 2002;44:143-61.

145. Niino D, Komohara Y, Murayama T, Aoki R, Kimura Y, Hashikawa K, et al. Ratio of M2 macrophage expression is closely associated with poor prognosis for Angioimmunoblastic T-cell lymphoma (AITL). Pathol. Int. 2010;60:278-83.

146. Monini P, Colombini S, Stürzl M, Goletti D, Cafaro A, Sgadari C, et al. Reactivation and persistence of human herpesvirus- 8 infection in B cells and monocytes by Th-1 cytokines increased in Kaposi’s sarcoma. Blood. 1999;4044-4058.

147. Coursey TG, Chen PW, Niederkorn JY. Abrogating TNF- $\alpha$ expression prevents bystander destruction of normal itssues diruing iNOS-mediated elimination of intraocular tumors. Cancer Res. 2012;71:2445-2454.

148. Biswas SK, Gangi L, Paul S, Schioppa T, Saccani A, Sironi M, et al. A distinct and unique transcriptional program expressed by tumor-associated macrophages (defective NF- $\kappa \mathrm{B}$ and enhanced IRF-3/STAT1 activation). .... 2006;107:2112-22.

149. Beck A, Espinosa I, Edris B, Li R. The macrophage colony-stimulating factor 1 response signature in breast carcinoma. Clin. cancer .... 2009;15:778-87.

150. Schmieder A, Michel J, Schönhaar K, Goerdt S, Schledzewski K. Differentiation and gene expression profile of tumor-associated macrophages. Semin. Cancer Biol. 2012;22:28997.

151. Sica A, Saccani A, Mantovani A. Tumor-associated macrophages: a molecular 
perspective. Int. Immunopharmacol. 2002;2:1045-54.

152. Gironella M, Calvo C, Fernández A, Closa D, Iovanna JL, Rosello-Catafau J, et al. Reg3 $\beta$ deficiency impairs pancreatic tumor growth by skewing macrophage polarization. Cancer Res. 2013;73:5682-94.

153. Liu C-Y, Xu J-Y, Shi X-Y, Huang W, Ruan T-Y, Xie P, et al. M2-polarized tumorassociated macrophages promoted epithelial-mesenchymal transition in pancreatic cancer cells, partially through TLR4/IL-10 signaling pathway. Lab. Invest. 2013;93:844-54.

154. Takai H, Ashihara M, Ishiguro T, Terashima H, Watanabe T, Kato A, et al. Involvement of glypican-3 in the recruitment of M2-polarized tumor-associated macrophages in hepatocellular carcinoma. Cancer Biol. Ther. 2009;8:2329-38.

155. Takai H, Kato A, Kato C, Watanabe T, Matsubara K, Suzuki M, et al. The expression profile of glypican-3 and its relation to macrophage population in human hepatocellular carcinoma. Liver Int. 2009;29:1056-64.

156. Donlan R, Costerton J. Biofilms: survival mechanisms of clinically relevant microorganisms. Clin. Microbiol. Rev. 2002;15.

157. Otto M. Staphylococcal biofilms. Bact. biofilms. 2008;207-228.

158. Hanke ML, Heim CE, Angle A, Sanderson SD, Kielian T. Targeting macrophage activation for the prevention and treatment of Staphylococcus aureus biofilm infections. J. Immunol. 2013;190:2159-68.

159. Diao Y, Xin Y, Zhou Y, Li N, Pan X, Qi S, et al. Extracellular polysaccharide from Bacillus sp. strain LBP32 prevents LPS-induced inflammation in RAW 264.7 
macrophages by inhibiting NF- $\mathrm{KB}$ and MAPKs activation and ROS production. Int. Immunopharmacol. 2013;18:12-19.

160. Song Y, Dou H, Gong W, Liu X, Yu Z, Li E, et al. Bis-N-norgliovictin, a small-molecule compound from marine fungus, inhibits LPS-induced inflammation in macrophages and improves survival in sepsis. Eur. J. Pharmacol. 2013;705:49-60.

161. Förster S, Brandt M, Mottok DS, Zschüttig A, Zimmermann K, Blattner FR, et al. Secretory expression of biologically active human Herpes virus interleukin-10 analogues in Escherichia coli via a modified Sec-dependent transporter construct. BMC Biotechnol. $2013 ; 13: 82$.

162. Yin MJ, Yamamoto Y, Gaynor RB. The anti-inflammatory agents aspirin and salicylate inhibit the activity of I(kappa)B kinase-beta. Nature. 1998;396:77-80.

163. Yuan M, Konstantopoulos N, Lee J, Hansen L, Li ZW, Karin M, et al. Reversal of obesity- and diet-induced insulin resistance with salicylates or targeted disruption of Ikkbeta. Science. 2001;293:1673-7.

164. Leman LJ, Maryanoff BE, Ghadiri MR. Molecules That Mimic Apolipoprotein A-I: Potential Agents for Treating Atherosclerosis. J. Med. Chem. 2013;

165. Neyen C, Mukhopadhyay S, Gordon S, Hagemann T. An apolipoprotein A-I mimetic targets scavenger receptor A on tumor-associated macrophages: A prospective anticancer treatment? Oncoimmunology. 2013;2:e24461.

166. Heusinkveld M, de Vos van Steenwijk PJ, Goedemans R, Ramwadhdoebe TH, Gorter A, Welters MJP, et al. M2 macrophages induced by prostaglandin E2 and IL-6 from cervical 
carcinoma are switched to activated M1 macrophages by CD4+ Th1 cells. J. Immunol. 2011;187:1157-65.

167. Duluc D, Corvaisier M, Blanchard S, Catala L, Descamps P, Gamelin E, et al. Interferongamma reverses the immunosuppressive and protumoral properties and prevents the generation of human tumor-associated macrophages. Int. J. Cancer. 2009;125:367-73.

168. Coscia M, Quaglino E, Iezzi M, Curcio C, Pantaleoni F, Riganti C, et al. Zoledronic acid repolarizes tumour-associated macrophages and inhibits mammary carcinogenesis by targeting the mevalonate pathway. J. Cell. Mol. Med. 2010;14:2803-15.

169. Huang Z, Zhang Z, Jiang Y, Zhang D, Chen J, Dong L, et al. Targeted delivery of oligonucleotides into tumor-associated macrophages for cancer immunotherapy. J. Control. Release. 2012;158:286-92.

170. Rolny C, Mazzone M, Tugues S, Laoui D, Johansson I, Coulon C, et al. HRG inhibits tumor growth and metastasis by inducing macrophage polarization and vessel normalization through downregulation of PIGF. Cancer Cell. 2011;19:31-44.

171. Knolle PA, Gerken G. Local control of the immune response in the liver. Immunol. Rev. 2000;174:21-34.

172. Dustin LB, Cashman SB, Laidlaw SM. Immune control and failure in HCV infection-tipping the balance. J. Leukoc. Biol. 2014;96:535-48.

173. Hoofnagle JH. Course and outcome of hepatitis C. Hepatology. 2002;36:S21-9.

174. Manickam C, Reeves RK. Modeling HCV disease in animals: virology, immunology and pathogenesis of HCV and GBV-B infections. Front. Microbiol. 2014;5:690. 
175. Crispe IN. Immune tolerance in liver disease. Hepatology. 2014;60:2109-17.

176. Strauss O, Dunbar PR, Bartlett A, Phillips A. The immunophenotype of antigen presenting cells of the mononuclear phagocyte system in normal human liver--a systematic review. J. Hepatol. 2015;62:458-68.

177. Chen Q, Xue Y, Sun J. Kupffer cell-mediated hepatic injury induced by silica nanoparticles in vitro and in vivo. Int. J. Nanomedicine. 2013;8:1129-40.

178. Boltjes A, Movita D, Boonstra A, Woltman AM. The role of Kupffer cells in hepatitis B and hepatitis C virus infections. J. Hepatol. 2014;61:660-71.

179. Labonte AC, Tosello-Trampont A-C, Hahn YS. The role of macrophage polarization in infectious and inflammatory diseases. Mol. Cells. 2014;37:275-85.

180. Penberthy KK, Ravichandran KS. Apoptotic cell recognition receptors and scavenger receptors. Immunol. Rev. 2016;269:44-59.

181. Bowdish DME, Gordon S. Conserved domains of the class A scavenger receptors: evolution and function. Immunol. Rev. 2009;227:19-31.

182. Martínez VG, Moestrup SK, Holmskov U, Mollenhauer J, Lozano F. The Conserved Scavenger Receptor Cysteine-Rich Superfamily in Therapy and Diagnosis. 2011;63:9671000.

183. Yu X, Guo C, Fisher PB, Subjeck JR, Wang X-Y. Scavenger Receptors: Emerging Roles in Cancer Biology and Immunology. Adv. Cancer Res. 2015;128:309-64.

184. Kzhyshkowska J, Neyen C, Gordon S. Role of macrophage scavenger receptors in atherosclerosis. Immunobiology. 2012;217:492-502. 
185. Hu Y, Zhang H, Lu Y, Bai H, Xu Y, Zhu X. Class A scavenger receptor attenuates myocardial infarction-induced cardiomyocyte necrosis through suppressing M1 macrophage subset polarization. Basic Res. Cardiol. 2011;1311-1328.

186. Beauvillain C, Meloni F, Sirard J-C, Blanchard S, Jarry U, Scotet M, et al. The scavenger receptors SRA-1 and SREC-I cooperate with TLR2 in the recognition of the hepatitis C virus non-structural protein 3 by dendritic cells. J. Hepatol. 2010;52:644-51.

187. Syder AJ, Lee H, Zeisel MB, Grove J, Soulier E, Macdonald J, et al. Small molecule scavenger receptor BI antagonists are potent HCV entry inhibitors. J. Hepatol. $2011 ; 54: 48-55$.

188. Dolina JS, Braciale TJ, Hahn YS. Liver-primed CD8+ T cells suppress antiviral adaptive immunity through galectin-9-independent T-cell immunoglobulin and mucin 3 engagement of high-mobility group box 1 in mice. Hepatology. 2014;59:1351-65.

189. Krueger PD, Kim TS, Sung S-SJ, Braciale TJ, Hahn YS. Liver-resident CD103+ dendritic cells prime antiviral CD8+ T cells in situ. J. Immunol. 2015;194:3213-22.

190. Zhu X, Zong G, Zhu L, Jiang Y, Ma K, Zhang H, et al. Deletion of class A scavenger receptor deteriorates obesity-induced insulin resistance in adipose tissue. Diabetes. 2014;63:562-77.

191. Fruhwürth S, Krieger S, Winter K, Rosner M, Mikula M, Weichhart T, et al. Inhibition of mTOR down-regulates scavenger receptor, class B, type I (SR-BI) expression, reduces endothelial cell migration and impairs nitric oxide production. Biochim. Biophys. Acta Mol. Cell Biol. Lipids. 2014;1841:944-953. 
192. Mwaikambo BR, Yang C, Chemtob S, Hardy P. Hypoxia up-regulates CD36 expression and function via hypoxia-inducible factor-1- and phosphatidylinositol 3-kinase-dependent mechanisms. J. Biol. Chem. 2009;284:26695-707.

193. Todt JC, Hu B, Curtis JL. The scavenger receptor SR-A I/II (CD204) signals via the receptor tyrosine kinase Mertk during apoptotic cell uptake by murine macrophages. J. Leukoc. Biol. 2008;84:510-518.

194. Gensel JC, Zhang B. Macrophage activation and its role in repair and pathology after spinal cord injury. Brain Res. 2015;1619:1-11.

195. Keeler GD, Durdik JM, Stenken JA. Localized delivery of dexamethasone-21-phosphate via microdialysis implants in rat induces $\mathrm{M}(\mathrm{GC})$ macrophage polarization and alters CCL2 concentrations. Acta Biomater. 2015;12:11-20.

196. Ohtsuki T, Kimura K, Tokunaga Y, Tsukiyama-Kohara K, Tateno C, Hayashi Y, et al. M2 Macrophages Play Critical Roles in Progression of Inflammatory Liver Disease in Hepatitis C Virus Transgenic Mice. J. Virol. 2015;90:300-7.

197. Saha B, Kodys K, Szabo G. Hepatitis C Virus-Induced Monocyte Differentiation Into Polarized M2 Macrophages Promotes Stellate Cell Activation via TGF- $\beta$. C. Cell. Mol. Gastroenterol. Hepatol. 2016;

198. Poczobutt JM, De S, Yadav VK, Nguyen TT, Li H, Sippel TR, et al. Expression Profiling of Macrophages Reveals Multiple Populations with Distinct Biological Roles in an Immunocompetent Orthotopic Model of Lung Cancer. J. Immunol. 2016;196:2847-59.

199. Radaeva S, Sun R, Jaruga B, Nguyen VT, Tian Z, Gao B. Natural Killer Cells Ameliorate 
Liver Fibrosis by Killing Activated Stellate Cells in NKG2D-Dependent and Tumor Necrosis Factor-Related Apoptosis-Inducing Ligand-Dependent Manners.

Gastroenterology. 2006;130:435-452.

200. Krizhanovsky V, Yon M, Dickins RA, Hearn S, Simon J, Miething C, et al. Senescence of activated stellate cells limits liver fibrosis. Cell. 2008;134:657-67. 